\title{
Determining a Total Dissolved Solids Release Index from Overburden in Appalachian Coal Fields
}

Jessica L. Odenheimer

West Virginia University

Follow this and additional works at: https://researchrepository.wvu.edu/etd

\section{Recommended Citation}

Odenheimer, Jessica L., "Determining a Total Dissolved Solids Release Index from Overburden in Appalachian Coal Fields" (2013). Graduate Theses, Dissertations, and Problem Reports. 230. https://researchrepository.wvu.edu/etd/230

This Thesis is protected by copyright and/or related rights. It has been brought to you by the The Research Repository @ WVU with permission from the rights-holder(s). You are free to use this Thesis in any way that is permitted by the copyright and related rights legislation that applies to your use. For other uses you must obtain permission from the rights-holder(s) directly, unless additional rights are indicated by a Creative Commons license in the record and/ or on the work itself. This Thesis has been accepted for inclusion in WVU Graduate Theses, Dissertations, and Problem Reports collection by an authorized administrator of The Research Repository @ WVU. For more information, please contact researchrepository@mail.wvu.edu. 


\title{
Determining a Total Dissolved Solids Release Index from Overburden in Appalachian Coal Fields
}

\author{
Jessica L. Odenheimer
}

Thesis submitted

to the Davis College of Agriculture, Natural Resources, and Design

At West Virginia University

\author{
in partial fulfillment of the requirements for the degree of \\ Master of Science in \\ Plant and Soil Science
}

Jeffrey Skousen, Ph.D., Chair

Louis M. McDonald, Ph.D.

Dorothy J. Vesper, Ph.D.

Division of Plant and Soil Sciences

West Virginia University

Morgantown, West Virginia

2013

Keywords: Total Dissolved Solids, Electrical Conductivity, Weathering, Overburden, AcidBase Account

Copyright 2013 Jessica Lee Odenheimer 


\title{
ABSTRACT \\ Determining an Index for Total Dissolved Solids Weathered from Overburden in Appalachian Coal Fields
}

\author{
Jessica L. Odenheimer
}

The Appalachian coal industry has been very successful in developing technologies to identify, handle, treat and isolate potentially acid-forming overburden materials at coal mines in the region. However, the techniques to predict acid mine drainage potential may not adequately predict the release of total dissolved solids (TDS). High concentrations of TDS have been linked to a decrease in survival of aquatic macroinvertebrates. Our objective was to determine the effect of different solutions on overburden dissolution, and to develop a TDS release index. Forty-one overburden samples were collected from surface mines in West Virginia, Virginia, and Kentucky. Samples were grinded to a $>2 \mathrm{~mm}$ particle size and combined with dilute $\mathrm{HNO}_{3}$, EDTA, and digested in the microwave to obtain the most efficient laboratory experiment to determine an index for TDS released. Supernatants were analyzed for $\mathrm{pH}$, Electrical Conductivity (EC), and other selected ions from the three solutions. Results were compared to Acid-Base Accounting parameters; i.e. maximum potential acidity and neutralization potential, as well as leaching column data from Virginia Tech to determine which parameter(s) were correlated to TDS release. EC was converted to TDS, and results showed that Maximum Potential Acidity (MPA) and TDS had the strongest relationship to TDS release. We determined a low, moderate, and high TDS release index using MPA ranging from 0.0-1.0, 1.0 - 3.0, and 3.0 + , respectively. 


\section{ACKNOWLEDGEMENTS}

This thesis is a product of the concepts I have learned, and the relationships I have formed during my time here at WVU. Thank you to Dr. Jeff Skousen for accepting me into this program, and for his mentorship and guidance. He pushed me be a better student and helped me grow as a scientist. My gratitude also goes to Dr. Louis McDonald for his patience and respect. He has provided a wealth of knowledge. Thank you to Dr. Dorothy Vesper for being a wonderful and inspiring teacher.

Thank you to my Virginia Tech mentors; Dr. Lee Daniels and Zenah Orndorff for sharing their data and insight.

A special thanks to Joan Wright for helping me with ICP analysis and the pulverizing mill. Thank you to my colleagues and friends; Marianne Mannix for her sulfur analysis, Saru PoudelAcharya for being an extremely helpful lab companion, and to Carol Brown for offering a fresh perspective on my many questions.

I also want to thank my family for their support and motivation, and my fiancé, Alex for his endless encouragement. 


\section{TABLE OF CONTENTS}

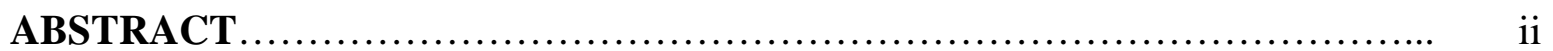

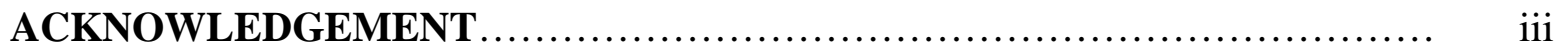

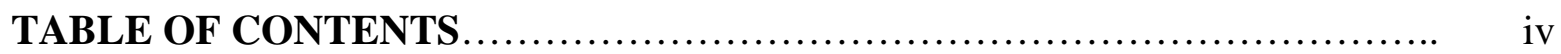

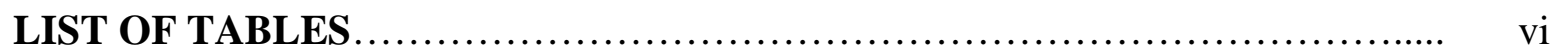

LIST OF FIGURES.................................................. vii

CHAPTER 1: Introduction and Literature Review....................... 1

1.1 Coal and Surface Mining Regulation................................ 1

1.1.2. Mining Procedures and Overburden Material.............. 2

1.2. Overburden Analysis and Acid-Base Accounting................... 3

1.3. Total Dissolved Solids ......................................... 4

1.3.1. TDS Effects on Human Health............................. 7

1.3.2. TDS Effects on Aquatic Health........................ 8

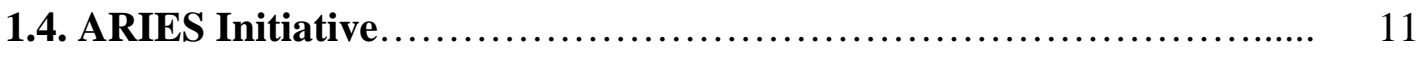

1.5. Research Objectives............................................ 12

1.6. Hypotheses................................................... 12

CHAPTER 2: Materials and Methods.................................. 14

2.1. Field Overburden Collection................................. 14

2.2. Sampling Processing.......................................... 15

2.3. Laboratory Analysis of Overburden Material..................... 23

2.3.1. Dilute Nitric Acid Method............................... 16

2.3.2. Ethylenediaminetetraacetic Acid Method................. 17

2.3.3. pH and EC analysis.................................. 17

2.3.4. Microwave Digestion.................................. 18 
2.4. Statistical Analysis.............................................. 19

CHAPTER 3: Results and Discussion.................................. 20

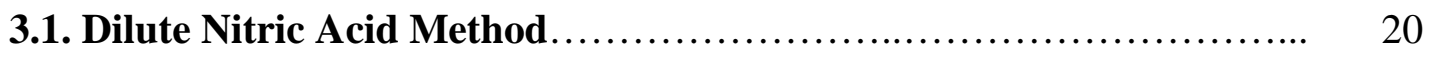

3.2. Ethylenediaminetetraacetic Acid Method......................... 24

3.3. Microwave Digestion....................................... 29

3.4. Percent of Elements Released Compared to Microwave Digestion..... 32

3.5. Comparison of the Three Methods............................. 35

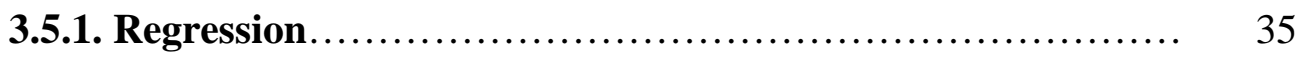

3.5.2. Elemental and Mineralogical Discussion................... 37

3.6. Determining the Best Method..................................... 39

3.7. Determination of a TDS Release Index.......................... 43

3.8. Calculated TDS from WVU compared to Virginia Tech's Leaching

Columns.................................................. 55

CHAPTER 4: Conclusion............................................... 61

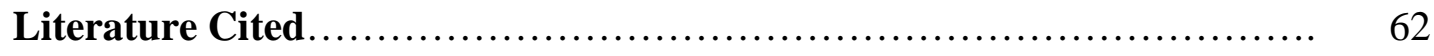

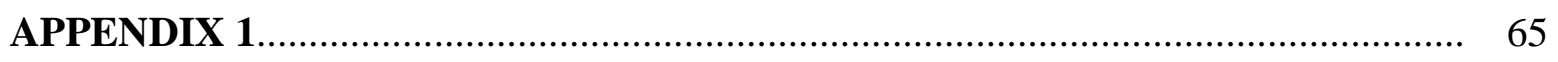




\section{LIST OF TABLES}

Table 1.1 Summary of aquatic life and human health criteria for metals.

Table 2.1 Acid-Base Accounts for fifteen overburden samples from West Virginia surface coal mines, provided by the coal company........................ 15

Table 3.1 Means of elemental release by time using the dilute $\mathrm{HNO}_{3}$ method........... 20

Table 3.2 Mean Elemental release after 72 hours of shaking in dilute $\mathrm{HNO}_{3} \ldots \ldots \ldots \ldots . .21$

Table 3.3 Mean elemental release at 168 hours of shaking in EDTA................ 26

Table $3.4 \quad$ Mean elemental release from microwave digestion...................... 30

Table 3.5 Means of elemental release from the three different methods...................... 32

Table 3.6 Relationship between dilute $\mathrm{HNO}_{3}$ and EDTA in respect to elements

Table 3.7 Relationship between microwave digestion and dilute $\mathrm{HNO}_{3}$ in respect to elements released.

Table 3.8 Relationship between microwave digestion and EDTA in respect to elements released.

Table 3.9 Summary table of the three methods

Table 3.10 Relationship between cations and calculated TDS for all samples, excluding outlier WV R

Table 3.11 Neutralization potential provided from the coal company. 50

Table 3.12 Mean values for $\% \mathrm{~S}$, MPA, paste $\mathrm{pH}$, and paste EC.

Table 3.13 TDS release index using MPA. 


\section{LIST OF FIGURES}

Figure 3.1 $\mathrm{pH}$ of all forty-one samples in dilute $\mathrm{HNO}_{3}$ over time (Mean of two replications)............................................................ 24

Figure 3.2 EC of all forty-one samples in dilute $\mathrm{HNO}_{3}$ over time (Mean of two replications) ...................................................................................... 24

Figure 3.3 $\quad \mathrm{pH}$ from all forty-one samples in EDTA over time (Mean of two replications) ........................................................................................ 28

Figure 3.4 EC from all forty-one samples in EDTA over time (Mean of two

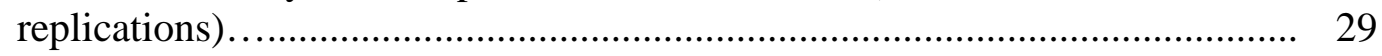

Figure 3.5 Percent of aluminum released from the two shaking methods compared to "total" digestion............................................................................................ 33

Figure 3.6 Percent of iron released from the two shaking methods compared to "total" digestion........................................................................ 33

Figure 3.7 Percent of calcium released from the two shaking methods compared to "total" digestion.................................................................................... 34

Figure 3.8 Percent of magnesium released from the two shaking methods compared to "total" digestion....................................................................................... 34

Figure 3.9 Percent of manganese released from the two shaking methods compared to "total" digestion......................................................................................... 35

Figure 3.10 The sum of cations released from the microwave digestion method, compared to EC.

Figure 3.11 The sum of cations released from the EDTA method, compared to EC.......... 42

Figure 3.12 The sum of cations released from the dilute $\mathrm{HNO}_{3}$ method, compared to EC.

Figure 3.13 Scree Plot for the determination of the appropriate number of principle components to use. ............................................................................... 45

Figure 3.14 Principle Components Analysis for the first two principle components....... 46

Figure 3.15 Paste $\mathrm{pH}$ versus TDS .............................................................................. 47

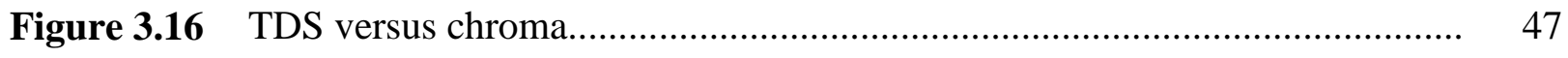


Figure 3.17 Neutralization Potential (NP) versus TDS............................................. 49

Figure 3.18 Neutralization potential versus TDS, excluding two outliers....................... 51

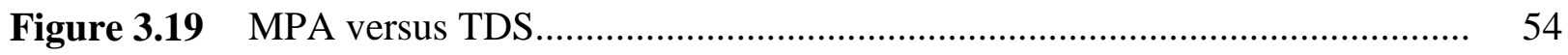

Figure 3.20 MPA versus TDS with high, medium, and low release indices.................... 54

Figure 3.21 Virginia Tech’s column leaching data for EC...................................... 56

Figure 3.22 Relationship between maximum, average, and minimum TDS calculated from EC at Virginia Tech versus TDS calculated from EC at WVU............. 57

Figure 3.23 MPA versus Average TDS from Virginia Tech....................................... 58

Figure 3.24 MPA versus Minimum TDS from Virginia Tech..................................... 59

Figure 3.25 MPA versus Maximum TDS from Virginia Tech.................................... 59

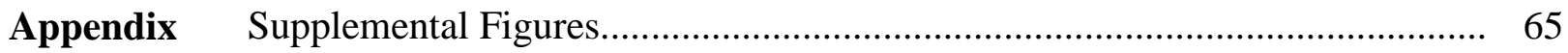




\section{Introduction and Literature Review}

\subsection{Coal and Surface Mining Regulation}

Coal is the most abundant fossil fuel produced in the United States and contributes to $42 \%$ of the 4 trillion kilowatt-hours of electricity generated nationwide (U.S. Energy Information Administration, 2013). On a world scale, China produces the most coal at 3,471 million tons, the United States is second with 1,004 million tons, and India comes in third with 585 million tons (World Coal Association, 2012). China is responsible for $47 \%$ of global coal consumption, which is almost as much as the entire rest of the world combined (World Coal Association, 2012). In the United States, Wyoming, West Virginia, and Kentucky are the three major coalproducing states (U.S. Energy Information Administration, 2012). Wyoming is part of the western coal region which has subbituminous and bituminous coal seams up to 31 meters thick under gently rolling plains and steep mountains. Large area mines and some contour mines dominate the western coal region. Kentucky and West Virginia are part of the Appalachian coal region, which is underlain by relatively thin bands of bituminous coal ranging on average from 0.3 to 1.5 meters thick. Due to the very steep and narrow valleys of the Appalachian coal mining region, local mining industries tend to extract coal via underground, mountaintop, and surface contour mining operations.

West Virginia is the largest coal-producing state in the Appalachian coal region (U.S. Energy Information Administration, 2012). West Virginia produced 139,424,080 short tons of coal, and employed 20,334 people in 2011 (West Virginia Coal Association, 2012). The coal industry is the backbone of West Virginia’s industrial economy, and has played a major leadership role in the state’s political and social history (McGehee, 2010). The coal industry has also been at the forefront of controversy concerning human and environmental health and safety. 
Deforestation, leveling mountains, acid mine drainage, erosion, subsidence, acid rain, air pollution, and the burying of streams are just a few of the environmental impacts caused by the extraction and burning of coal. West Virginia was the first state in the nation to pass laws regulating surface mining in 1939. Surrounding states followed this example, and laws and regulations evolved throughout the nation. Almost forty years later, a federal surface mining law was passed in 1977 called the Surface Mining Control and Reclamation Act (SMCRA). SMCRA enacted mandatory performance standards for all coal mining operations in the nation. These standards include permitting requirements and resource inventories on geology, soils, vegetation, and water resources before mining, as well as operation and mining plans during mining to minimize disturbances, and a reclamation plan to develop a suitable post-mining land use (OSM, 2012). Operation and performance standards (including air, land, soil, and water quality) must be met during the mining and reclamation phases in order to achieve successful closure of the site.

\subsubsection{Mining Procedures and Overburden Material}

Proper planning prior to coal mining can help alleviate or minimize many environmental impacts. Proper planning includes the identification and consideration of resources such as stream locations, water quality, water wells, homes and structures, geologic and soil conditions, and ecosystem components such as rare and endangered species.

During surface mining activities, the rock units which cover the coal seam, otherwise known as overburden material, are blasted apart and moved in order to expose the coal. All of the blasted overburden cannot be put back into the same place because of the increase in volume (Merricks et al., 2007). This excess material is commonly placed in valley fills or other constructed fills (Robins, 1979; White and Barata, 1995; Peng, 2000; Messinger and Paybins, 2003; Pond et al., 2008). Once the overburden material has been blasted, it is then subject to 
accelerated weathering processes due to the smaller particle size, larger surface area, and greater exposure to the sun, the atmosphere, and precipitation. The physical and chemical weathering of the overburden material promotes the release of soluble constituents into the environment. Depending on the chemical composition of the rock, weathering of these broken rocks can promote acid mine drainage, alkaline mine drainage (Berhhardst et al., 2012) as well as the release of heavy metals, and total dissolved solids (TDS).

\subsection{Overburden Analysis and Acid-Base Accounting}

The application of innovative procedures has helped alleviate negative impacts of coal mining activities. Researchers from West Virginia University formulated the Acid-Base Account (ABA) to better understand the chemical production potential of overburden material and to determine potential topsoil substitutes (Smith et al., 1974). Overburden cores in areas which are to be mined are extracted and used to gather information about rock layers before they are disturbed. The geologic layers of each core are identified by rock color, hardness, fizz, and $\mathrm{pH}$, and samples from these layers are then analyzed for total sulfur or maximum potential acidity (MPA) and neutralization potential (NP).

The ABA procedure is a method used to determine the total amount of acidity and alkalinity that may be produced from overburden material upon weathering (Skousen et al., 1997). The acidity or MPA (metric ton (mt) per $1000 \mathrm{mt}$ of material) comes from total sulfur analysis, and the alkalinity or NP (mt per $1000 \mathrm{mt}$ of material) is a measure of alkaline carbonates, exchangeable bases, and weatherable silicates present in the overburden material. The ABA accurately quantifies potential acidity when all of the sulfur in the rock is present as pyritic minerals (sulfides). However, the ABA overestimates MPA when the overburden is also comprised of organic sulfur, and/or sulfates. To calculate NP, a sample is treated with a known 
amount of standardized hydrochloric acid and hydrogen peroxide to rid the sample of organic matter and oxides. Once these samples are treated with acids they are then neutralized with sodium hydroxide. The amount of acid consumed is used to calculate NP.

Toxic and alkaline materials are defined using MPA and NP parameters. Subtracting the MPA from the NP yields a net neutralizing potential (NNP). A positive NNP indicates potentially acid-neutralizing rock units, and a negative NNP indicates a potential acid-producing rock unit.

The ABA functions under certain assumptions: 1) If the overburden sample consumes acid in the laboratory, it will generate alkalinity in the field. 2) All of the sulfur in the overburden sample will react to form acid. 3) The rate of pyrite oxidation is less than or equal to the rate of carbonate mineral dissolution (Perry, 1985).

Many studies have been conducted to test whether MPA, NP, or a combination or ratio of parameters can best predict post-mining water quality. Skousen et al. (2002) found in a study of 56 surface coal mining sites that MPA was poorly correlated to post-mining water quality, NP was moderately correlated, and the NP to MPA ratio and NNP were equally good in predicting water quality from overburden. They found that in general, an NP to MPA ratio of $<1$ will primarily generate acidic drainage. NP to MPA ratio of 1-2 will primarily generate alkaline drainage, and ratios $>2$ will generally produce alkaline drainage (Skousen et al., 2002). The application of ABA has been successful in helping operators minimize acid mine drainage and alkaline mine drainage from surface mines (Skousen et al., 1987).

\subsection{Total Dissolved Solids}

ABA is the most common method for predicting post-mining water quality (Perry, 1985) and as mentioned has been very successful in its implementation to minimize water quality 
impacts from mining. In recent years, however, researchers have determined that TDS are responsible for polluting waterways and harming aquatic insects. Therefore, the United States Environmental Protection Agency (USEPA) has attempted to regulate the release of TDS from surface mines by setting effluent standards through their interpretation and implementation of the Clean Water Act. In order to regulate TDS discharge standards, the USEPA, researchers and operators need a better understanding of how TDS constituents are released from mined and reclaimed overburden materials and how these constituents enter streams. Unfortunately, no such method currently exists for the prediction of TDS release from overburden material.

TDS are defined as the total sum of cations and anions in solution, but more specifically as any inorganic and/or organic constituent in water that can pass through a 2.0 micron filter (APHA, 1992). Common ions are $\mathrm{SO}_{4}{ }^{2-}, \mathrm{HCO}_{3}{ }^{-}, \mathrm{Cl}^{-}, \mathrm{Ca}^{2+}, \mathrm{K}^{+}, \mathrm{Na}^{+}$, and $\mathrm{Mg}^{2+}$, but any element that is present in solution will contribute to TDS. Depending on the properties of rock, physical and chemical weathering can produce high concentrations of TDS in streams. Physical weathering is the physical breakdown of rock into smaller particle sizes via climate, flora, and fauna. Chemical weathering may promote TDS release via proton-promoted dissolution, ligandpromoted dissolution, hydroxide-promoted dissolution, and/or redox-promoted dissolution.

The approximate concentration of TDS found in most of the world's rivers is $120 \mathrm{mg} \mathrm{L}^{-1}$ (Wetzel, 1983). When TDS exceeds $1,000 \mathrm{mg} \mathrm{L}^{-1}$, the water body is termed brackish. In North America, the major ion found in natural waters is bicarbonate $\left(\mathrm{HCO}_{3}^{-}\right)$at an average of $68 \mathrm{mg} \mathrm{L}^{-}$ ${ }^{1}$. Sulfate is the second most common ion found in natural waters with an average concentration of $20 \mathrm{mg} \mathrm{L}^{-1}$. Calcium is the most common cation found in fresh water with an average concentration of $21 \mathrm{mg} \mathrm{L}^{-1}$ (Wetzel, 1983). 
The gravimetric procedure for measuring TDS involves filtering out the total suspended solids from solution and collecting the filtrate. The filtrate is then transferred to a pre-weighed beaker and evaporated in an oven at $180^{\circ} \mathrm{C}$, until a constant weight is maintained. Once the beaker has cooled, the beaker is reweighed. TDS is calculated in $\mathrm{mg} \mathrm{L}^{-1}$ (APHA, 2002). Since ion concentrations control electrical conductivity (EC) in water, EC can be used to estimate TDS with a conversion factor of 640 . The number 640 in the equation comes from the number 64 , which represents the average equivalent weight of salts commonly found in natural waters and is multiplied by the constant 10. Equation (1) is used when EC is less than $1 \mathrm{dS} \mathrm{m}^{-1}$, and equation (2) is used when EC is greater than $1 \mathrm{dS} \mathrm{m}^{-1}$. However, this conversion factor generally underestimates TDS in chloride-rich solutions, and overestimates TDS in sulfate-rich solutions.

$$
\begin{aligned}
& \mathrm{TDS}=640 * \mathrm{EC}\left(\mathrm{dS} \mathrm{m}^{-1}\right) \\
& \mathrm{TDS}=640 *\left[\mathrm{EC}\left(\mathrm{dS} \mathrm{m}^{-1}\right)\right]^{1.087}
\end{aligned}
$$

TDS is only one of many water quality parameters that can create stress in aquatic ecosystems and it is not independent of other stressors in Central Appalachian streams. TDS is a difficult parameter to monitor because there may be one dominate ion in solution, or a couple of ions that are controlling the TDS of a stream. It is likely that a certain ion concentration or an ionic ratio may be more critical to understanding aquatic health effects than a total TDS value. In some cases, a single constituent such as $\mathrm{SO}_{4}{ }^{2-}$ can be the dominate stressor in polluted streams, contributing up to 50\% (w/v) of the TDS (Timpano et al., 2010). Therefore, a laboratory or field technique for estimating TDS release potentials from coal overburden material would be helpful 
for mine planning, the placement of high-producing TDS rocks, and abatement procedures for coal operators.

\subsubsection{TDS Effects on Human Health}

Congress passed the Safe Drinking Water Act in 1974, which requires the USEPA to determine safe levels of chemicals in drinking water. TDS is considered a secondary pollutant with a maximum criteria limit of $500 \mathrm{mg} \mathrm{L}^{-1}$. TDS is not expected to harm human health at this level, but may be toxic to aquatic life and can damage water treatment equipment (USEPA, 2012). Appalachian streams not influenced by coal mining commonly have TDS concentrations less than $75 \mathrm{mg} \mathrm{L}{ }^{-1}$ and are primarily comprised of $\mathrm{HCO}_{3}{ }^{-}, \mathrm{SO}_{4}{ }^{-2}, \mathrm{Ca}^{2+}$, and $\mathrm{Cl}^{-1}$. TDS levels in streams that are impacted by coal mining can range from $400-2,000 \mathrm{mg} \mathrm{L}^{-1}$ and TDS of mining-impacted streams are primarily made up of $\mathrm{SO}_{4}{ }^{2-}, \mathrm{HCO}_{3}{ }^{-}$, and $\mathrm{Ca}^{2+}$ (Timpano et al., 2010; Pond et al., 2008).

Current West Virginia water quality standards can be found in the Requirements Governing Water Quality Standards Rule - Title 47CRS2. These rules establish requirements concerning the release of sewage, industrial wastes, and other wastes into the waters of West Virginia. Table 1.1 displays a summary of aquatic and human health criteria for metals effective June 27, 2011. All of these parameters (in addition to other constituents not included in this table) account for the TDS in waters of West Virginia. 
Table 1.1: Summary of Aquatic Life and Human Health Criteria for Metals ${ }^{\dagger}$

\begin{tabular}{|c|c|c|c|c|c|c|}
\hline \multirow{4}{*}{ Parameter } & \multicolumn{6}{|c|}{ Use Designation } \\
\hline & \multicolumn{4}{|c|}{ Aquatic Life } & \multicolumn{2}{|c|}{ Human Health } \\
\hline & \multicolumn{2}{|c|}{ B1, B4 } & \multicolumn{2}{|c|}{ B2 } & \multirow{2}{*}{$\mathrm{C}^{3}$} & \multirow{2}{*}{$A^{4}$} \\
\hline & Acute & Chronic & Acute & Chronic & & \\
\hline Dissolved Aluminum $(\mu \mathrm{g} / \mathrm{l})$ & 750 & 750 & 750 & 87 & & \\
\hline Antimony $(\mu \mathrm{g} / \mathrm{L})$ & & & & & 4300 & 14 \\
\hline Arsenic $(\mu \mathrm{g} / \mathrm{L})$ & & & & & 10 & 10 \\
\hline Barium (mg/L) & & & & & & 1.0 \\
\hline Beryllium (mg/L) & 130 & & 130 & & & 0.0077 \\
\hline Chloride (mg/L) & 860 & 230 & 860 & 230 & 250 & 250 \\
\hline Copper $(\mu \mathrm{g} / \mathrm{L})$ & & & & & & 1000 \\
\hline Cyanide & 22 & 5.0 & 22 & 5.0 & 5.0 & 5.0 \\
\hline Fluoride (mg/L) & & & & & & 1.4 \\
\hline Iron $(\mathrm{mg} / \mathrm{L})$ & & 1.5 & & 1.0 & & 1.5 \\
\hline Lead $(\mu \mathrm{g} / \mathrm{L})$ & & & & & & 50 \\
\hline Manganese (mg/L) & & & & & & 1.0 \\
\hline Nickel $(\mu \mathrm{g} / \mathrm{L})$ & & & & & 4600 & 510 \\
\hline Nitrate (mg/L) & & & & & & 10 \\
\hline Nitrite (mg/L) & 1.0 & 1.0 & 0.060 & 0.060 & & \\
\hline Selenium $(\mu \mathrm{g} / \mathrm{L})$ & 20 & 5 & 20 & 5 & & 50 \\
\hline
\end{tabular}

${ }^{\dagger}$ Title 47 Legislative Rule DEP Water Resources 47CSR2 Appendix E, Table 1

All metals must be converted to a dissolved concentration by multiplying each numerical value by the appropriate conversion factor

A: Water supply for human consumption

B1: Warm water fishery streams

B2: Trout waters

B4: Wetlands

C: Water contact recreation

\subsubsection{TDS Effects on Aquatic Health}

Aquatic organisms are affected by TDS on a cellular level. Aquatic organisms must perform osmotic regulation to maintain homeostasis. High concentrations of TDS in the water will promote the diffusion of water out of the organism's cells and into the surrounding water, causing the cells of an aquatic organism to shrink. However, low concentrations of TDS are also problematic, where water can move into the cell, causing cellular swelling. TDS becomes toxic because of the increase in salinity (Potts, 1954). 
Indicator species are commonly used in lab toxicity tests to determine levels that are toxic to these organisms over a range of TDS concentrations. Common indicator species are benthic macroinvertebrates. Pond et al. (2008) found that mining activity impacted benthic macroinvertebrate communities with a strong correlation to ionic strength. Background EC in the Appalachian region are generally less than $0.075 \mathrm{dS} \mathrm{m}^{-1}$, compared to up to 30 times over background levels downstream of mountain top mining sites (Pond et al., 2008). Aquatic insects make up a large portion of benthic macroinvertebrates. Ephemeroptera (mayflies), Plecoptera (stoneflies), and Trichoptera (caddisflies) are orders of aquatic insects that are collectively termed EPT. These aquatic insects are often indicators of the highest quality streams in the Appalachian region (Pond, 2010). These organisms are the foundation for many food chains, and are critical for the processing and cycling of nutrients (WVDEP, 2012). These three orders in particular are commonly analyzed because of their sensitivity to pollution. Using Pearson Product-Moment correlations for biological metrics and water quality parameters, Timpano et al. (2010) found that the number of EPT taxa had a strong negative correlation to TDS (-0.76) as well as to individual ions $\mathrm{Ca}^{2+}(-0.81), \mathrm{SO}_{4}{ }^{2-}(-0.81)$, and $\mathrm{Mg}^{2+}(-0.79)$.

Other common macroinvertebrates used for TDS toxicity tests include Ceriodaphnia dubia (water flea), Chironomids (midge), and Corbicula (freshwater clam). Kennedy et al. (2002) found that the mean survival of Ceriodaphnia is inversely related to TDS. Research suggests that EC levels that exceed about $3.7 \mathrm{dS} \mathrm{m}^{-1}$ will impair sensitive invertebrates (Kennedy et al., 2002). Fish have also been tested for TDS toxicity. For fathead minnow (Pimephales promelas), researchers saw a significant decrease in percent survival at about $6.18 \mathrm{dS} \mathrm{m}^{-1}$, and a significant decrease in mean reproduction growth at about $4.84 \mathrm{dS} \mathrm{m}^{-1}$ (Kennedy et al., 2002). However, rainbow trout were not significantly impaired at a maximum TDS concentration of 
2,000 $\mathrm{mg} \mathrm{L}^{-1}$ (Chapman et al., 1999). Mount et al. (2009) found that in general, relative ion toxicity was found to be in the order of $\mathrm{K}^{+}>\mathrm{HCO}_{3}{ }^{-}=\mathrm{Mg}^{2+}>\mathrm{C}^{--}>\mathrm{SO}_{4}{ }^{2-}$, and cations $\mathrm{Ca}^{2+}$ and $\mathrm{Na}^{+}$produced insignificant toxicity. Some species, however, prefer increased concentrations of TDS. Derry et al. (2003) found that Brachionus plicatilis (rotifer) and Cletocamptus sp. (harpactacoid copepod) showed population growth in $\mathrm{Cl}^{-}$dominated water. Leptodiaptoums sicillis and Diaptomus nevadenis (calanoid copepods) prevailed in $\mathrm{SO}_{4}{ }^{2-}$ and $\mathrm{CO}_{3}{ }^{2-}$ dominated water (Derry et al., 2003).

Weber-Scannell and Duffy (2007) categorized potential TDS water quality standards into three possible approaches: 1) Set the standard low enough to protect all species at all life stages exposed to the most toxic ions or combination of ions; 2) Set the standard to protect most species at most life stages for most ions and/or combination of ions; 3) Set different limits based on different categories of ions or combinations of ions, with a lower limit during fish spawning. They determined that the third approach would provide the least amount of unnecessary restriction to coal operators and provide the greatest protection to aquatic species (WeberScannell and Duffy, 2007).

Levels of EC in discharge water and standards established for effluent limits in surface mine permits continue to be very controversial subjects among the coal industry, federal and state regulatory agencies such as the USEPA and the West Virginia Division of Environmental Protection (WVDEP), and environmental groups. EC levels exceeding $0.5 \mathrm{dS} \mathrm{m}^{-1}\left(500 \mu \mathrm{S} \mathrm{cm}^{-1}\right)$ can potentially have a negative effect on aquatic species, and therefore has become an upper limit in permitting by the USEPA. The Science Advisory Board (SAB) conducted evaluations of the science behind the $0.5 \mathrm{dS} \mathrm{m}{ }^{-1}$ threshold, and determined that although there is clear evidence that valley fills are associated with increased EC, EC should be used as a "coarse" indicator of 
water quality because of confounding factors. The SAB concluded that the USEPA should not over-rely on EC for determining damage to streams, and advised that many other environmental factors and parameters must also be included in assessments (Copeland, 2013).

\subsection{ARIES Initiative}

A consortium of seven major research universities joined together to form the Appalachian Research Initiative for Environmental Science (ARIES). This initiative was formed to address the environmental impacts of the discovery, development, production, and use of energy resources in Appalachia. The universities involved are: West Virginia University, Virginia Tech, University of Kentucky, Ohio State University, University of Pittsburgh, Pennsylvania State University, and the University of Pennsylvania. ARIES is supported by numerous industrial affiliates including Alpha Natural Resources, Natural Resource Partners, TECO Coal Corporation, Patriot Coal Corporation, Cliffs Natural Resources, MEPCO, and Norfolk Southern (Craynon, 2013).

ARIES is focused on six areas. Area 1 is the assessment of mining impacts on ecosystem health and diversity. Area 2 focuses on the treatment and minimization of constituent discharges. Area 3 addresses an accurate prediction of constituent release (i.e. TDS) from overburden and refuse material. Area 4 focuses on overburden handling plans and designs to minimize release of constituents into the environment. Area 5 is the next-generation design for eco-friendly mining systems, and Area 6 evaluates and optimizes the impacts of mining on community well-being (Craynon, 2013). Our research explores Area 3, the release of constituents from overburden. The Appalachian coal industry has been very successful in developing technologies to identify, handle, treat and isolate potentially acid-forming overburden materials at coal mines in the region. However, the techniques used to predict acid mine drainage potential may not adequately predict the release of TDS. This often leads to handling plans that actually increase TDS release 
due to the blending of net acid-forming and alkaline strata. The primary goal of research Area 3 is to develop new methods for characterizing and predicting constituent release potentials from coal overburden and refuse materials (Craynon, 2013).

\subsection{Research Objective}

The objective of this research was to determine a laboratory weathering method to determine an index for TDS release (high, moderate, and low) from overburden materials so that operators can properly treat, isolate and/or handle their overburden in a manner that will decrease TDS runoff from their site. Microwave-assisted digestion and a shaking/weathering technique using two extracting solutions (dilute nitric acid and Ethylenediaminetetraacetic acid) were utilized to obtain estimates of TDS release rates. These results were compared to ABA parameters such as MPA and NP, and discharge data from leaching columns.

\subsection{Hypotheses}

We hypothesized that there would be significant differences in TDS released from overburden materials using three different techniques. We predicted that overburden shaken in dilute $\mathrm{HNO}_{3}$ would provide a lower limit on TDS release from overburden and that microwave digestion would provide the upper limit on TDS release. The EDTA extraction solution would provide an intermediate value between the other two.

- $\mathrm{H}_{0}$ : There will be no significant difference in the mean concentration of TDS released among the three extraction techniques.

- $\mathrm{H}_{\mathrm{a}}$ : There will be significant differences in mean concentrations of TDS released among the three extraction techniques. 
We also hypothesized that different overburden types would be significantly different in terms of TDS release. For example, overburdens comprised of shales or sandstones with high sulfur contents or high carbonate (neutralization potential, NP) contents or a combination of the two would produce the most TDS. Rock units with medium TDS release potential would be shales or other rocks with low to moderate sulfur and/or carbonate content. And rock units with low TDS potential would be hard sandstones or oxidized/weathered sandstones or soil-like materials.

- $\mathrm{H}_{0}$ : There will be no significant difference in mean TDS among varying rock types.

- $\mathrm{H}_{\mathrm{a}}$ : There will be significant differences in mean TDS among overburden rock types. 


\section{Materials and Methods}

\subsection{Field Overburden Collection}

Forty-one overburden samples were collected in 5-gallon buckets from surface coal mines in West Virginia, Virginia, and Kentucky (fifteen samples from WV, fifteen samples from VA, and eleven samples from KY). Emphasis was placed in collecting samples that represented a wide variety of rock type, such as mudstones, siltstones, and gray and brown sandstones. Rocks with high TDS may be those with high sulfur contents and/or high carbonate contents (neutralization potential). Rock units with medium TDS potential may be shales or other rocks with moderate sulfur and/or neutralization potential. Rocks with low TDS potential may be hard sandstones and/or oxidized/weathered sandstones. A preference was placed upon sampling rock units that would most likely be disposed of in valley fills or backfills instead of those strata that would be isolated as toxic strata or removed from the site. 
Table 2.1: Acid-Base Accounts for fifteen overburden samples from West Virginia surface coal mines, provided by the coal company.

\begin{tabular}{|c|c|c|c|c|c|c|c|c|c|}
\hline Sample \# & Munsel Color & Rock Type & pH & \% S & MPA & NP & NET & Se & $\begin{array}{c}\text { Predicted } \\
\text { TDS }\end{array}$ \\
\hline WV 1 & 10 YR 8/1 & SS & 6.4 & 0 & 2.5 & 5.0 & 2.5 & ND & Low \\
\hline WV 2 & 10 YR 8/1 & SS & 6.4 & 0 & 2.5 & 5.0 & 2.5 & ND & Low \\
\hline WV 3 & 10 YR 6/1 & SH & 8.3 & 0.018 & 0.44 & 17 & 16.66 & 0.85 & Low \\
\hline WV 4 & 10 YR 8/1 & SS & 8.3 & 0.03 & 1.8 & 15 & 13.2 & ND & Medium \\
\hline WV 5 & 10 YR 8/1 & SS & 8.3 & 0.006 & 0.25 & 10 & 9.75 & ND & Low \\
\hline WV 6 & $5 Y$ 7/1 & Gray SS & 7.2 & 0.018 & 0.6 & 25 & 24.6 & $\begin{array}{c}\text { Not } \\
\text { Listed }\end{array}$ & Medium \\
\hline WV 7 & $2.5 Y$ 6/1 & Black Sh & 6.0 & 0.15 & 30 & 30 & 0 & $\begin{array}{c}\text { Not } \\
\text { Listed }\end{array}$ & High \\
\hline WV 8 & $5 Y$ 7/1 & Gray Sh & 8.1 & 0.001 & 0.25 & 60 & 59.75 & $\begin{array}{c}\text { Not } \\
\text { Listed }\end{array}$ & Medium \\
\hline WV 9 & $2.5 Y$ 3/1 & SS & 5.0 & 0.1 & 4.0 & 3.0 & -1.0 & $\begin{array}{c}\text { Not } \\
\text { Listed }\end{array}$ & Low \\
\hline WV 10 & $5 Y 7 / 1$ & Sh & 8.0 & 0.001 & 0.03 & 27 & 26.07 & $\begin{array}{c}\text { Not } \\
\text { Listed }\end{array}$ & Medium \\
\hline WV 11 & $2.5 Y$ 6/1 & Brown SS & 6.1 & 0.02 & 0.47 & 23 & 22.53 & $<0.2$ & Medium \\
\hline WV 12 & N/2/0 & Black Sh & 7.0 & 2.0 & 65 & 5.0 & 60 & 0.3 & High \\
\hline WV 13 & $2.5 Y$ 8/1 & White SS & 7.0 & 0.02 & 0.7 & 18 & 17.3 & $<0.2$ & Low \\
\hline WV 14 & $2.5 Y 7 / 1$ & SS & 6.3 & 0.03 & 0.6 & 17 & 16.4 & $<0.2$ & Low \\
\hline WV 15 & $2.5 Y 7 / 1$ & SS & 6.3 & 0.02 & 0.3 & 15 & 14.7 & $<0.2$ & Low \\
\hline
\end{tabular}

\% S: percent sulfur; MPA: Maximum Potential Acidity; NP: Neutralization Potential; NET: Net Neutralizing Potential; Se: Selenium

\subsection{Sample Processing}

Samples were air-dried in the greenhouse at Virginia Tech and then the entire volume of each sample was crushed and passed through a $1.25 \mathrm{~cm}$ (0.5 in) sieve. Approximately $2000 \mathrm{~g}$ of each sample was sent to West Virginia University (WVU). The samples were halved, and then further ground at WVU using a BICO pulverizing mill (BICO, Inc. Burbank, CA) until roughly all of the sample could pass through a 2-mm (0.0787 in) sieve (the other half was archived at WVU). After preliminary weathering tests involving two overburden sieve sizes $(250 \mu \mathrm{m}$ and $106 \mu \mathrm{m})$, we found no statistical difference in the concentrations of constituents released between the two particle sizes. Therefore, we concluded that the current particle size $(<2 \mathrm{~mm})$ would suffice for our weathering experiments (Odenheimer et al., 2012). 


\subsection{Laboratory Analysis of Overburden Material}

\subsubsection{Dilute Nitric Acid Method}

One microwave digestion technique and two extracting solutions: dilute nitric acid $\left(\mathrm{HNO}_{3}\right)$, and Ethylenediaminetetraacetic acid (EDTA), were utilized to determine TDS release potential from overburden material.

A solution of $0.0159 \mathrm{M}$ dilute $\mathrm{HNO}_{3}$ (pH of 2 and $\mathrm{EC}$ of $6.1 \mathrm{dS} \mathrm{m} \mathrm{m}^{-1}$ ) was prepared in the lab by a 1/1000 dilution of trace metal grade $\mathrm{HNO}_{3}(15.9 M)$. Approximately $200 \mathrm{~mL}( \pm 2.0 \mathrm{~mL})$ of dilute $\mathrm{HNO}_{3}$ was combined with $1.00 \mathrm{~g}$ ( $\pm 0.005 \mathrm{~g}$ ) of 2-mm sized overburden material. The solution and overburden were placed in $250 \mathrm{~mL}$ plastic Nalgene bottles (twenty-four samples at a time) on a Wrist Action Shaker (Burrell, Model 75, Pittsburgh, PA) at approximately 200 shakes per minute for a total of 120 hours (five days). Aliquots of $20 \mathrm{~mL}$ were extracted from the bottles using disposable plastic pipette tips after 6, 24, 72, and 120 hours of shaking. Samples rested for one hour to let all solids settle prior to extraction. About $15 \mathrm{~mL}$ of the leachate were filtered and used for analysis of selected cations $\left(\mathrm{Ca}^{2+}, \mathrm{Mg}^{2+}, \mathrm{Na}^{+}, \mathrm{K}^{+}, \mathrm{P}, \mathrm{Fe}, \mathrm{Al}^{3+}, \mathrm{Mn}^{2+}\right)$ by inductively coupled plasma emission spectrometer, ICP-OES (Optima DV-2100, Perkin Elmer, Norwalk, CT). A volume of $3 \mathrm{~mL}$ was used to measure $\mathrm{pH}$ and EC using a Mettler Toledo SevenEasy $\mathrm{pH}$ meter, and Mettler Toledo SevenCompact conductivity meter, respectively. The remaining $2 \mathrm{~mL}$ were analyzed for anions $\left(\mathrm{Fl}^{-}, \mathrm{Cl}^{-}, \mathrm{NO}_{2}{ }^{-}, \mathrm{Br}^{-}, \mathrm{PO}_{4}{ }^{3-}, \mathrm{SO}_{4}{ }^{2-}\right.$ ) using Ion Chromatograph analysis (ICS-3000, Sunnydale, CA). Simulated weathering using dilute $\mathrm{HNO}_{3}$ was replicated twice. 


\subsubsection{Ethylenediaminetetraacetic Acid Method}

A solution of $0.5 M$ Ethylenediaminetetraacetic Acid (EDTA), pH of 8.0 and EC of 49.1 $\mathrm{dS} \mathrm{m}^{-1}$, was prepared by combining $372.2 \mathrm{~g}$ of EDTA disodium salt to a total of $2 \mathrm{~L}$ of deionized water in a volumetric flask. Sodium hydroxide $(\mathrm{NaOH})$ pellets were added to the solution over a three-day period until the salt was completely dissolved (approximately $40 \mathrm{~g}$ of $\mathrm{NaOH}$ pellets). The final $\mathrm{pH}$ was brought to 8.0 with the addition of 1-4 $\mathrm{mL}$ of $10 \mathrm{M} \mathrm{NaOH}$. A volume of 200 $\mathrm{mL}( \pm 2.0 \mathrm{~mL})$ of EDTA was combined with $1.00 \mathrm{~g}( \pm 0.005 \mathrm{~g})$ of 2-mm sized overburden. The solution and overburden samples were placed in $250 \mathrm{~mL}$ plastic Nalgene bottles (twenty-four samples at a time) on a Wrist Action Shaker (Burrell, Model 75) at approximately 200 shakes per minute for a total of 168 hours (one week). Aliquots of $20 \mathrm{~mL}$ were extracted from the bottles using disposable plastic pipettes after 6, 24, 72, and 168 hours of shaking. Samples sat for one hour to let all solids settle prior to extraction. About $15 \mathrm{~mL}$ of the leachate were filtered (Whatman 42) and analyzed for selected cations $\left(\mathrm{Ca}^{2+}, \mathrm{Mg}^{2+}, \mathrm{Fe}, \mathrm{Al}^{3+}, \mathrm{Mn}^{2+}\right)$ as described above. Prior to ICP analysis, the samples were diluted by one-fifth. A volume of $3 \mathrm{~mL}$ of the leachate were used for $\mathrm{pH}$ and EC analysis, as described above. Simulated weathering using EDTA was replicated twice.

\subsection{3. $\mathrm{pH}$ and $\mathrm{EC}$ analysis}

To determine overburden $\mathrm{pH}, 5 \mathrm{~g}$ of overburden were combined with $5 \mathrm{~mL}$ of de-ionized water. The mixture was placed on a reciprocating shaker table and mixed for 15 minutes, then allowed to equilibrate for an hour. A Mettler Toledo SevenEasy $\mathrm{pH}$ meter was used to take the $\mathrm{pH}$ readings. Overburden EC was determined by combining $5 \mathrm{~g}$ of overburden with $10 \mathrm{~mL}$ deionized water. The mixture was placed on a reciprocating shaker table and mixed for 15 minutes, 
then allowed to equilibrate for an hour. A Mettler Toledo SevenCompact Conductivity meter was used to determine EC readings.

\subsubsection{Microwave Digestion}

Microwave-assisted acid dissolution using a modified USEPA Method 3051 procedure was used to provide an almost total elemental composition of each overburden sample. Microwave-assisted digestion is designed to be an alternative to conventional heating extraction with nitric acid $\left(\mathrm{HNO}_{3}\right)$ or alternatively, $\mathrm{HNO}_{3}$ and hydrochloric acid (HCl) (USEPA, 1997). This method is not intended for analyzing total decomposition of a sample, but only what would be considered bioavailable under extreme conditions. Microwave-assisted digestion provides a rapid multi-element acid extraction so that decisions can be made about materials and site cleanup levels, the need for Toxicity Characteristic Leaching Procedure (TCLP) testing, and whether a Best Demonstrated Available Technology (BDAT) is providing acceptable performance. When "total" quantities of trace elements are required, the hydrofluoric (HF) method will be employed.

This procedure is an alternative to conventional extraction according to EPA Method 200.2 and EPA Method 3050. A mass of $0.500 \mathrm{~g}( \pm 0.005 \mathrm{~g})$ of overburden (sieved to $<2 \mathrm{~mm}$ ) was pre-weighed on weigh paper, and then transferred into a Teflon vessel. A volume of $9 \mathrm{~mL}$ of $16 \mathrm{M} \mathrm{HNO}_{3}$ and $3 \mathrm{~mL}$ of $12 \mathrm{M}$ hydrochloric acid (HCl) were added to each sample in Teflon vessels under the fume hood. The combination of these two acids (also known as aqua regia) achieves equivalent results with EPA Method 3050 for certain elements of concern: $\mathrm{Fe}^{\text {total }}, \mathrm{Al}^{3+}$, and $\mathrm{Mg}^{2+}$ (USEPA, 1997). Overburden samples and aqua regia were pre-digested under the fume hood overnight to allow any vigorous oxidation to vent. On the following day, the Teflon vessels were digested using microwave heating with a laboratory microwave unit (CEM, Mars 5, 
Mathews, North Carolina). The sealed Teflon microwave vessels (seven at a time) were placed in the microwave and reached $175^{\circ} \mathrm{C}$ in the 5-min ramp time, and was held with constant temperature and pressure (350 psi) for fifteen minutes. After cooling, the vessel contents were diluted by $1 / 50$, filtered (Fisherbrand grade P8) and analyzed for cations $\left(\mathrm{Ca}^{2+}, \mathrm{Mg}^{2+}, \mathrm{Na}^{+}, \mathrm{K}^{+}, \mathrm{P}\right.$, $\left.\mathrm{Fe}, \mathrm{Al}^{3+}, \mathrm{Mn}^{2+}\right)$, as described above. This microwave procedure was replicated twice.

\subsection{Statistical Analysis}

Software programs; R and JMP were used to perform statistical analyses to determine significant differences among samples and methods. The three methods were compared via regression to test for relationships among concentrations of constituents released at their respective endpoints. Analysis of variance (ANOVA) was also utilized to find significant differences between methods as well as the length of time the samples were left on the shaker. Principle Components Analysis (PCA) was used as an exploratory analysis to determine which factors were most correlated to TDS and to quickly discard factors that were not useful for TDS analysis. Regression was also used to examine relationships between TDS and other parameters. 


\section{Results and Discussion}

\subsection{Dilute Nitric Acid Method}

Forty-one overburden samples were subjected to simulated weathering in a dilute nitric acid $\left(\mathrm{HNO}_{3}\right)$ solution. In general, elemental concentrations remained constant after 72 hours (three days) of shaking (Table 3.1). Figures 1A to 1E (Appendix 1) depict the release of elements over time. Aluminum concentrations ranged from 170 to $2,030 \mathrm{mg} \mathrm{kg}^{-1}$ (Table 3.2). Iron and calcium were released in the highest quantities from the overburden samples. Iron release ranged from 700 to $28,000 \mathrm{mg} \mathrm{kg}^{-1}$. Calcium concentrations ranged from 250 to $1,870 \mathrm{mg}$ $\mathrm{kg}^{-1}$; however the refuse sample (WV R) was an outlier, releasing 28,000 $\mathrm{mg} \mathrm{kg}^{-1}$. Magnesium concentrations ranged from 140 to $3,000 \mathrm{mg} \mathrm{kg}^{-1}$ with the refuse sample (WV R) releasing concentrations up to $6,000 \mathrm{mg} \mathrm{kg}^{-1}$. Of the cations we measured, manganese was released from the overburden samples in the smallest quantities with a mean concentration from all forty-one samples ranging from 25 to $650 \mathrm{mg} \mathrm{kg}^{-1}$ at 72 hours of shaking.

Table 3.1: Means of elemental ${ }^{*}$ release by time using the dilute $\mathrm{HNO}_{3}$ method.

\begin{tabular}{|c|c|c|c|c|c|c|c|c|}
\hline Time & $\mathrm{Al}$ & $\mathrm{Fe}$ & Mn & $\mathrm{Mg}$ & $\mathrm{Ca}$ & K & $\mathrm{Na}$ & $\mathrm{P}$ \\
\hline hours & \multicolumn{8}{|c|}{-------------------------------------- mg kg } \\
\hline 6 & $707^{\mathrm{A}}$ & $3406^{\mathrm{C}}$ & $171^{\mathrm{C}}$ & $760^{\mathrm{B}}$ & $2455^{\mathrm{A}}$ & $208^{\mathrm{B}}$ & $47^{\mathrm{A}}$ & $148^{\mathrm{A}}$ \\
\hline 24 & $523^{\mathrm{B}}$ & $6661^{\mathrm{B}}$ & $274^{\mathrm{B}}$ & $1023^{\mathrm{AB}}$ & $2651^{\mathrm{A}}$ & $229^{\mathrm{AB}}$ & $55^{\mathrm{A}}$ & $144^{\mathrm{A}}$ \\
\hline 72 & $368^{\mathrm{C}}$ & $8624^{\mathrm{A}}$ & $338^{\mathrm{A}}$ & $1167^{\mathrm{A}}$ & $2725^{A}$ & $281^{\mathrm{A}}$ & $52^{\mathrm{A}}$ & $142^{\mathrm{A}}$ \\
\hline 120 & $824^{A}$ & $8630^{\mathrm{A}}$ & $332^{\mathrm{A}}$ & $1138^{\mathrm{A}}$ & $2598^{A}$ & $327^{A}$ & $69^{\mathrm{A}}$ & $129^{A}$ \\
\hline
\end{tabular}

Means with different letters signify significant differences at $\mathrm{p}=0.05$ level *Only cations were utilized to determine shaking times 


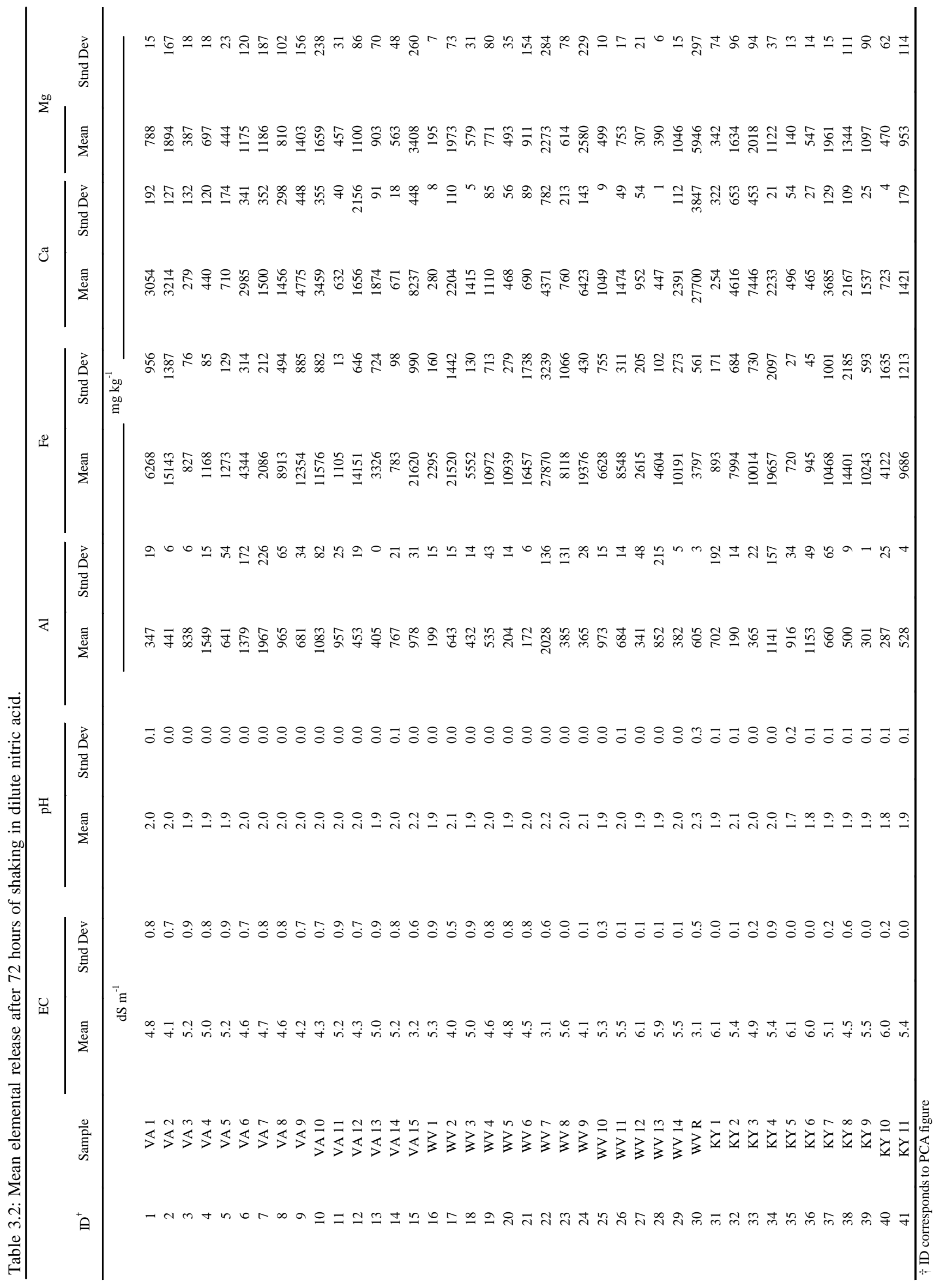




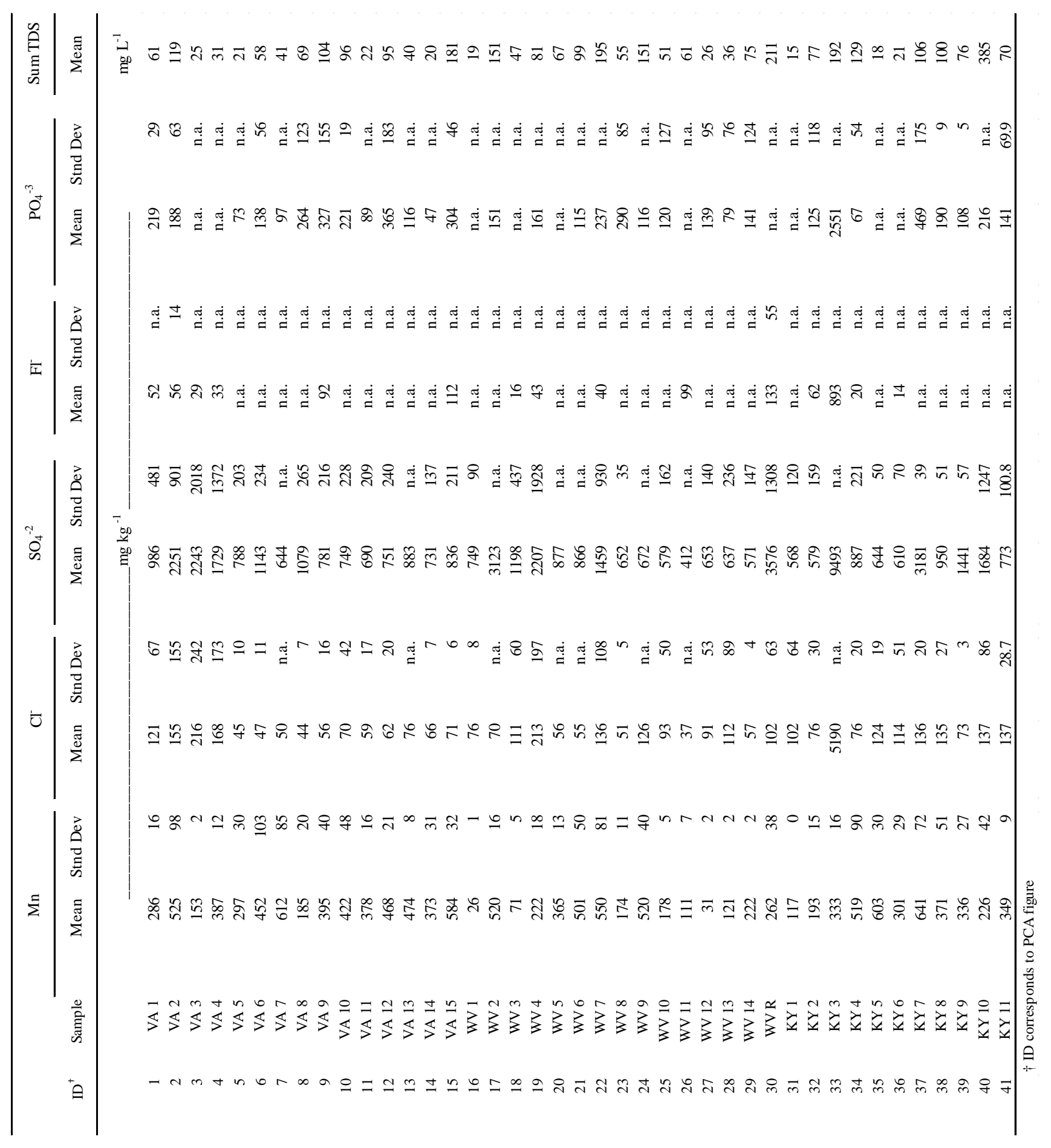


For the anions that were analyzed, chloride concentrations ranged from 35 to 5,200 mg $\mathrm{kg}^{-1}$ (Table 3.2). The overburden samples released sulfate ranging in concentrations of 400 to 9,500 $\mathrm{mg} \mathrm{kg}^{-1}$. Fluoride was released in concentrations ranging from 10 to $900 \mathrm{mg} \mathrm{kg}^{-1}$. Phosphate was also released from these samples ranging from 45 to $2,600 \mathrm{mg} \mathrm{kg}^{-1}$. The forty-one samples used for this research were chosen based on the assumption that varying rock types and stratigraphic position in the geologic column would produce varying TDS potential, as well as data from acid-base accounts provided by the coal operators; hence a large range in elemental release was expected.

The average $\mathrm{pH}$ of the solutions for all forty-one samples stayed constant at $2.0 \pm 0.05$ at 72 hours of shaking (Figure 3.1). Electrical Conductivity (EC) did not change drastically over the duration of the shaking period (Figure 3.2). The average EC for all forty-one samples was $4.9 \pm$ $0.5 \mathrm{dS} \mathrm{m}^{-1}$ at 72 hours of shaking. The EC and $\mathrm{pH}$ of the background solution (2.0 and $6.1 \mathrm{dS} \mathrm{m}^{-}$ ${ }^{1}$, respectively) controlled the $\mathrm{EC}$ and $\mathrm{pH}$ of the solutions during shaking of all forty-one samples.
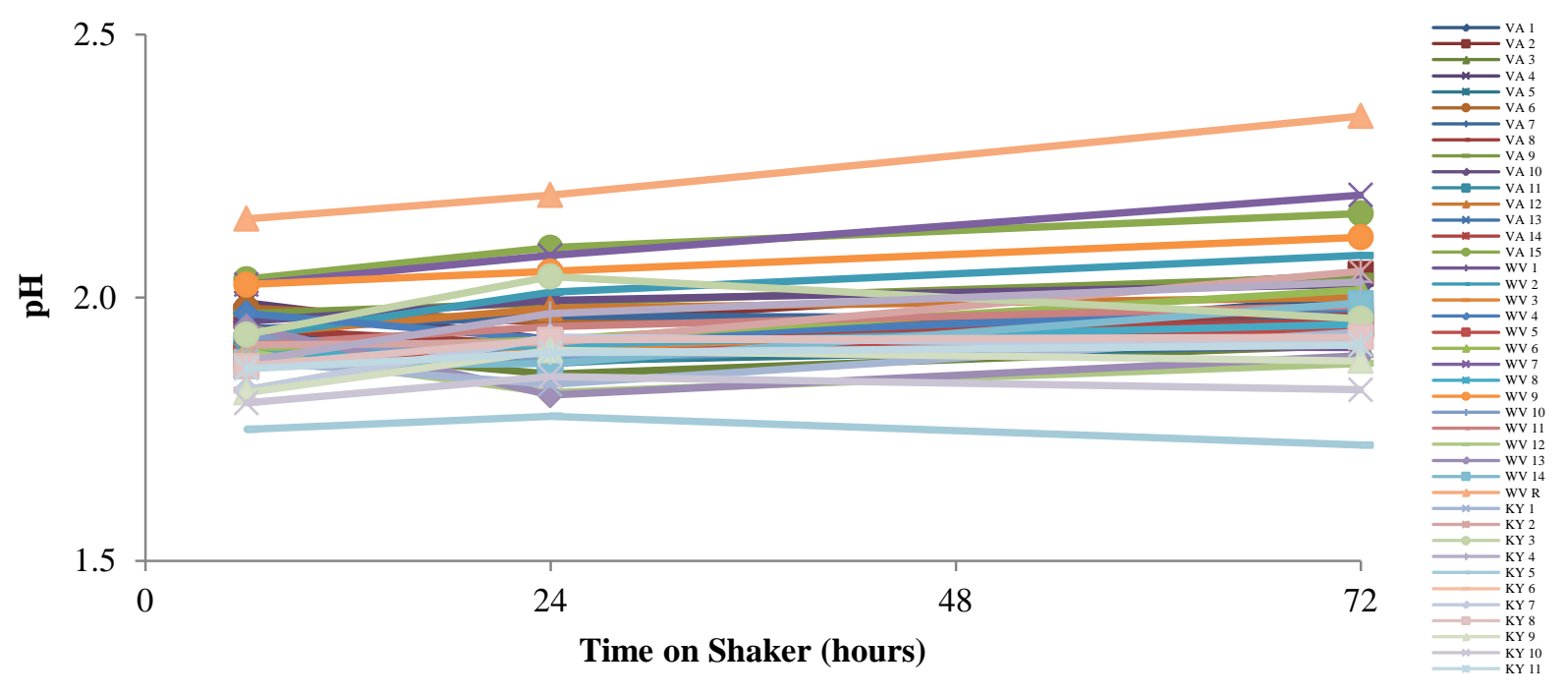

Figure 3.1: $\mathrm{pH}$ of all forty-one samples in dilute $\mathrm{HNO}_{3}$ over time (Average of two replications). 


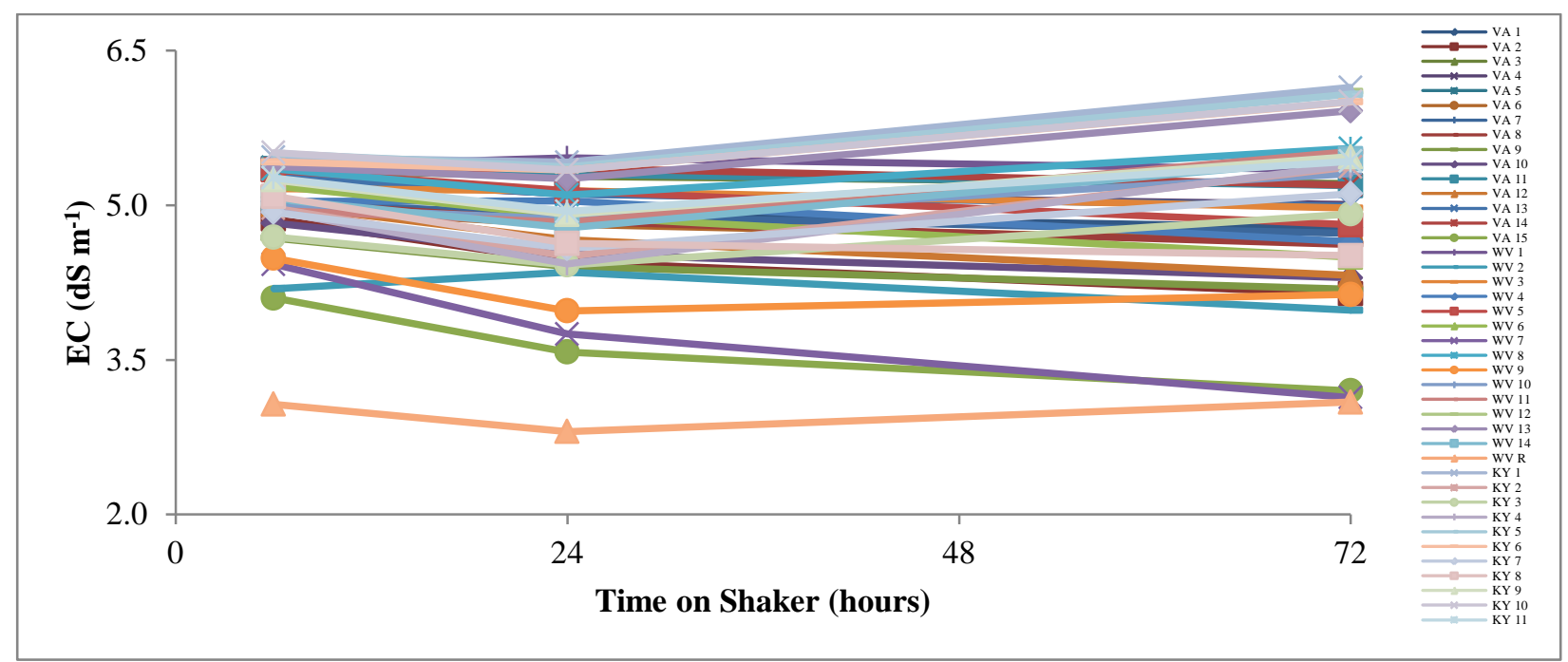

Figure 3.2: EC of all forty-one samples in dilute $\mathrm{HNO}_{3}$ over time (Average of two replications).

\subsection{Ethylenediaminetetraacetic Acid Method}

All forty-one overburden samples were also subjected to simulated weathering in $0.5 \mathrm{M}$ Ethylenediaminetetraacetic Acid (EDTA) solution. The elements released by shaking with this solution resulted in different elemental concentrations than those released with the dilute $\mathrm{HNO}_{3}$ solution; some were much less, while some were similar (Table 3.3). However, the proportion of elemental release was similar between EDTA and the dilute $\mathrm{HNO}_{3}$ solution; i.e., iron and calcium were released in the greatest concentrations and manganese was released in the lowest concentrations. In general, elemental concentrations were constant after 168 hours (1 week of shaking) with EDTA as seen in Figures $1 \mathrm{~F}$ to $1 \mathrm{~J}$ (Appendix 1). Some samples continued to release high concentrations of elements even after a month of shaking, however due to time constraints, the shaking procedure was terminated at 168 hours.

In general, EDTA released lower amounts of elements during shaking compared to the dilute $\mathrm{HNO}_{3}$ solution (Table 3.5). Aluminum concentrations ranged from 30 to 1,200 mg kg-1 
with EDTA, which were similar to aluminum concentrations released with the dilute $\mathrm{HNO}_{3}$ solution. Also similar to the dilute $\mathrm{HNO}_{3}$ solution, EDTA released a high concentration of iron and calcium. Average iron concentrations released from the overburden samples ranged from 180 to $7,000 \mathrm{mg} \mathrm{kg}^{-1}$, which was essentially four times less than that from the dilute $\mathrm{HNO}_{3}$ solution. Calcium concentrations, however, were greater with EDTA compared to dilute $\mathrm{HNO}_{3}$ solution with concentrations ranging from 190 to 5,400 $\mathrm{mg} \mathrm{kg}^{-1}$, which was a similar finding in an EDTA-weathering study which found calcium to have the highest dissolution rate (Nowack and Sigg, 1996). The refuse sample (WV R) was an outlier, releasing 28,000 $\mathrm{mg} \mathrm{kg}^{-1}$ of calcium after 168 hours of shaking. Magnesium concentrations ranged from 35 to 1,700 mg $\mathrm{kg}^{-1}$ with the refuse sample (WV R) releasing concentrations up to 4,600 $\mathrm{mg} \mathrm{kg}^{-1}$. Manganese was released from the overburden samples in the smallest quantities with average concentrations for all fortyone samples ranging from 4.0 to $1,200 \mathrm{mg} \mathrm{kg}^{-1}$ after 168 hours of shaking. Manganese release was not very different from the release of elements with the dilute $\mathrm{HNO}_{3}$ solution. Anions were not analyzed due to the interference of EDTA with the seven anion standard solution. 


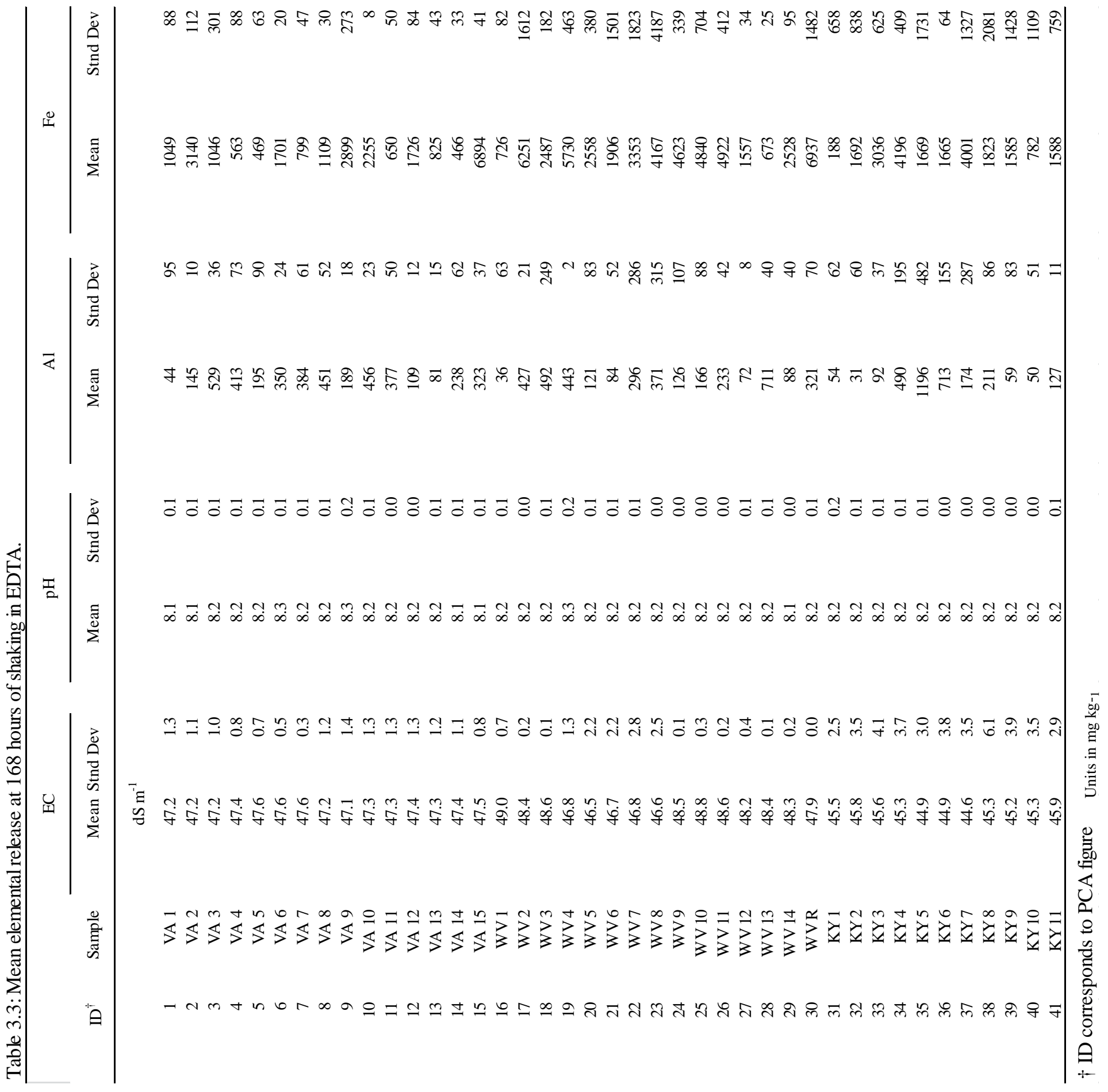




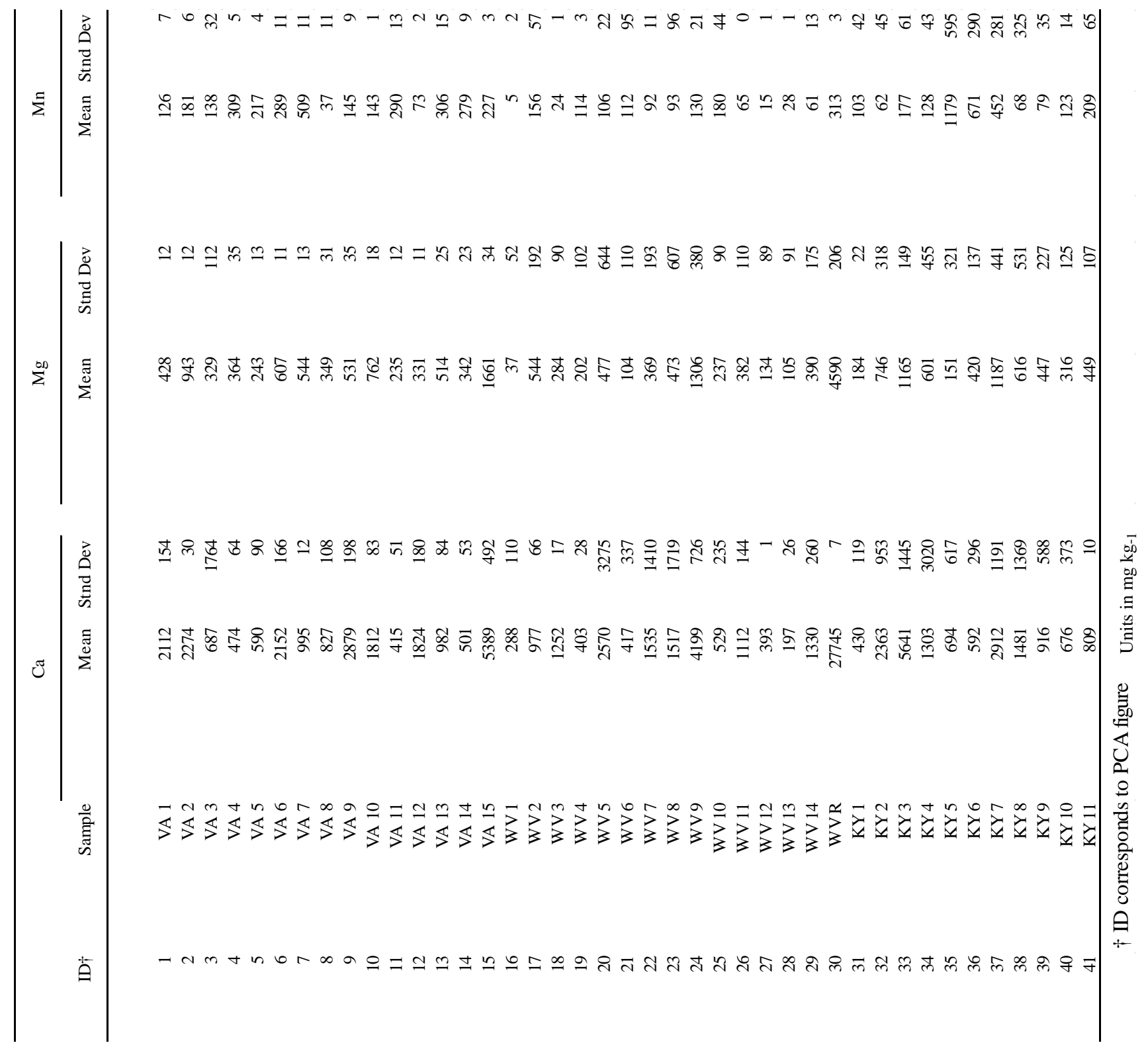


For samples that were shaken in EDTA, the $\mathrm{pH}$ and EC of all overburden samples stayed relatively constant over the duration of the shaking period. Mean pH (Figure 3.3) for all fortyone samples was $8.2 \pm 0.08$ after 168 hours of shaking. Mean EC (Figure 3.4) for all overburden samples was $47.3 \pm 1.68 \mathrm{dS} \mathrm{m}^{-1}$ after 168 hours of shaking. The background EDTA solution had a pH and EC of 8.0 and $49.1 \mathrm{dS} \mathrm{m}^{-1}$, respectively, and controlled the $\mathrm{pH}$ and EC of all samples shaken in the solution.

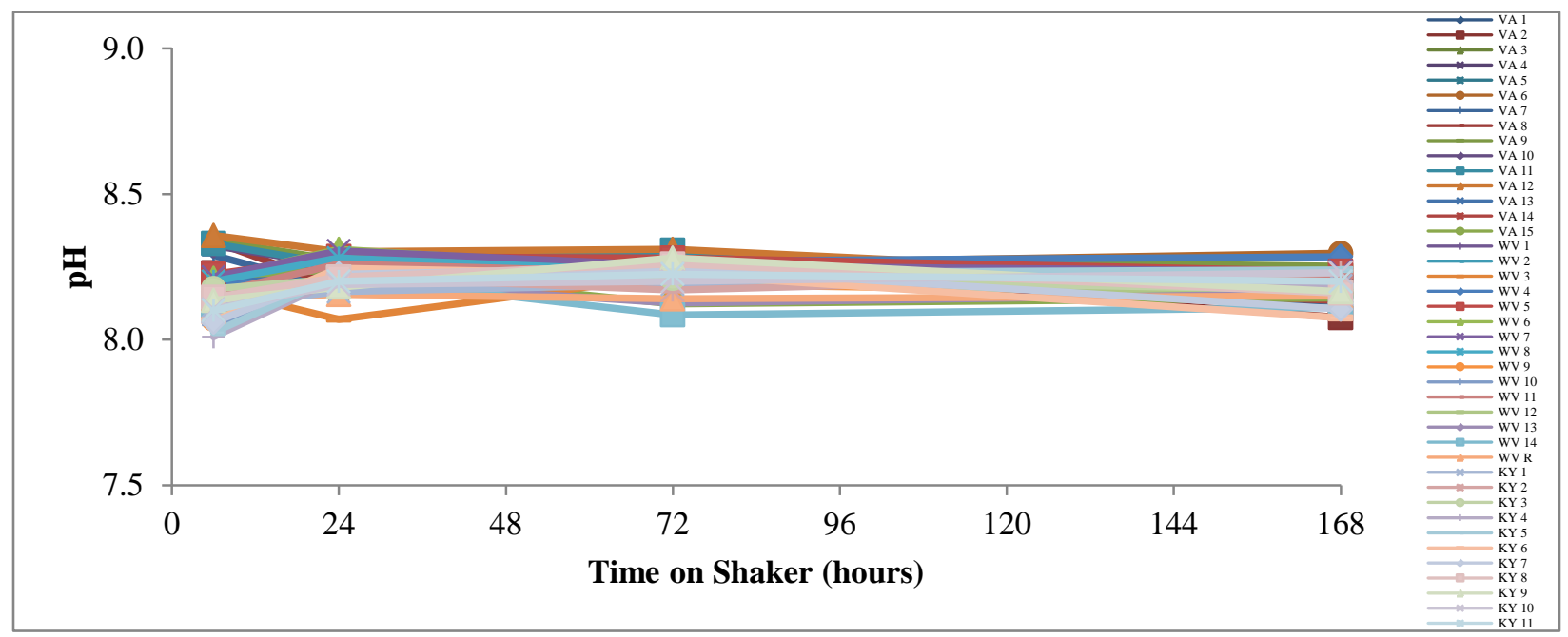

Figure 3.3: $\mathrm{pH}$ from all forty-one samples in EDTA over time (Mean of two replications). 


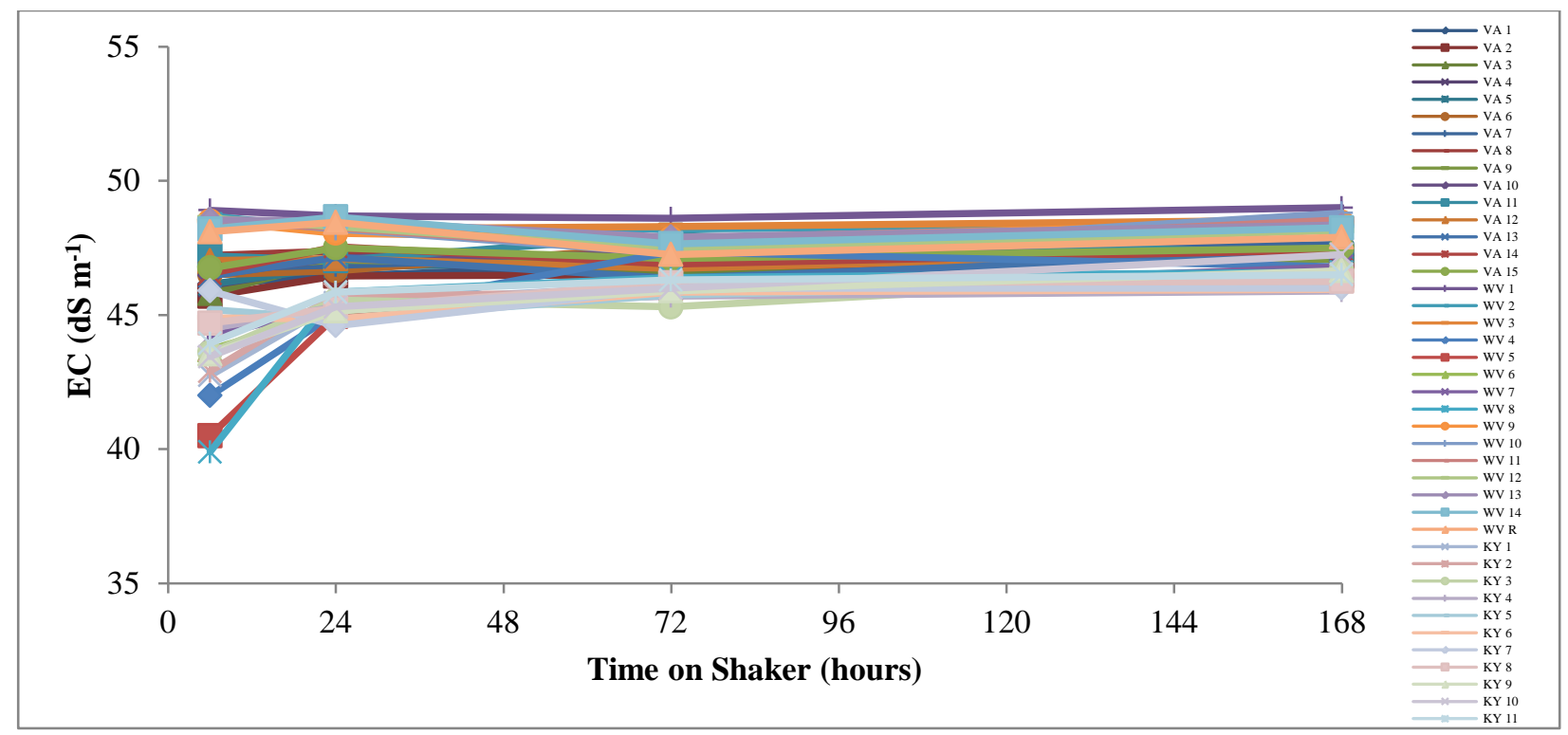

Figure 3.4: EC from all forty-one samples in EDTA over time (Mean of two replications).

\subsection{Microwave Digestion Method}

Microwave-assisted acid digestion is capable of breaking the mineral structure of the overburden samples and therefore released the largest quantity of elements compared to the two shaking methods (Table 3.3). This was expected due to the utilization of boiling concentrated nitric acid and hydrochloric acid. Table 3.4 displays the mean concentration of elements released via microwave digestion. In general, this method released constituent concentrations four to nine times more than the other two methods. Iron was released in the highest concentrations from the forty-one overburden samples. Mean iron concentrations ranged from 7,900 to $111,800 \mathrm{mg} \mathrm{kg}^{-1}$. Aluminum concentrations ranged from 8,700 to $62,200 \mathrm{mg} \mathrm{kg}^{-1}$. Calcium was also released in high concentrations, ranging from 600 to 41,800 $\mathrm{mg} \mathrm{kg}^{-1}$. Mean potassium concentrations for all forty-one samples ranged from 2,400 to $17,100 \mathrm{mg} \mathrm{kg}^{-1}$. Magnesium ranged from 1,700 to $14,100 \mathrm{mg} \mathrm{kg}^{-1}$, and sodium concentrations ranged from 440 to 2,800 $\mathrm{mg} \mathrm{kg}^{-1}$. Manganese and 


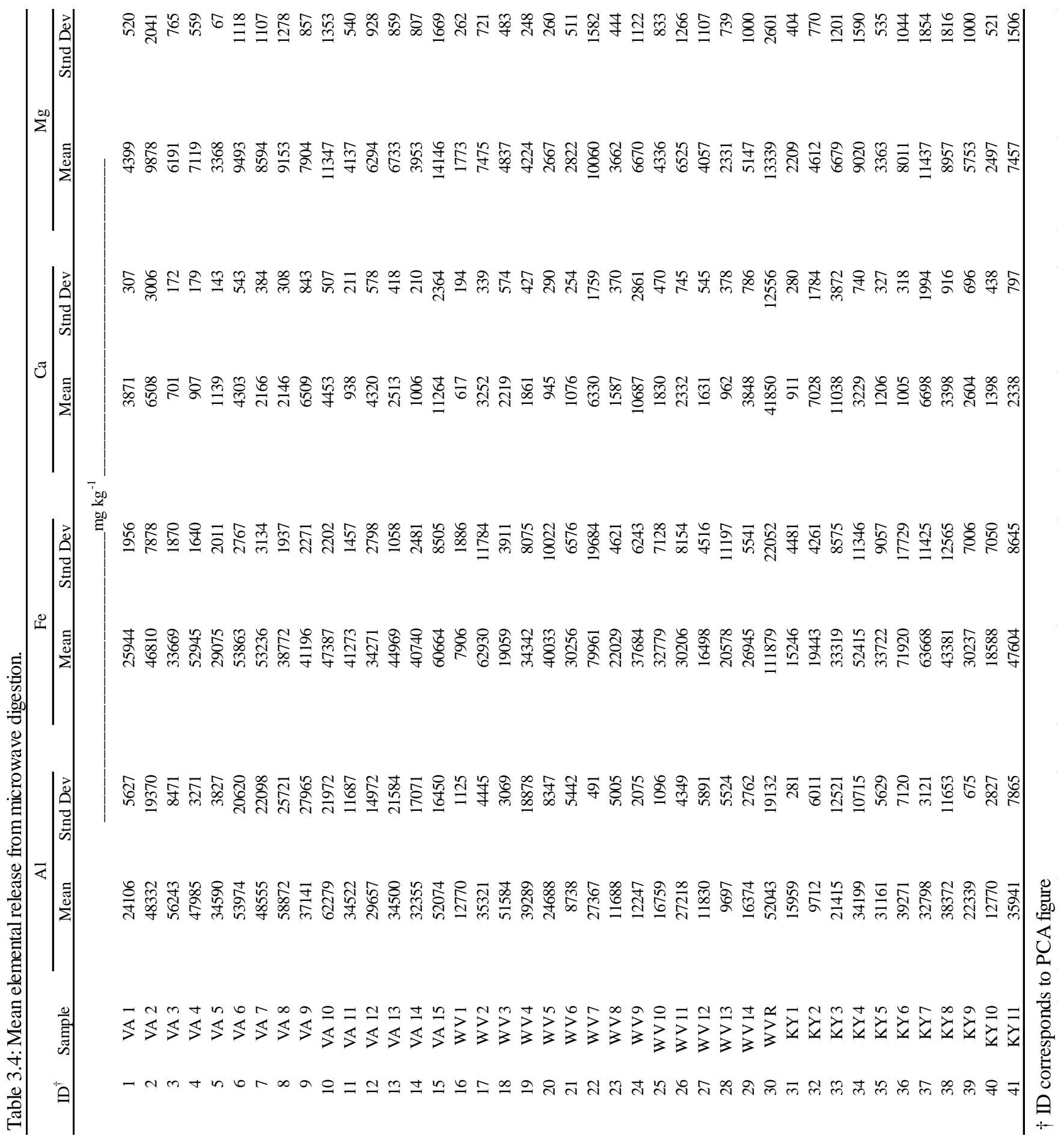




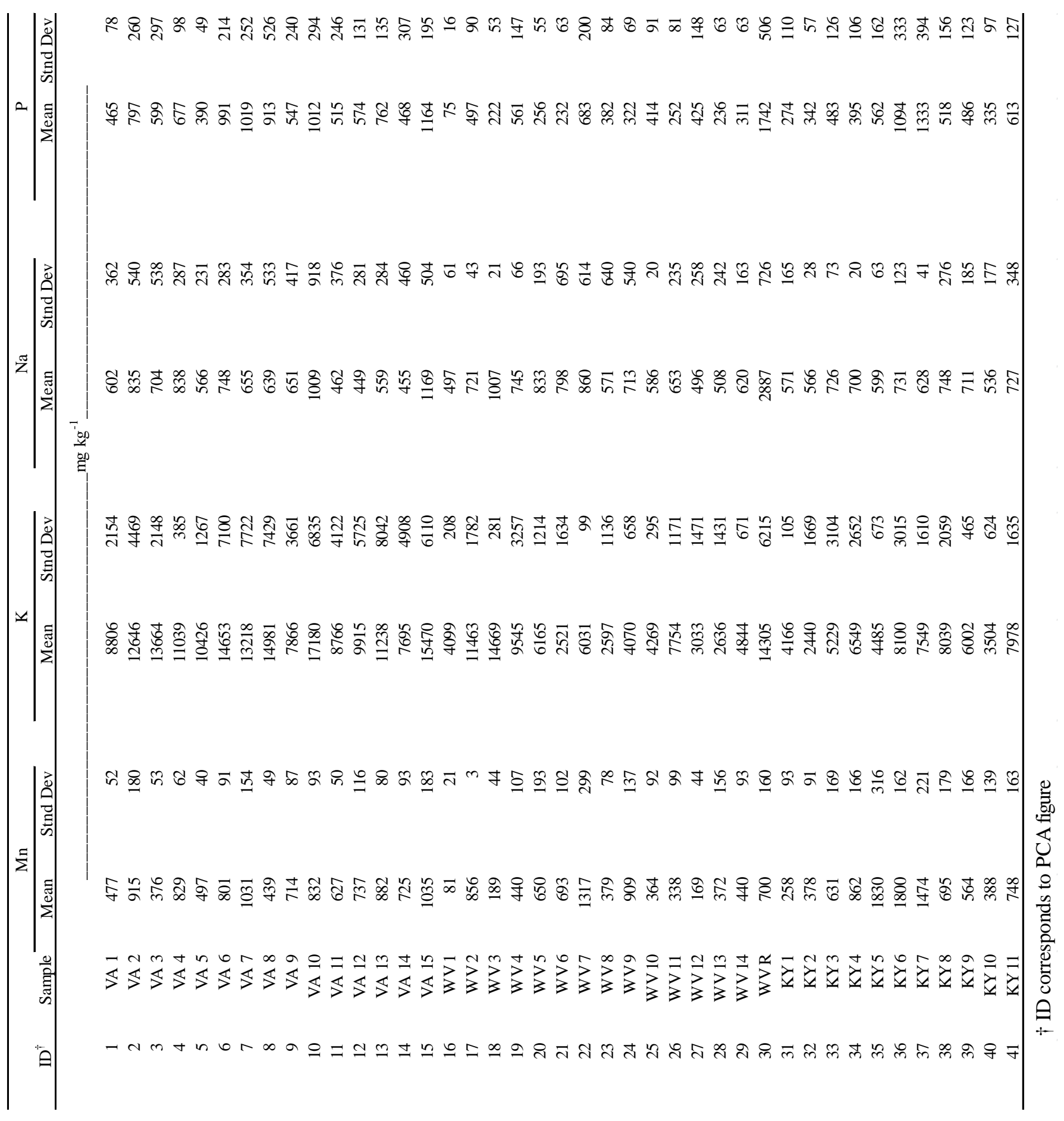


phosphorus were released in the lowest concentrations ranging from 80 to $1,800 \mathrm{mg} \mathrm{kg}^{-1}$ and 75 to $1,700 \mathrm{mg} \mathrm{kg}^{-1}$, respectively.

Table 3.5: Mean of elemental release from the three different methods.

\begin{tabular}{lccccc}
\hline Method & Al & Fe & Mn & Mg & Ca \\
\hline Dilute $\mathrm{HNO}_{3}$ & $707^{\text {B }}$ & $8624^{\text {B }}$ & $338^{\text {B }}$ & $1167^{\text {B }}$ & $2725^{\text {B }}$ \\
EDTA & $223^{\text {B }}$ & $1790^{\text {C }}$ & $155^{\text {C }}$ & $533^{\text {C }}$ & $1968^{\text {C }}$ \\
Microwave Digestion & $35034^{\text {A }}$ & $40933^{\text {A }}$ & $703^{\text {A }}$ & $6702^{\text {A }}$ & $4060^{\text {A }}$ \\
\hline Different letters signify significant differences at $\mathrm{p}=0.05$ level &
\end{tabular}

\subsection{Percent of Elements Released Compared to Microwave Digestion}

Assuming that microwave digestion provided an almost total amount of each element that could be potentially released during weathering into the environment for each sample, the percentages released from the dilute $\mathrm{HNO}_{3}$ and EDTA methods were calculated. For samples shaken in dilute $\mathrm{HNO}_{3}$, low concentrations of aluminum (Figure 3.5) were release compared to the total amount available from microwave digestion, ranging from $0.5 \%$ to $9.0 \%$ for all fortyone samples. Iron concentrations released from the dilute $\mathrm{HNO}_{3}$ solution ranged from $1.0 \%$ to 55\% (Figure 3.6) of the total. Very high percentages of calcium were released with the dilute $\mathrm{HNO}_{3}$ solution, ranging from $27 \%$ to $80 \%$ of the total (Figure 3.7). Magnesium concentrations ranged from $4.0 \%$ to $45 \%$ (Figure 3.8). Figure 3.9 displays the high percent of manganese released ranging from $16 \%$ to $73 \%$. 


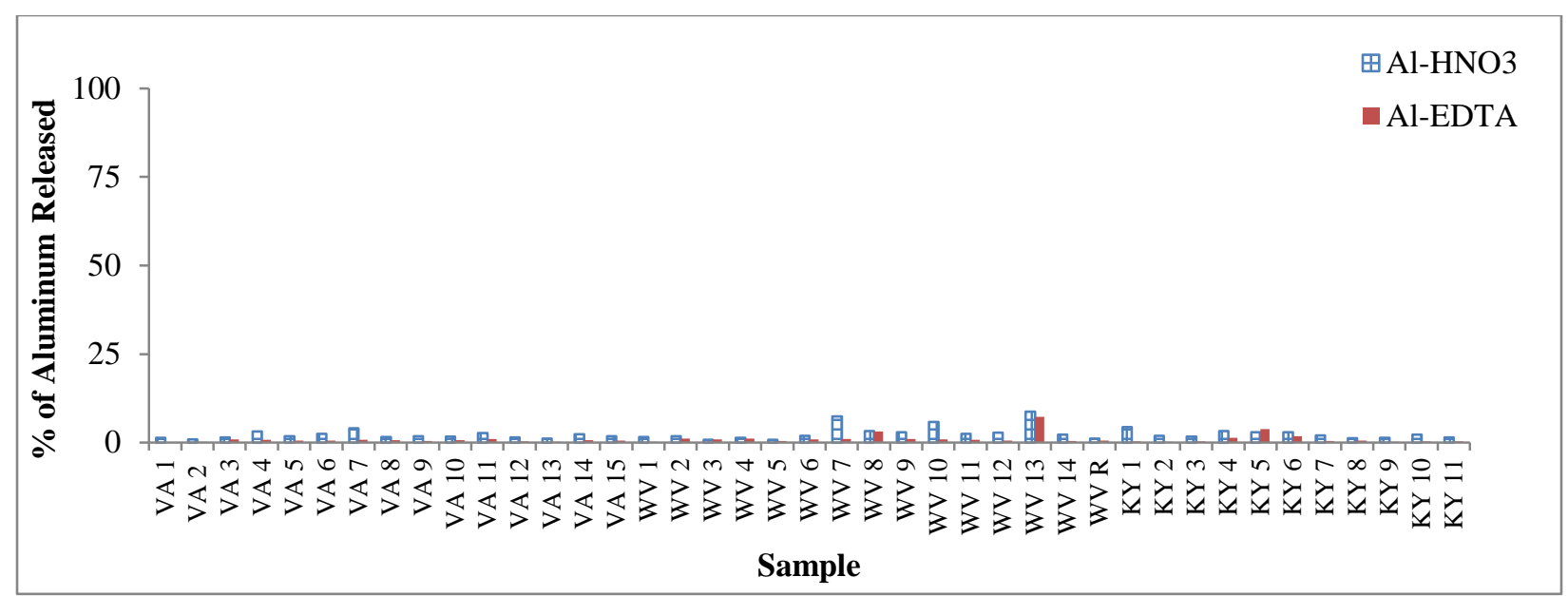

Figure 3.5: Percent of aluminum released from the two shaking methods compared to "total" digestion.

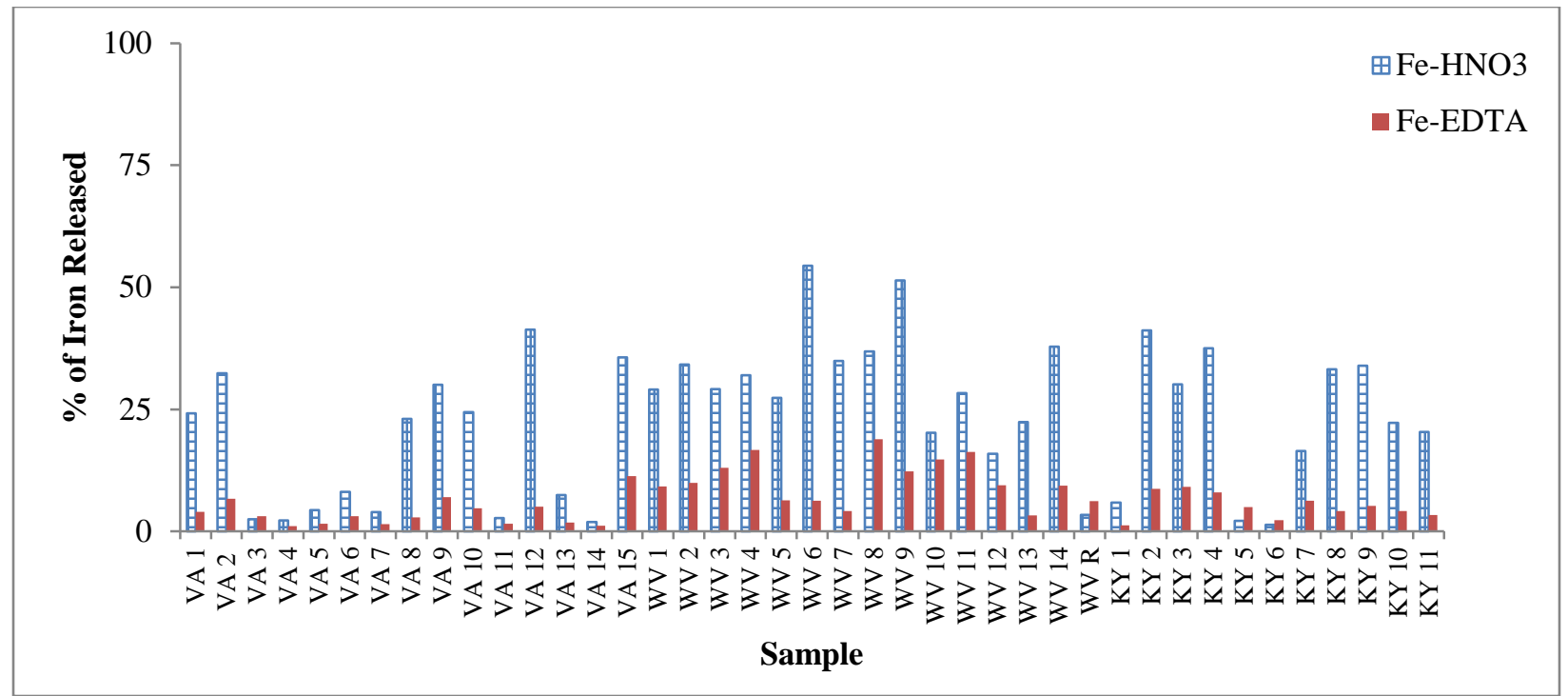

Figure 3.6: Percent of iron released from the two shaking methods compared to "total” digestion. 


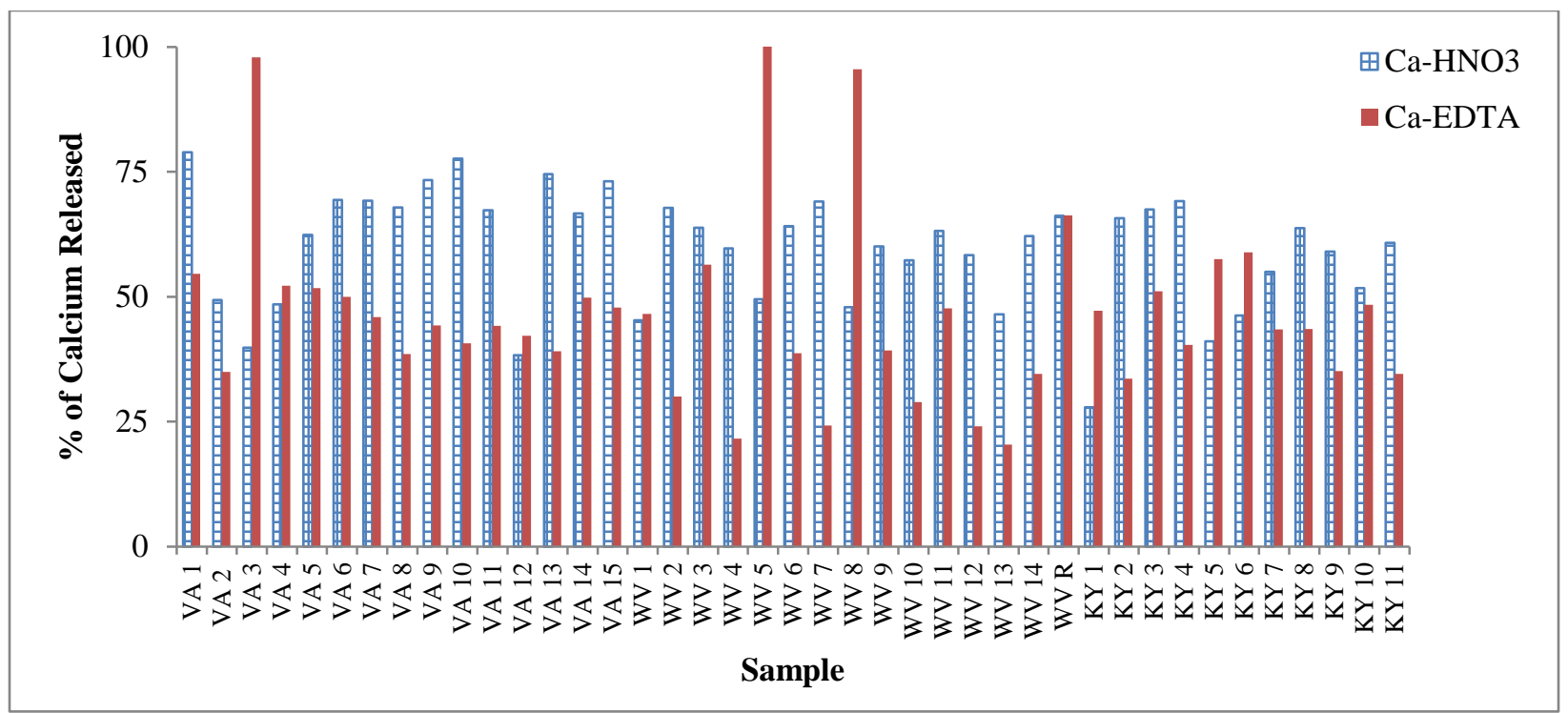

Figure 3.7: Percent of calcium released from the two shaking methods compared to "total" digestion.

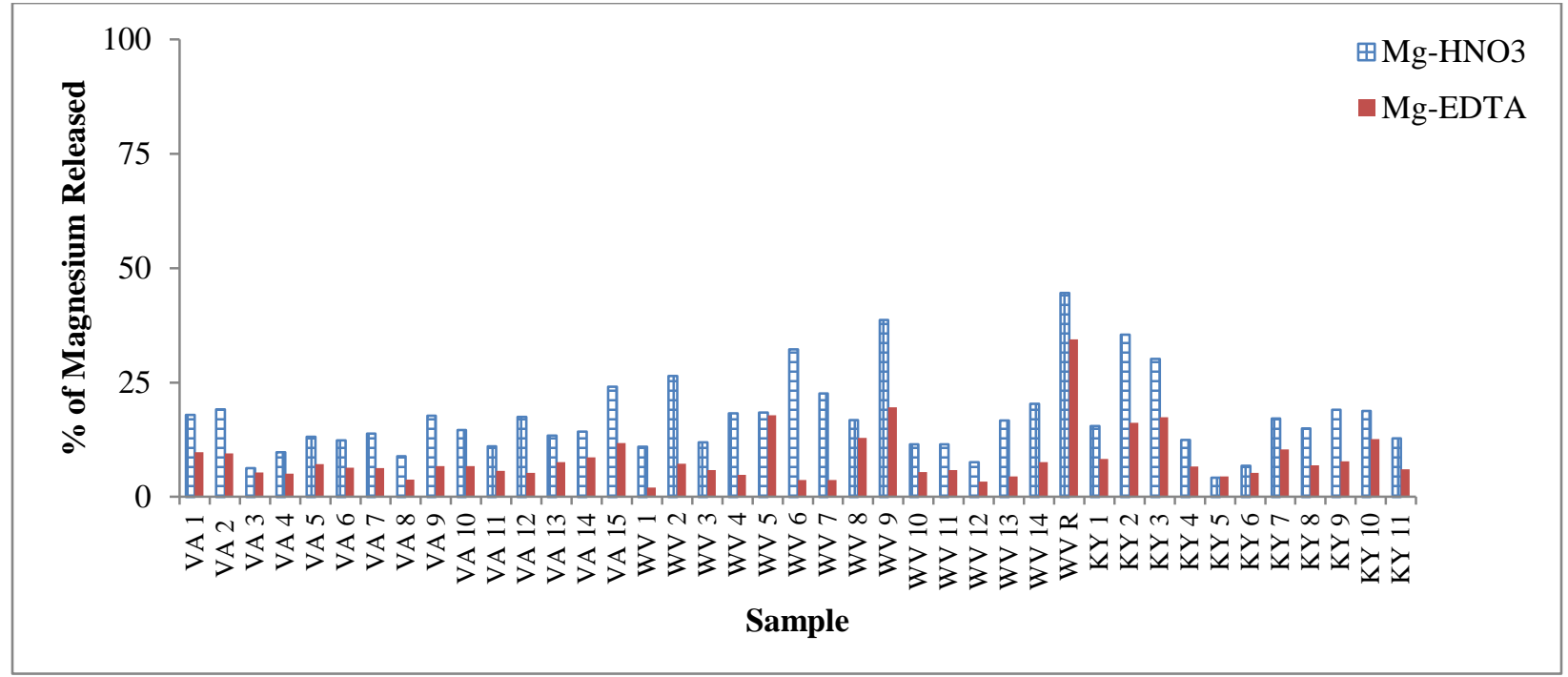

Figure 3.8: Percent of magnesium released from the two shaking methods compared to "total" digestion. 


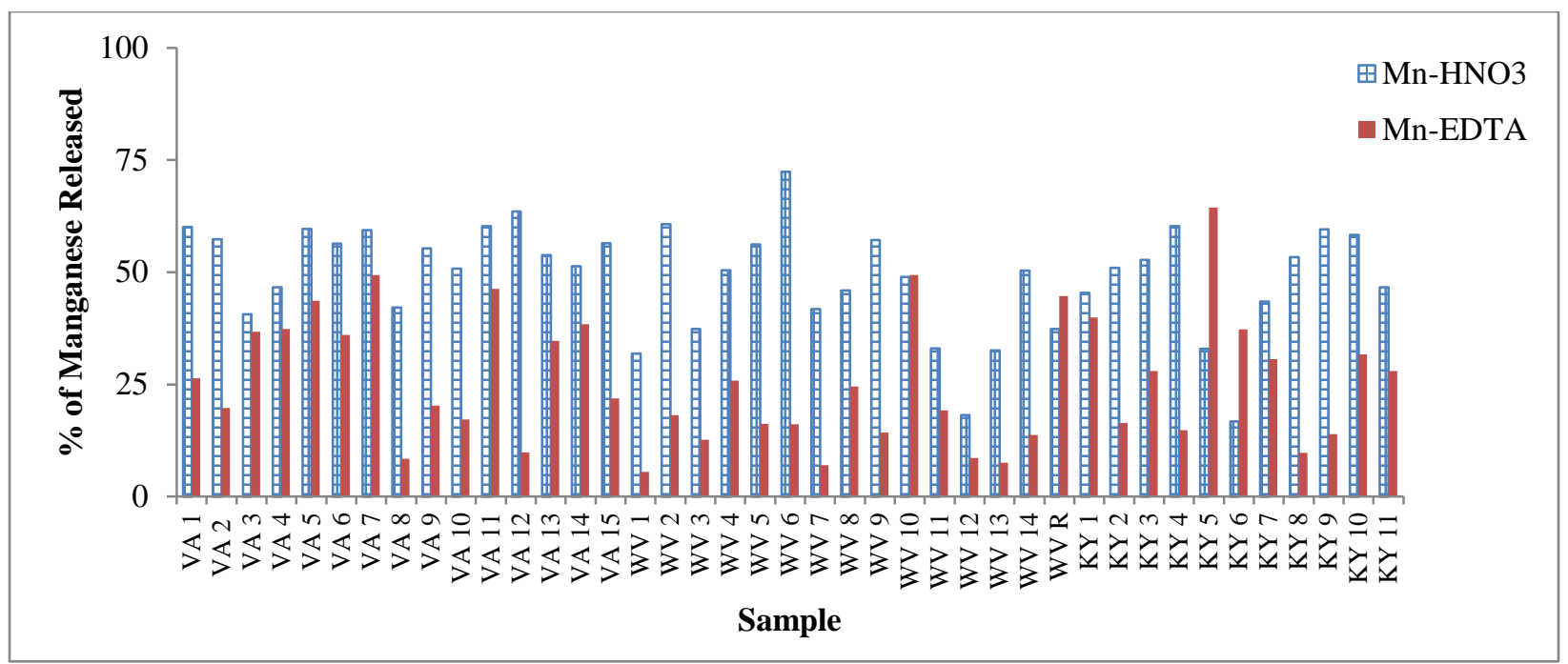

Figure 3.9: Percent of manganese released from the two shaking methods compared to "total" digestion.

Elements released from samples shaken in the EDTA solution were also compared to the microwave digestion concentrations to find percent release. Figures 3.5 through 3.9 present a visual representation of these percentages by element. Aluminum release ranged from $0.1 \%$ to $8.0 \%$ out of total microwave digestion concentrations for all forty-one samples. Iron release ranged from $1.0 \%$ to $20 \%$. The percent of release for manganese ranged from $5.0 \%$ to $65 \%$. Magnesium and calcium ranged from $2 \%$ to $35 \%$, and $20 \%$ to $100 \%$, respectively.

\subsection{Comparison of the Three Methods}

\subsubsection{Regression}

These three methods were compared via regression to test for relationships among concentrations of constituents released at their respective endpoints (i.e. 72 hours for the dilute $\mathrm{HNO}_{3}$ samples, 168 hours for the samples shaken in EDTA, and concentrations obtained after microwave digestion.) Table 3.6 lists $\mathrm{R}^{2}$ values for elements released using the dilute $\mathrm{HNO}_{3}$ and 
EDTA methods. The two shaking methods displayed strong relationships with respect to calcium, magnesium and manganese concentrations. Table 3.7 displays the relationship between microwave digestion and the dilute $\mathrm{HNO}_{3}$ shaking method with respect to elements released. These two methods were strongly related in terms of calcium concentrations $\left(r^{2}=0.95\right)$ released. Microwave digestion and shaking in dilute $\mathrm{HNO}_{3}$ also showed a strong relationship with magnesium concentrations released from the overburden samples. Table 3.8 highlights $\mathrm{R}^{2}$ values for elements released via microwave digestion and the EDTA method. As expected, calcium, magnesium, and manganese proved to be strongly correlated among all three methods.

Table 3.6: Relationship between dilute $\mathrm{HNO}_{3}$ and EDTA in respect to elements released.

\begin{tabular}{lll}
\hline Element & $\mathbf{R}^{2}$ & Trend \\
\hline Aluminum & $0.35^{* * * *}$ & Linear \\
Iron & $0.60^{* * * *}$ & Linear \\
Manganese & $0.34^{* * * *}$ & Linear \\
Magnesium & $0.89 * * * *$ & Linear \\
Calcium & $0.91^{* * * *}$ & Linear \\
\hline
\end{tabular}

**** Significant at the 0.0001 probability level. 
Table 3.7: Relationship between microwave digestion and dilute $\mathrm{HNO}_{3}$ in respect to elements released.

\begin{tabular}{lll}
\hline Element & $\mathbf{R}^{2}$ & Trend \\
\hline Aluminum & $0.19^{* * *}$ & Linear \\
Iron & $0.13^{*}$ & Linear \\
Manganese & $0.66^{* * * *}$ & Linear \\
Magnesium & $0.58^{* * * *}$ & Linear \\
Calcium & $0.95^{* * * *}$ & Linear \\
\hline
\end{tabular}

*, ***, **** Significant at the $0.05,0.001$ and 0.0001 probability levels, respectively.

Table 3.8: Relationship between microwave digestion and EDTA in respect to elements released.

\begin{tabular}{lll}
\hline Element & $\mathbf{R}^{2}$ & Trend \\
\hline Aluminum & $0.20^{*}$ & Linear \\
Iron & $0.19^{*}$ & Linear \\
Manganese & $0.67^{* * * *}$ & Linear \\
Magnesium & $0.59^{* * * *}$ & Linear \\
Calcium & $0.91^{* * * *}$ & Linear
\end{tabular}

*, **** Significant at the 0.05 and 0.0001 probability levels, respectively.

\subsubsection{Elemental and Mineralogical Discussion}

The earth’s outer surface layer is primarily composed of oxygen (47\%), silica (28\%) aluminum (8\%), iron (5\%), calcium (4\%), magnesium (2\%), and sodium (3\%) (Evangelou, 1998). Calcium from overburden samples in the Appalachian region is presumably in the form of calcite $\left(\mathrm{CaCO}_{3}\right)$ and is relatively soluble $\left(\mathrm{K}_{\mathrm{sp}}=3.36 \mathrm{X} 10^{-9}\right.$ at $\left.25^{\circ} \mathrm{C}\right)$. In a mineralogical study conducted by the United States Geologic Service (USGS), they found that cores drilled in northern and southern coal fields of West Virginia were comprised of on average only $0.8 \% \pm$ 3\% calcite using X-ray Fluorescence (XRF) (Dulong et al., 2002). However, due to the relatively 
high solubility of this mineral, strong relationships among these three methods were expected. Magnesium in the form of magnesium (II) carbonate is also relatively soluble $\left(\mathrm{K}_{\mathrm{sp}}=3.5 \times 10^{-8}\right.$ at $25^{\circ} \mathrm{C}$ ). The USGS found that West Virginia strata were on average comprised of $0.3 \% \pm 0.7 \%$ dolomite (Ca, $\left.\mathrm{Mg}\left(\mathrm{CO}_{3}\right)_{2}\right)$ using XRF analysis. Magnesium could also be a by-product of weathered chlorite $\left.(\mathrm{Mg}, \mathrm{Fe})_{3}(\mathrm{Si}, \mathrm{Al})_{4} \mathrm{O}_{10}\right)$, which makes up on average $2.0 \% \pm 1.7 \%$ of the coal bearing strata in West Virginia. Magnesium, however, may come from illite $\left(\mathrm{K}, \mathrm{H}_{3} \mathrm{O}\right)(\mathrm{Al}, \mathrm{Mg}, \mathrm{Fe})_{2}(\mathrm{Si}, \mathrm{Al})$, which makes up $17.8 \% \pm 12.4 \%$ of the overburden strata in West Virginia coal fields (Dulong et al., 2002). Microwave digestion is capable of breaking the mineral structure, which could potentially release magnesium in 2:1 clays such as vermiculite $\left(\mathrm{Mg}, \mathrm{Fe}_{2}, \mathrm{Al}\right)_{3}(\mathrm{Al}, \mathrm{Si})_{4} \mathrm{O}_{10}(\mathrm{OH})_{2} \bullet 4\left(\mathrm{H}_{2} \mathrm{O}\right)$ and illite (Evangelou, 1998). Manganese ions in solution result from weathered manganese oxides and hydroxides. These three methods involve the submersion of overburden material in various solutions, which encouraged weathering of manganese oxides and hydroxides, thereby increasing solubility through the reduction of manganese (IV) to manganese (II) (Schwertmann, 1985).

Although iron release was not strongly correlated among the three methods, iron was released in the highest concentrations from all three methods. One reason may be that iron is commonly found in many minerals of the Appalachian region such as chlorite, siderite $\left(\mathrm{FeCO}_{3}\right)$, illite, hematite $\left(\mathrm{Fe}_{2} \mathrm{O}_{3}\right)$, and pyrite $\left(\mathrm{FeS}_{2}\right)$, none of which are very soluble $\left(\mathrm{FeCO}_{3} \mathrm{~K}_{\mathrm{sp}}=3.13 \mathrm{X}\right.$ $10^{-11}, \mathrm{Fe}(\mathrm{OH})_{2} \mathrm{~K}_{\mathrm{sp}}=4.87 \times 10^{-17}, \mathrm{FeS} \mathrm{K} \mathrm{sp}=8 \times 10^{-19}, \mathrm{Fe}(\mathrm{OH})_{3} \mathrm{~K}_{\mathrm{sp}}=2.79 \times 10^{-39}$ at $25^{\circ}$ Celsius). Aluminum concentrations were also released in large amounts from the overburden samples due to the presence of aluminum in many minerals in this region. Planes of aluminum molecules are arranged hexagonally in dioctahedral sheets and these octahedral sheets combine with tetrahedral sheets to form layers that make up various minerals. Common minerals in the 
Appalachian region which contain aluminum are chlorite, kaolinite $\left(\mathrm{Al}_{2} \mathrm{Si}_{2} \mathrm{O}_{5}(\mathrm{OH})_{4}\right)$, illite, albite $\left(\mathrm{NaAlSi}_{3} \mathrm{O}_{8}\right)$, and orthoclase $\left(\mathrm{KAlSi}_{3} \mathrm{O}_{8}\right)$. Kaolinite and illite make up the largest proportions of the shale strata in this region (15\% $\pm 6.5 \%$ and $17.8 \% \pm 12.4 \%$, respectively) (Dulong et al., 2002). Sulfate in the form of calcium sulfate is relatively soluble $\left(\mathrm{K}_{\mathrm{sp}}=9.1 \mathrm{X} 10^{-}\right.$

${ }^{6}$ ) and is a major ion of concern in contaminated mine drainage. Sulfate can contribute to as much as 50\% of the TDS (Timpano et al., 2010), which was verified with some of the overburden samples in this study.

\subsection{Determining the Best Method}

When selecting a method to determine release of elements from overburden samples, several factors are important. Sample preparation, reproducibility, accurate correlation to field water quality measurements, time, the human health risk of exposure to chemicals, the amount of training needed for personnel to conduct analyses, and cost are all factors to consider. When considering four of these factors (time, risk, training, and cost), shaking with dilute $\mathrm{HNO}_{3}$ proved to be a best method of the three alternatives (Table 3.9). Although shaking with dilute $\mathrm{HNO}_{3}$ takes three days to get a maximum constituent release index, very little effort is needed to take the samples off of the shaker and to filter the samples prior to ICP-OES analysis. EDTA takes the same amount of effort, but at least five days are required to reach a maximum constituent release index, and aliquots from the samples must be diluted before ICP-OES analysis, unless special nebulizers are used. Microwave digestion only takes one day to run, but it takes more effort for sample preparation. Prior to microwave digestion, the samples are combined with hazardous concentrated acids and left in a fume hood for one day to let all emerging gases escape. For safety and risk, extreme caution should be taken when working with concentrated acids. The dilute $\mathrm{HNO}_{3}$ solution is prepared by adding $2 \mathrm{~mL}$ of concentrated $\mathrm{HNO}_{3}$ to $2 \mathrm{~L}$ of 
water, so only a one-time exposure to a small volume of concentrated $\mathrm{HNO}_{3}$ gave this method a moderate safety rating. EDTA is only slightly hazardous in case of skin and eye contact, as well as ingestion and inhalation, and was ranked a low safety risk. Microwave digestion had a high safety risk because it involved $12 \mathrm{~mL}$ of concentrated $\mathrm{HNO}_{3}$ and $\mathrm{HCl}$ per sample. Extreme caution must be taken when working frequently with concentrated acids and in large quantities. No formal training is required for the dilute $\mathrm{HNO}_{3}$ and EDTA methods, except for learning how to properly dilute and filter samples. Formal training is necessary for properly preparing samples and assembling digestion vessels for microwave digestion, and programming the microwave. The cost for the dilute $\mathrm{HNO}_{3}$ method is relatively minimal. Very little acid is necessary for the preparation of dilute $\mathrm{HNO}_{3}$ solution for a large number of samples. The preparation of EDTA requires a large mass of ethylenediaminetetraacetic acid disodium salt for $2 \mathrm{~L}$ of solution. Both of these methods also have costs associated with the Wrist-Action Shaker, the bottles used, filter paper, and ICP capabilities. The start-up cost associated with microwave digestion is very expensive if you do not have a laboratory-grade microwave and the appropriate vessels and associated equipment for preparation and operation. The use of two acids also increases the cost for this method. In terms of time, safety, training, and cost, the best method for determining elemental release from overburden material is the dilute $\mathrm{HNO}_{3}$ method. 
Table 3.9 Summary table of the three methods.

\section{Factors}

\begin{tabular}{lcccc}
\cline { 2 - 4 } Method & Time & Safety Risk & Training & Cost \\
\hline Dilute $\mathrm{HNO}_{3}$ & 3 days & Moderate & Low & $\$$ \\
EDTA & 5+ days & Low & Low & $\$ \$$ \\
Microwave & 2 days & High & High & $\$ \$ \$ \$$ \\
\hline
\end{tabular}

Although dilute $\mathrm{HNO}_{3}$ was the best method in terms of time, safety, training, and cost, it was imperative to test this method's (as well as the other two methods') ability to predict TDS release. We are assuming that EC is a preliminary indicator for TDS release potential. The sum of cations released from each method should give an approximate TDS concentration, and should ideally correlate with EC. The sum of cations released from all 41 samples from the microwave digestion technique was compared to the 2:1 EC obtained from all overburden samples (Figure 3.10). The $\mathrm{R}^{2}$ of these two parameters was 0.31 , however if you remove the refuse sample (WV R) from the dataset the relationship decreases to 0.07 . The lack of relationship provided strong evidence that elements released from the microwave digestion method are not a useful tool for TDS release prediction. In a similar fashion, the sum of cations released from all 41 samples after 168 hours of shaking in the EDTA solution was compared to EC (Figure 3.11). No relationship ( $\mathrm{R}^{2}=0.55$, but decreases to 0.08 with the removal of WV R) existed between these two parameters, ruling out EDTA as a useful tool for TDS prediction. We had hoped that the cations released from the dilute $\mathrm{HNO}_{3}$ method would have a strong relationship with EC, unfortunately this was not the case. The sum of cations released after 72 hours of shaking in dilute $\mathrm{HNO}_{3}$ did not show a relationship with $\mathrm{EC}\left(\mathrm{R}^{2}=0.25\right.$, but decreases to 0.09 with the 
removal of WV R) (Figure 2.12). Although the dilute $\mathrm{HNO}_{3}$ method was a relatively quick and easy method for weathering overburden material, it does not prove to be effective for TDS release prediction, and neither do the other two methods.

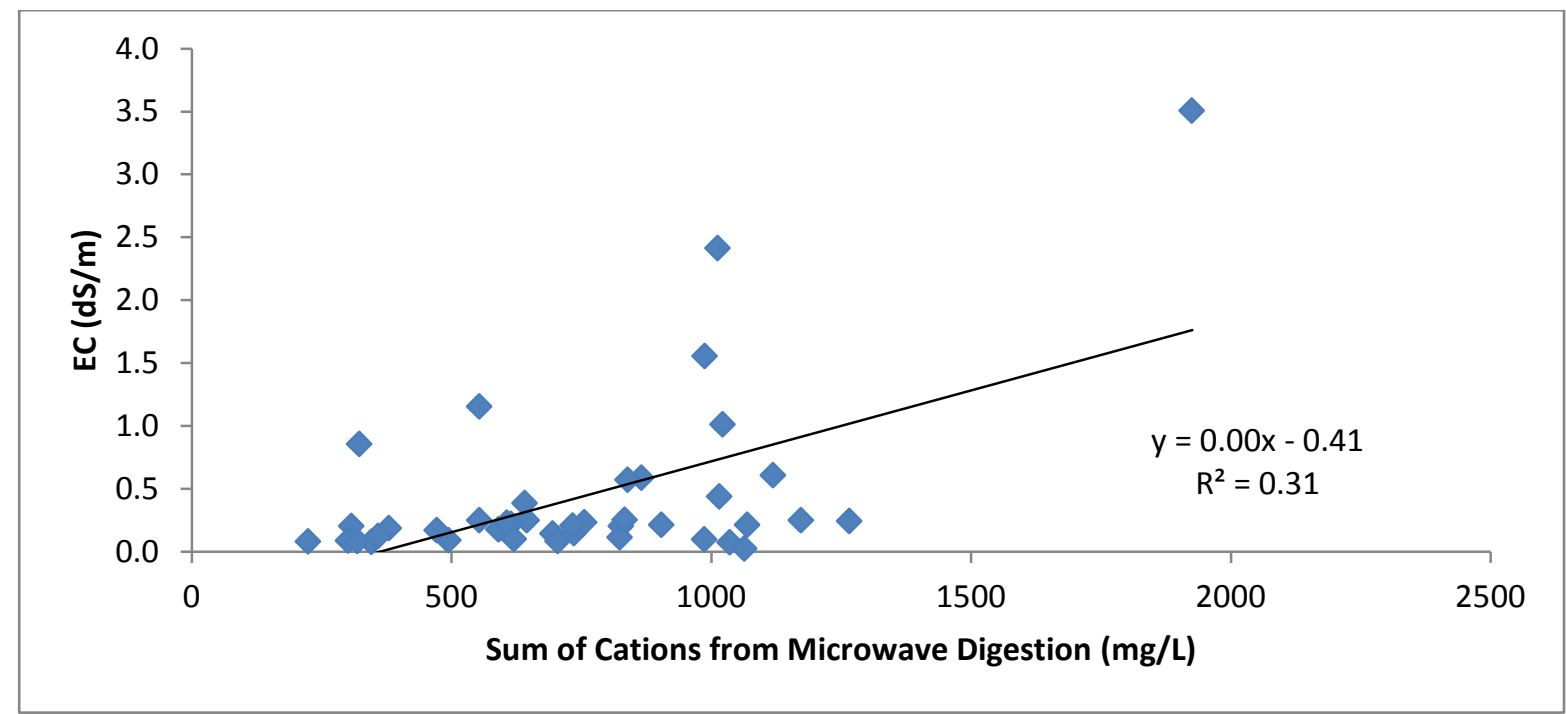

Figure 3.10: The sum of cations released from the microwave digestion method, compared to EC of the bulk sample.

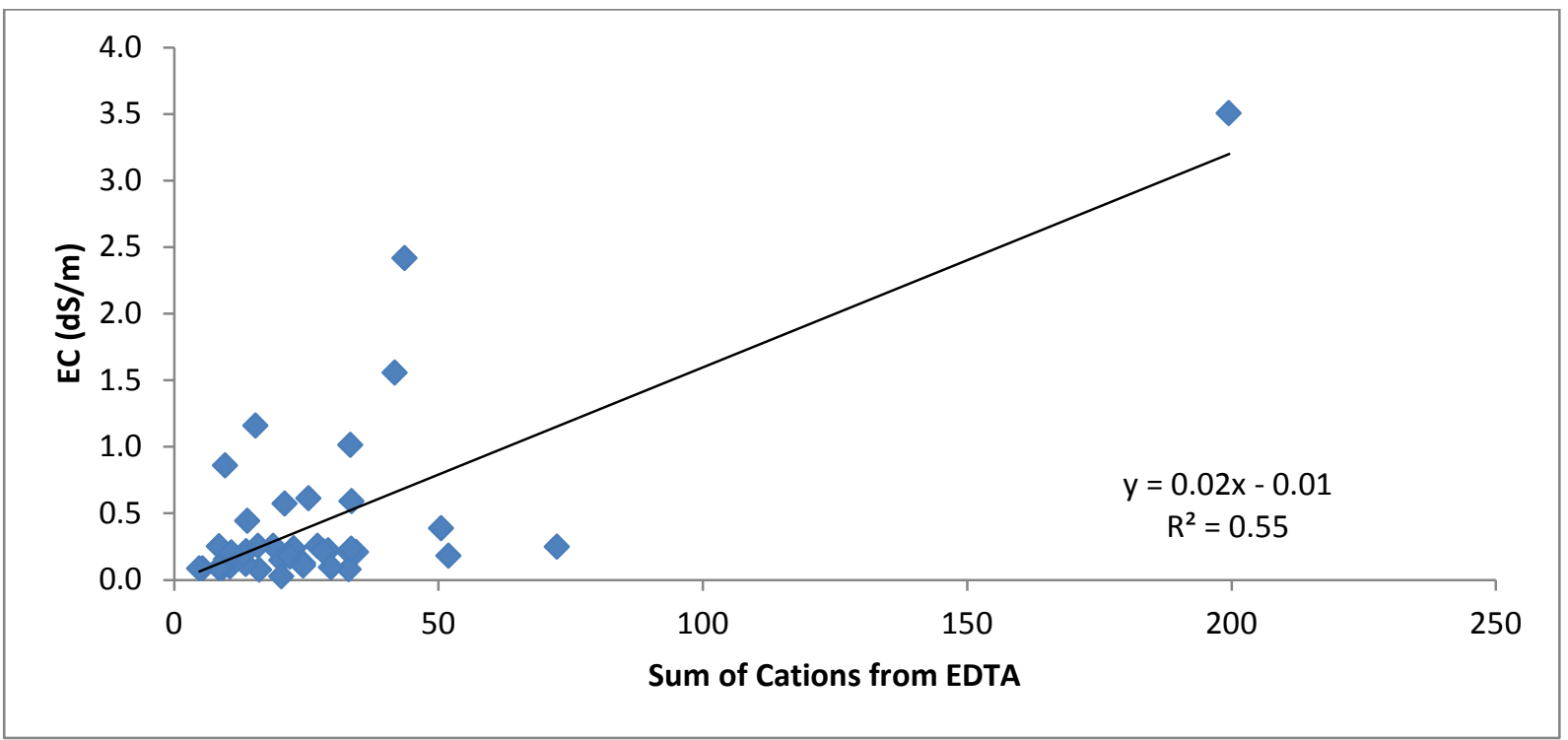

Figure 3.11: The sum of cations released from the EDTA method, compared to EC of the bulk sample. 


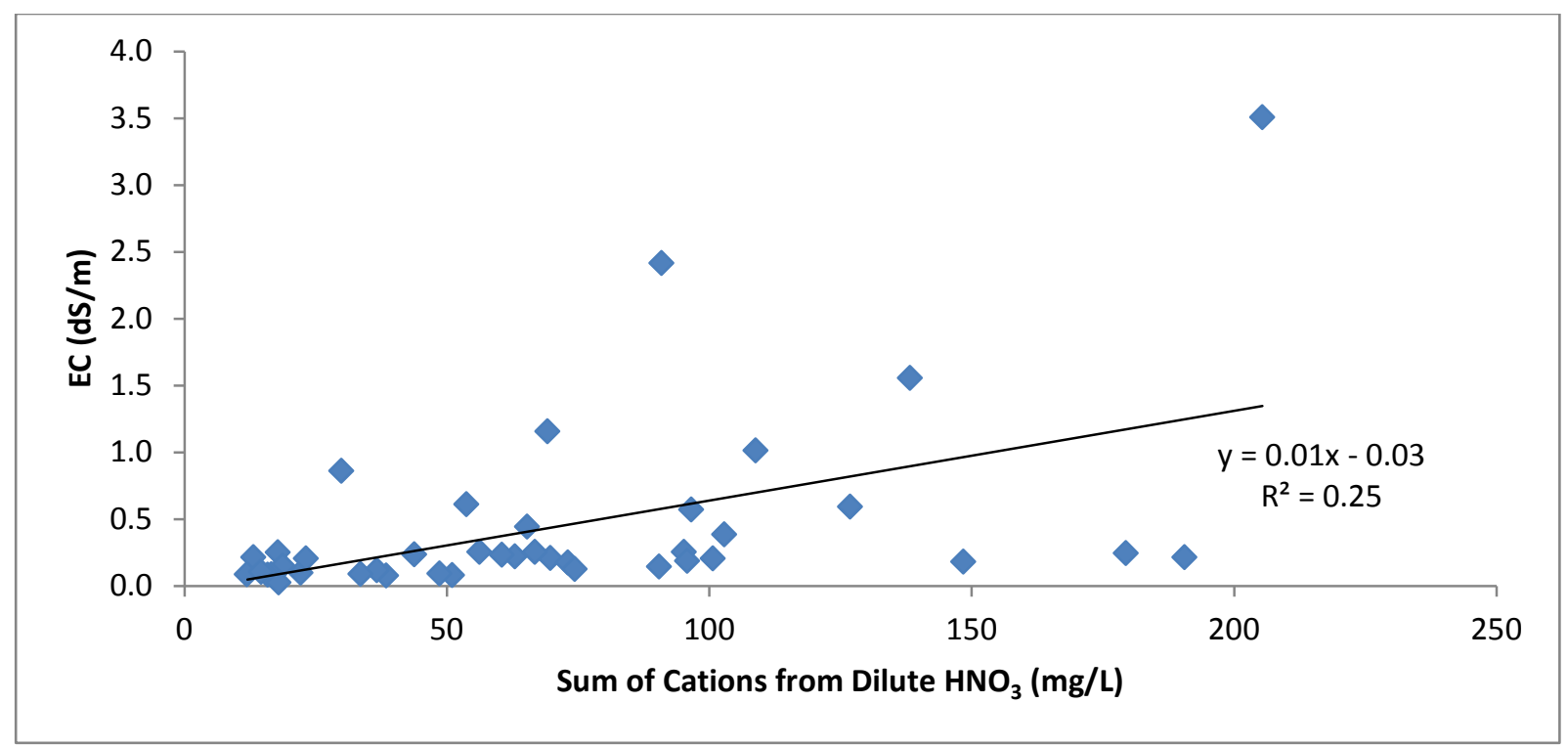

Figure 3.12: The sum of cations released from the dilute $\mathrm{HNO}_{3}$ method, compared to EC of the bulk sample.

\subsection{Determination of a TDS Release Index}

Although the sum of cations from all three methods were ruled out as useful techniques for predicting TDS release, it was important to look at other parameters that may influence TDS. To do this, all further analysis was performed on concentrations acquired after three days of shaking using the dilute $\mathrm{HNO}_{3}$ method. These samples had a charge balance error ranging from 41 to 97 percent. A positive charge balance error may indicate that one or more anions have been under-determined. We are making two assumptions that (1) bicarbonate is a prominent factor missing from this charge balance, and (2) carbonate is a by-product of weathering calcium carbonate. To validate these assumptions, the difference between the sum of cations (eq/L) and sum of anions (eq/L) was compared to calcium concentrations (eq/L). The resulting relationship suggested that bicarbonate was an essential component missing from the charge balance.

Principle Components Analysis (PCA) was first used as an exploratory analysis to determine which factors were most strongly related to TDS, and to quickly discard factors that 
were not useful for TDS analysis. Figure 3.13 is a Scree Plot which is used as a visual representation of the appropriate number of principle components to use in a PCA. In this case, the first principle components accounted for about $64 \%$ of the variability within the original data set, and principle component 2 accounted for about 30\% of the variation. Seventeen factors were analyzed for PCA: the cations - aluminum, iron, calcium, magnesium, manganese, potassium, phosphorus and sodium, and the sum of those cations; the anions - sulfate and chloride; chroma; paste $\mathrm{pH}$; paste EC; calculated TDS from the paste EC; TDS measured as the sum of the cations and anions; and maximum potential acidity (MPA). Factor loadings are graphically demonstrated in Figure 3.14. The eigenvectors pointing in the lower left section of the plot showed strong similarities among paste EC ( $\mathrm{dS} \mathrm{m}^{-1}$ ), maximum potential acidity (MPA) from the acid-base account analysis, and calculated TDS ( $\left.\mathrm{mg} \mathrm{L}^{-1}\right)$. TDS was calculated using equations (1) and (2) provided by Evangelou, 1998.

$$
\begin{aligned}
& \mathrm{TDS}=640 * \mathrm{EC}\left(\mathrm{dS} \mathrm{m}^{-1}\right) \\
& \mathrm{TDS}=640 *\left[\mathrm{EC}\left(\mathrm{dS} \mathrm{m}^{-1}\right)\right]^{1.087}
\end{aligned}
$$

Since this TDS value was calculated from paste EC, this relationship was expected. However, it was not expected that a strong similarity existed between MPA and TDS. Paste pH, chroma, and cation eigenvectors point in opposite directions of calculated TDS, therefore we investigated this relationship further. Figure 3.15 examines the relationship between paste $\mathrm{pH}$ and calculated TDS. We expected to see an inverse relationship between $\mathrm{pH}$ and TDS because metals tend to go into solution at lower $\mathrm{pH}$ values, thus producing more dissolved solids, but this was not the case. Inspection of the relationship between chroma and calculated TDS produced an 
apparent trend (Figure 3.16). Overburden samples with a chroma of 1 (gray) tended to produce high TDS (although with high variability), compared to samples with a chroma of 4 (brown), which produced very low TDS. The cation eigenvectors from PCA did not appear to influence TDS. $\mathrm{R}^{2}$ values from linear regression verify PCA results that cation concentrations do not predict TDS release (Table 3.10).

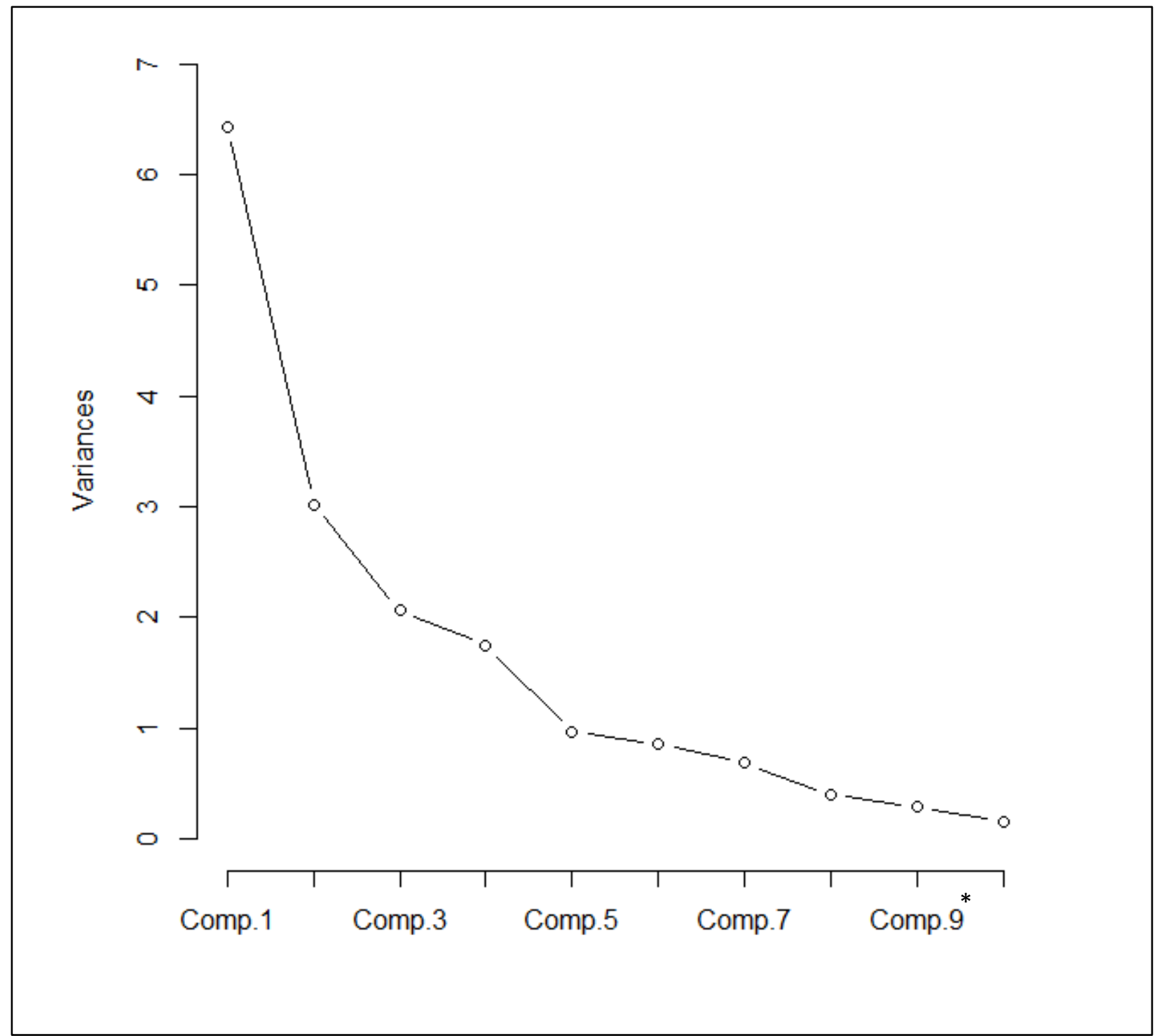

Figure 3.13: Scree Plot for the determination of the appropriate number of principle components to use.

* Seventeen components were analyzed, but the variance after the ninth component was negligible and therefore not included in the figure. 


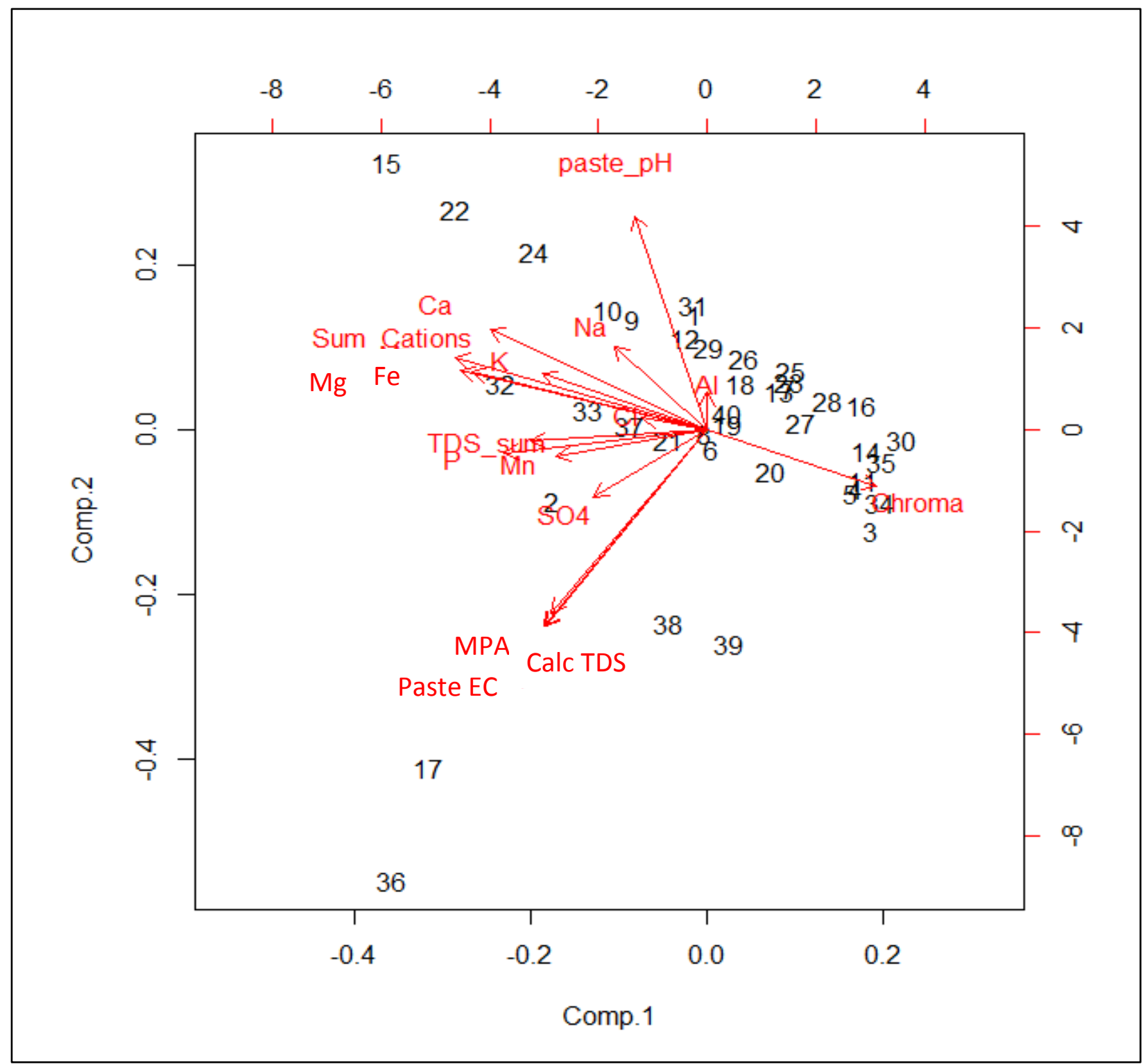

Figure 3.14: Principle Components Analysis for the first two principle components. Numbers correspond to the sample ID described in figures 3.3 to 3.5. 


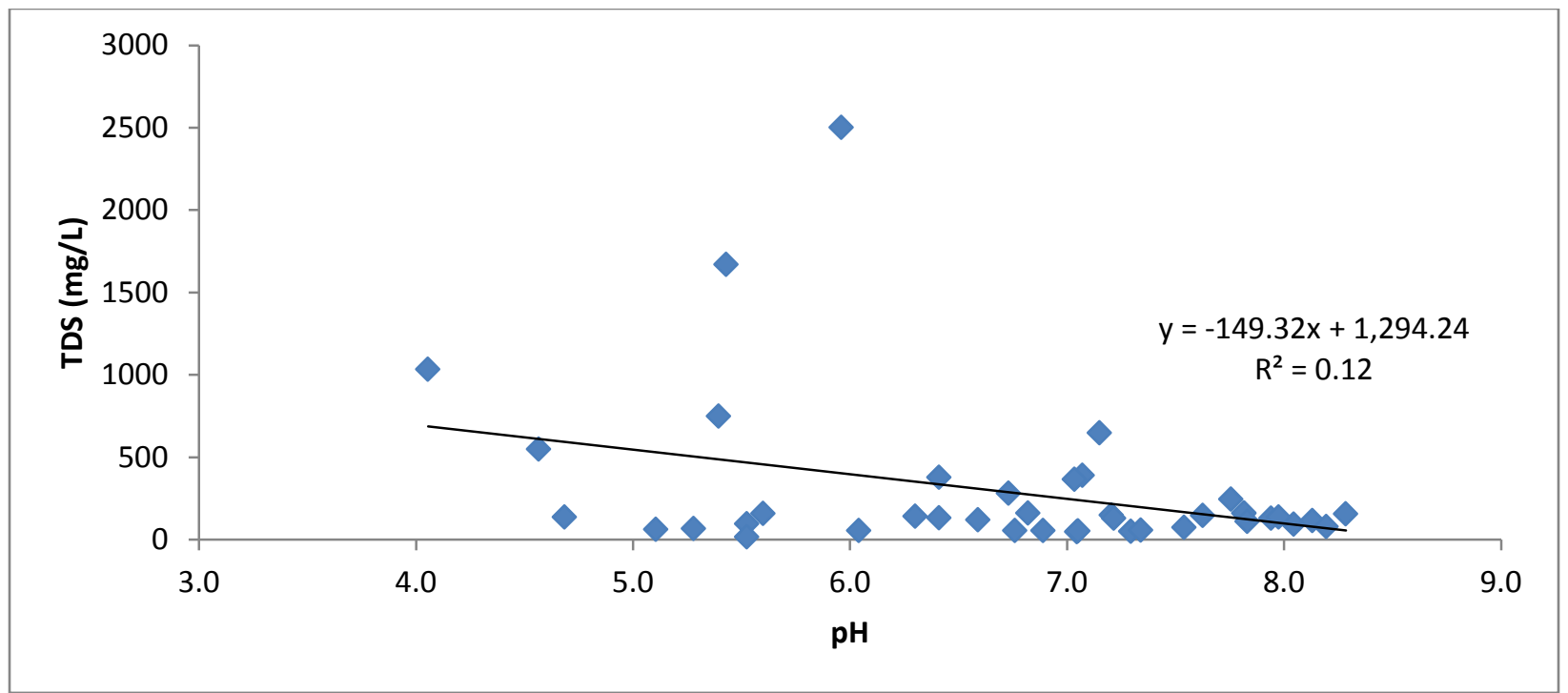

Figure 3.15: The relationship between $\mathrm{pH}$ and TDS for all forty-one overburden samples.

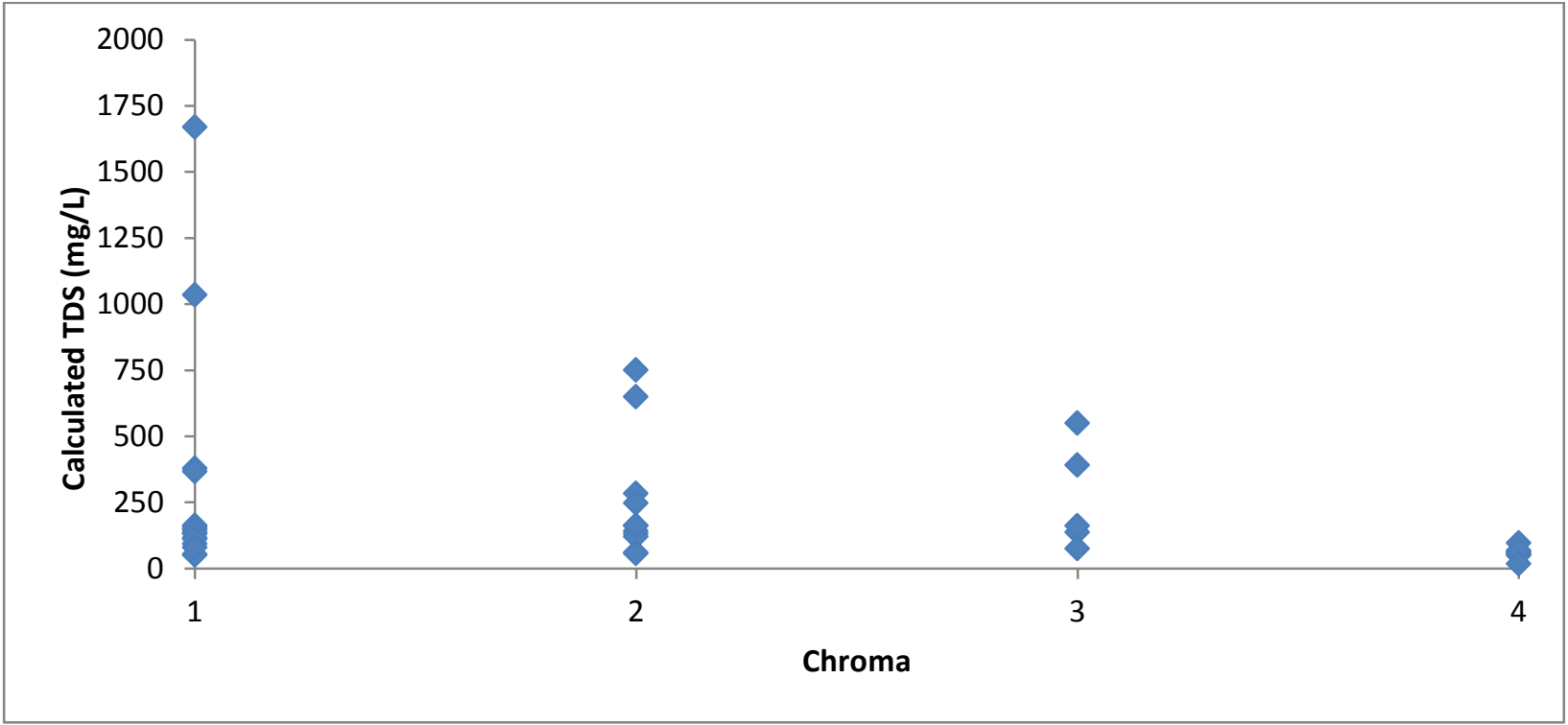

Figure 3.16: The relationship between chroma and TDS for all forty-one overburden samples. 
Table 3.10: The relationship between individual cations and calculated TDS for all samples, excluding outlier WV R.

\begin{tabular}{lll}
\hline Element & $\mathbf{R}^{2}$ & Trend \\
\hline Aluminum & 0.01 & Linear \\
Iron & 0.08 & Linear \\
Manganese & 0.13 & Linear \\
Magnesium & 0.12 & Linear \\
Calcium & 0.03 & Linear \\
\hline
\end{tabular}

Neutralization potential (NP) (mt per $1000 \mathrm{mt}$ of material) is an important parameter of the acid-base account that measures the alkalinity of overburden. We obtained NP data for the 14 West Virginia samples (not including the refuse sample WV R) from the coal company. NP versus TDS shows two outliers which happen to be WV 2 and WV 3 (Figure 3.17). These two samples had the highest NP (30 and $60 \mathrm{mt}$ per $1000 \mathrm{mt}$ of material) and also had the highest MPA (34 and $6.3 \mathrm{mt}$ per $1000 \mathrm{mt}$ of material) out of all of the West Virginia samples (Table 3.11). WV 2 is the only sample that produced more than $500 \mathrm{mg} / \mathrm{L}$ of TDS, and when looking more closely had the highest net acidity. WV 2 had almost equally high amounts of NP and MPA, which account for both the acidic and alkaline properties of the sample. When an acid and base react they produce water and a salt, which verifies the high TDS concentration of this particular sample. When removing these two outliers, NP and TDS have a relationship of $\mathrm{R}^{2}=$ 0.48, which indicates that in general, as NP decreases, TDS increases (Figure 3.18). 


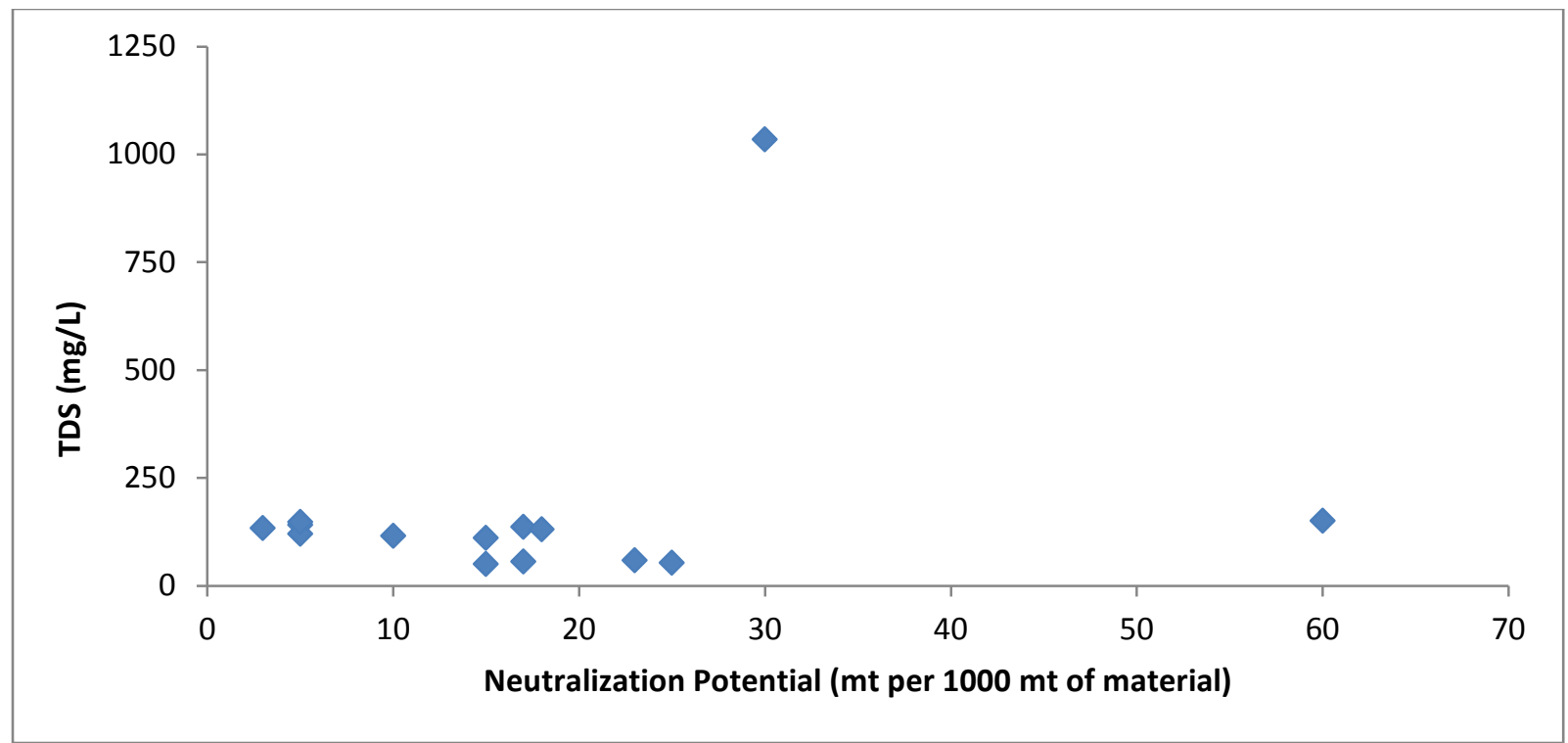

Figure 3.17: Neutralization Potential (NP) versus TDS for all West Virginia samples. 
Table 3.11: Neutralization potential provided from the coal company.

\begin{tabular}{|c|c|c|c|c|c|}
\hline Sample & TDS $^{*}$ & $\mathrm{NP}$ & MPA & Net & $\mathrm{pH}$ \\
\hline & $\mathrm{mg} \mathrm{L}^{-1}$ & $-m t$ & $0 \mathrm{mt}$ of & & \\
\hline WV 1 & 53 & 25 & 0.7 & -24 & 7.1 \\
\hline WV 2 & 1034 & 30 & 34 & +4 & 4.1 \\
\hline WV 3 & 150 & 60 & 6.3 & -54 & 7.2 \\
\hline WV 4 & 133 & 3 & 1.4 & -2 & 6.4 \\
\hline WV 5 & 141 & 5 & 6.3 & +1 & 6.3 \\
\hline WV 6 & 120 & 5 & 4.0 & -1 & 6.6 \\
\hline WV 7 & 137 & 17 & 1.8 & -15 & 8.0 \\
\hline WV 8 & 50 & 15 & 0.8 & -14 & 7.3 \\
\hline WV 9 & 115 & 10 & 1.0 & -9 & 8.1 \\
\hline WV 10 & 59 & 23 & 0.5 & -23 & 7.3 \\
\hline WV 11 & 148 & 5 & 2.3 & -3 & 7.6 \\
\hline WV 12 & 131 & 18 & 2.2 & -16 & 7.2 \\
\hline WV 13 & 56 & 17 & 0.7 & -16 & 6.9 \\
\hline WV 14 & 111 & 15 & 1.8 & -13 & 7.8 \\
\hline
\end{tabular}

*TDS value is from the conversion of EC to TDS using Evangelou's equations.

NP: Neutralization Potential; MPA: Maximum Potential Acidity; Net: Net Neutralizing Potential 


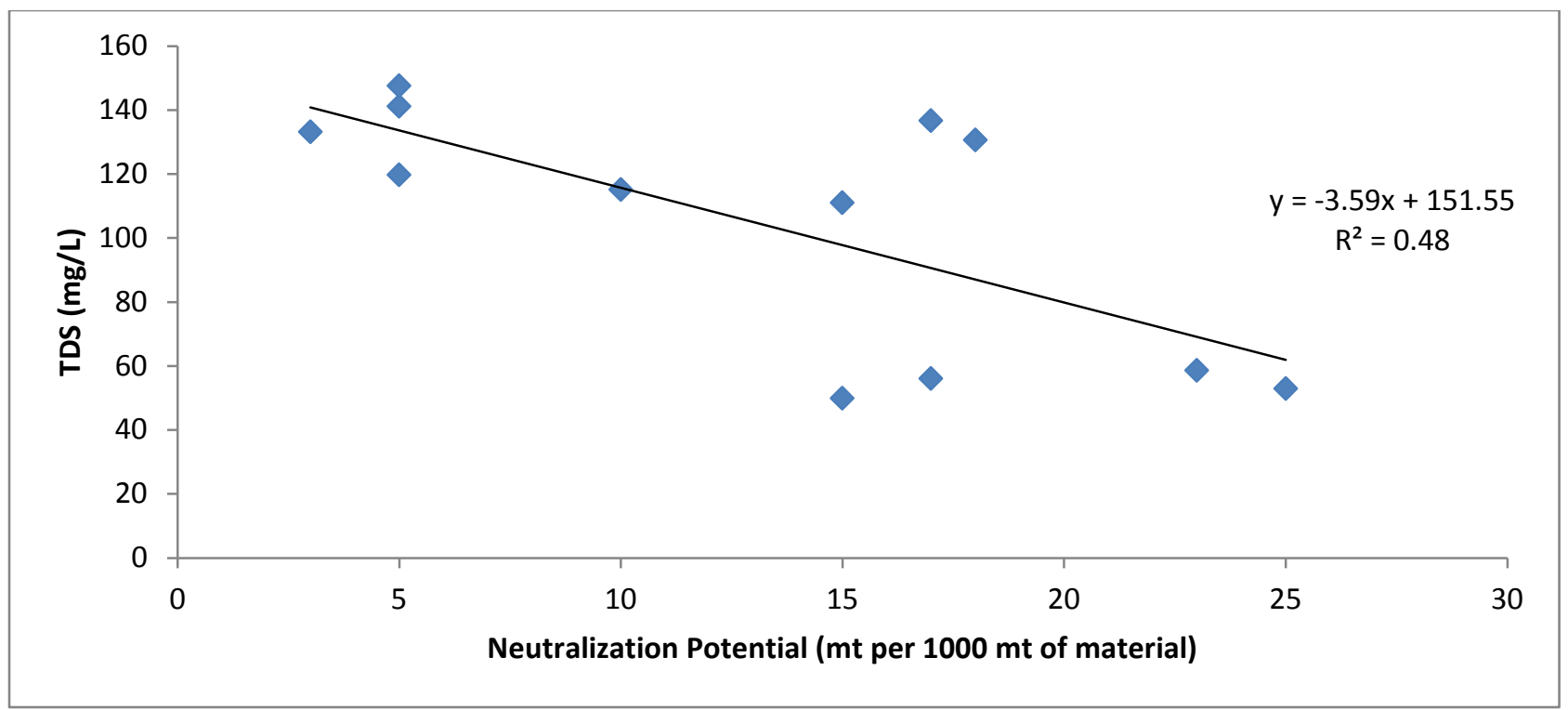

Figure 3.18: Neutralization potential versus TDS, excluding two outliers.

Percent sulfur was measured by another WVU student, Marianne Mannix, with a LECO CNS analyzer (TruSpec S, St. Joseph, MI). Percent sulfur, MPA, pH, and EC are shown in Table 3.11 for all overburden samples. MPA (mt per $1000 \mathrm{mt}$ of material) was calculated by multiplying \%S by 31.25. This conversion factor comes from the assumption that overburden containing 1\% pyritic sulfur will yield an amount of sulfuric acid which would require $31.25 \mathrm{mt}$ of calcium carbonate to neutralize $1000 \mathrm{mt}$ of the material (Skousen et al., 1990). Figure 3.19 shows the relationship between MPA and TDS. When the y-axis is transformed to a log-scale, a strong relationship $\left(\mathrm{R}^{2}=0.80\right)$ is apparent with a power function. Based on this relationship, MPA ranging from $0.0-1.0 \mathrm{mt}$ per $1000 \mathrm{mt}$ of material will be categorized in the low TDS potential category because TDS did not exceed $150 \mathrm{mg} \mathrm{L}^{-1}$. MPA roughly ranging from 1.0 to $3.0 \mathrm{mt}$ per $1000 \mathrm{mt}$ of material (Figure 3.17) produced a moderate amount of TDS (less than 300 $\mathrm{mg} \mathrm{L}^{-1}$ ), while MPA greater than $3.0 \mathrm{mt}$ per $1000 \mathrm{mt}$ of material produced concentrations of TDS that exceeded the USEPA's maximum contaminant limit of $500 \mathrm{mg} \mathrm{L}^{-1}$. This high TDS limit is 
not too distant from other literature where a value greater than $5.0 \mathrm{mt}$ per $1000 \mathrm{mt}$ in the Max Needed column of an acid-base account is flagged as likely to produce acid mine drainage, and samples below 5.0 are not likely to produce acid mine drainage (Skousen et al., 2002). 
Table 3.12: Mean values for \%S, MPA, paste $\mathrm{pH}$, and paste EC

\begin{tabular}{|c|c|c|c|c|}
\hline Sample & $\% S^{\mp}$ & MPA & $\mathrm{pH}$ & $\mathrm{EC}^{*}$ \\
\hline VA 1 & 0.07 & 2.2 & 7.8 & 0.25 \\
\hline VA 2 & 0.26 & 8.0 & 7.2 & 1.01 \\
\hline VA 3 & 0.05 & 1.6 & 4.7 & 0.21 \\
\hline VA 4 & 0.02 & 0.8 & 5.1 & 0.10 \\
\hline VA 5 & 0.04 & 1.2 & 5.6 & 0.25 \\
\hline VA 6 & 0.12 & 3.7 & 7.1 & 0.61 \\
\hline VA 7 & 0.02 & 0.5 & 7.0 & 0.08 \\
\hline VA 8 & 0.16 & 5.0 & 6.7 & 0.44 \\
\hline VA 9 & 0.08 & 2.4 & 7.9 & 0.20 \\
\hline VA 10 & 0.08 & 2.6 & 7.8 & 0.25 \\
\hline VA 11 & 0.02 & 0.6 & 5.5 & 0.15 \\
\hline VA 12 & 0.04 & 1.4 & 8.0 & 0.14 \\
\hline VA 13 & 0.04 & 1.2 & 7.5 & 0.12 \\
\hline VA 14 & 0.02 & 0.7 & 6.0 & 0.09 \\
\hline VA 15 & 0.09 & 2.7 & 8.3 & 0.25 \\
\hline WV 1 & 0.02 & 0.7 & 7.1 & 0.08 \\
\hline WV 2 & 1.08 & 34 & 4.1 & 1.56 \\
\hline WV 3 & 0.20 & 6.3 & 7.2 & 0.24 \\
\hline WV 4 & 0.04 & 1.4 & 6.4 & 0.21 \\
\hline WV 5 & 0.20 & 6.3 & 6.3 & 0.22 \\
\hline WV 6 & 0.13 & 4.0 & 6.6 & 0.19 \\
\hline WV 7 & 0.06 & 1.8 & 8.0 & 0.21 \\
\hline WV 8 & 0.02 & 0.8 & 7.3 & 0.08 \\
\hline WV 9 & 0.03 & 1.0 & 8.1 & 0.18 \\
\hline WV 10 & 0.02 & 0.5 & 7.3 & 0.09 \\
\hline WV 11 & 0.07 & 2.3 & 7.6 & 0.23 \\
\hline WV 12 & 0.07 & 2.2 & 7.2 & 0.20 \\
\hline WV 13 & 0.02 & 0.7 & 6.9 & 0.09 \\
\hline WV 14 & 0.06 & 1.8 & 7.8 & 0.17 \\
\hline WV R & 6.83 & 213 & 6.0 & 3.51 \\
\hline KY 1 & 0.02 & 0.6 & 6.8 & 0.08 \\
\hline KY 2 & 0.01 & 0.2 & 8.2 & 0.12 \\
\hline KY 3 & 0.09 & 2.8 & 7.8 & 0.39 \\
\hline KY 4 & 0.12 & 3.9 & 6.4 & 0.59 \\
\hline KY 5 & 0.01 & 0.4 & 5.3 & 0.10 \\
\hline KY 6 & 0.02 & 0.5 & 5.5 & 0.03 \\
\hline KY 7 & 0.90 & 28 & 5.4 & 2.42 \\
\hline KY 8 & 0.12 & 3.7 & 7.0 & 0.57 \\
\hline KY 9 & 0.23 & 7.3 & 5.4 & 1.16 \\
\hline KY 10 & 0.13 & 3.9 & 4.6 & 0.86 \\
\hline KY 11 & 0.05 & 1.5 & 6.8 & 0.25 \\
\hline
\end{tabular}

${ }^{*} \mathrm{EC}$ in $\mathrm{dS} \mathrm{m}^{-1}$

${ }^{\mathrm{F}}$ Values obtained by Marianne Mannix 


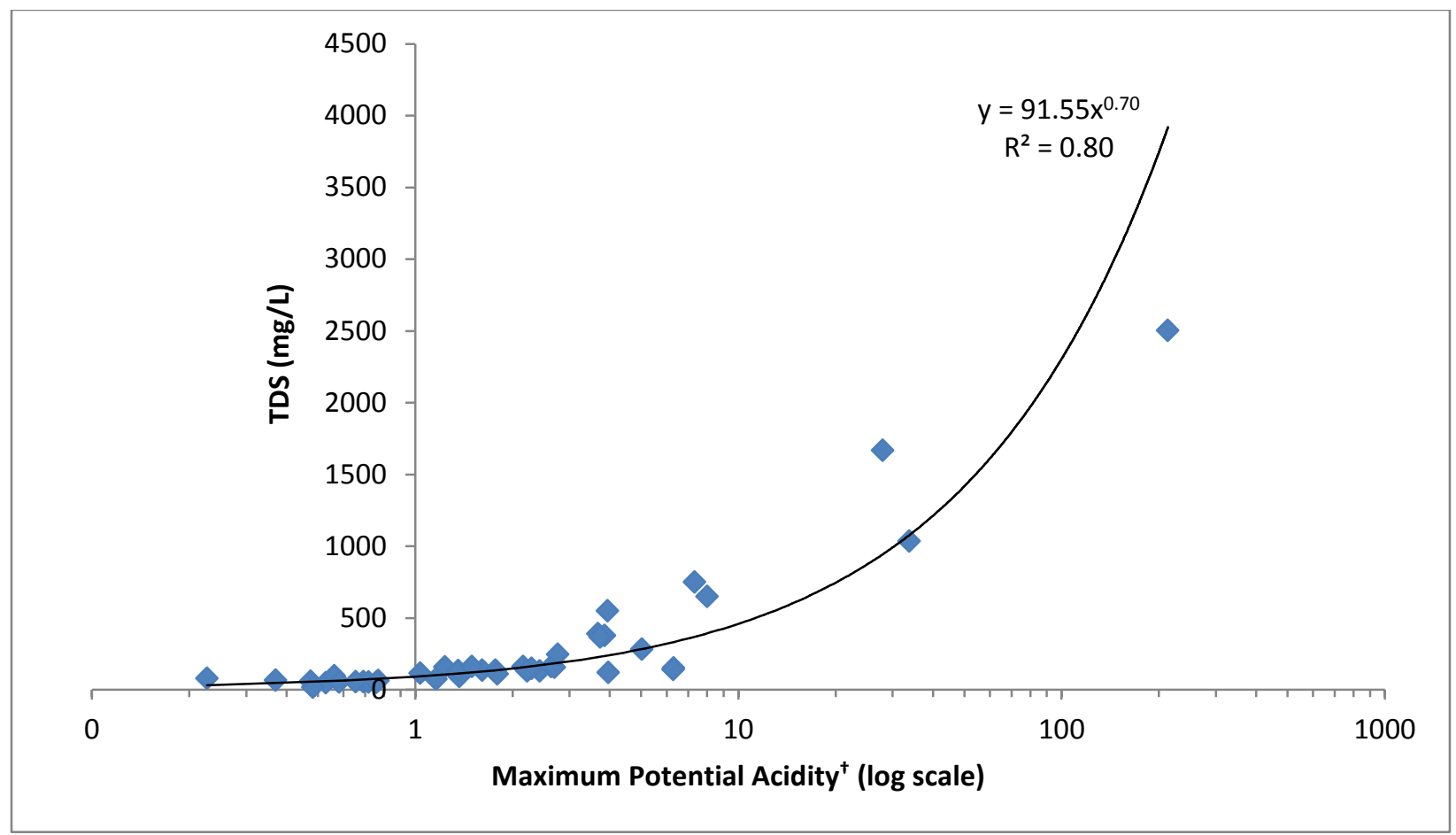

Figure 3.19: Maximum Potential Acidity versus TDS.

${ }^{\dagger} \mathrm{MPA}$ in units of mt per $1000 \mathrm{mt}$ of material

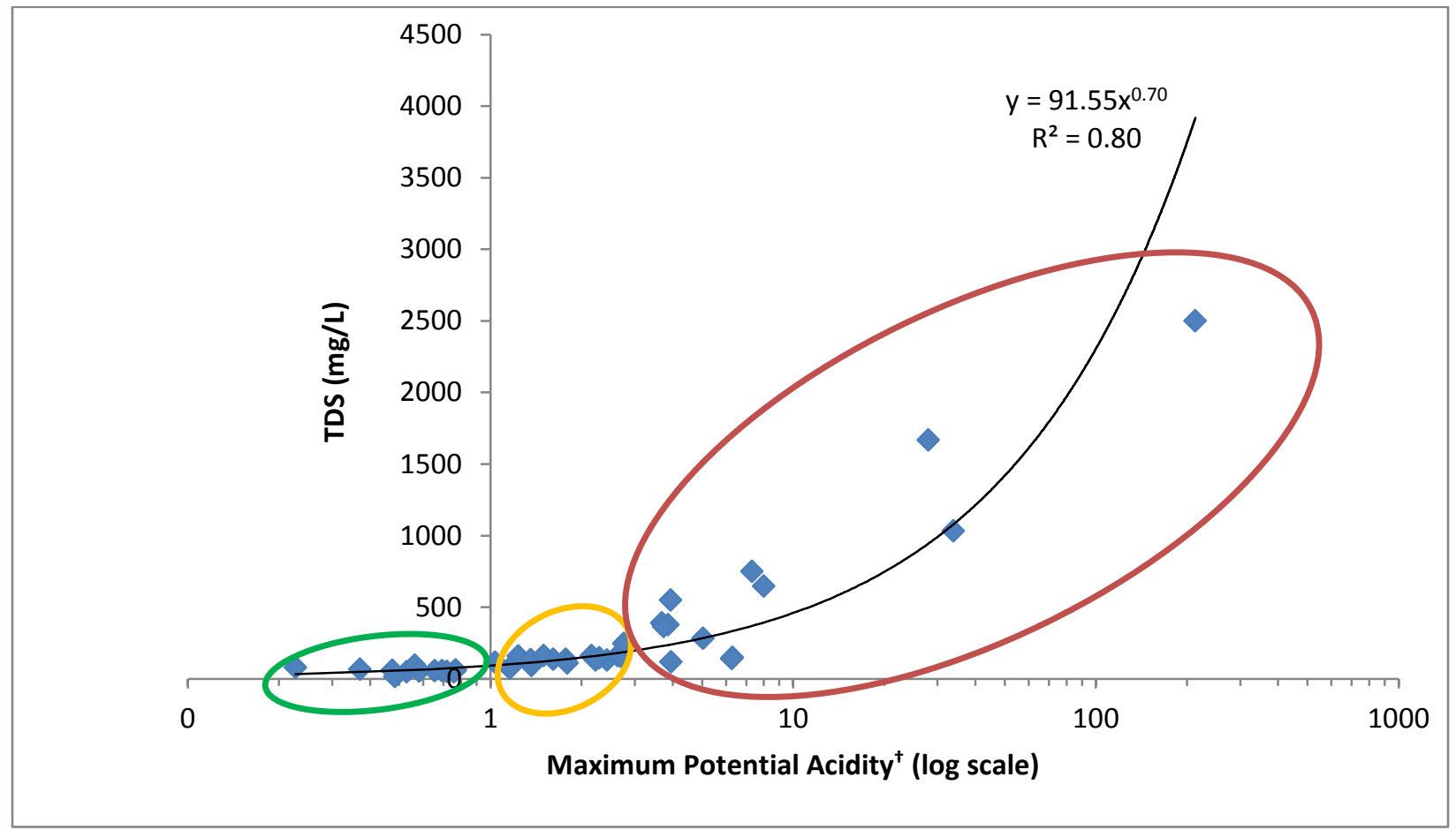

Figure 3.20: MPA versus TDS with high, medium, and low release indices.

${ }^{\dagger}$ MPA in units of mt per $1000 \mathrm{mt}$ of material 
This TDS release index is effective when comparing various elemental concentrations with TDS release from the forty-one overburden samples shaken in dilute nitric acid (Figures $1 \mathrm{~K}$ to 1P, Appendix 1). Future research will be conducted to obtain NP values for all of these samples. Some particular samples have an MPA greater than 3.0 but do not produce TDS concentrations greater than $500 \mathrm{mg} \mathrm{L}^{-1}$. This may be due to a high NP value, which can balance out the acidity, and potentially decrease TDS. Likewise, few samples have an MPA less than 3.0 but produce greater than $500 \mathrm{mg} \mathrm{L}^{-1} \mathrm{TDS}$ and this may also be due to a high NP value.

\subsection{Calculated TDS from WVU Compared to Virginia Tech's Leaching Columns}

For this section, I will refer to the results of the shaking experiment with dilute $\mathrm{HNO}_{3}$ as the "WVU study," and the results of a leaching experiment conducted at Virginia Polytechnic Institute and State University as the "Virginia Tech study." The TDS index obtained from the WVU study is only hypothetical unless it can be correlated and compared to other laboratory and field leaching studies. Virginia Tech has been conducting a similar weathering experiment using leaching columns with the same overburden samples used in the WVU study. Virginia Tech's data on elements leached from columns (Daniels et al., 2012) were compared to the results from the WVU study to determine how WVU's TDS release index relates to Virginia Tech's column leaching data. Figure 3.21 displays EC from Virginia Tech’s leaching columns for fifteen overburden samples. The EC is high during the first few leachings and decreases drastically until it tails out for the remainder of the leachings. The peak provides a prediction for short-term EC release, and the tail provides a prediction for long-term EC release. To test if the index of low TDS potential (0.0 - 1.0 MPA), moderate TDS potential (1.0- 3.0 MPA), and high TDS potential (3.0 + MPA) fits Virginia Tech’s leaching data; Virginia Tech’s maximum, minimum,

and average EC was first converted to calculated TDS (mg L ${ }^{-1}$ ) using formulas (1) and (2), and 
then compared to the MPA values obtained by WVU. Prior to correlating Virginia Tech's samples to MPA, the sum of cations released from the three WVU methods were first compared to Virginia Tech's calculated TDS, but still no relationship was found (Figures 1W-1Y, Appendix 1). Fortunately, The TDS of the WVU samples had a strong relationship with Virginia Tech's maximum, average, and minimum TDS with an $\mathrm{R}^{2}$ of $0.85,0.81$, and 0.86 , respectively (Figure 3.22).

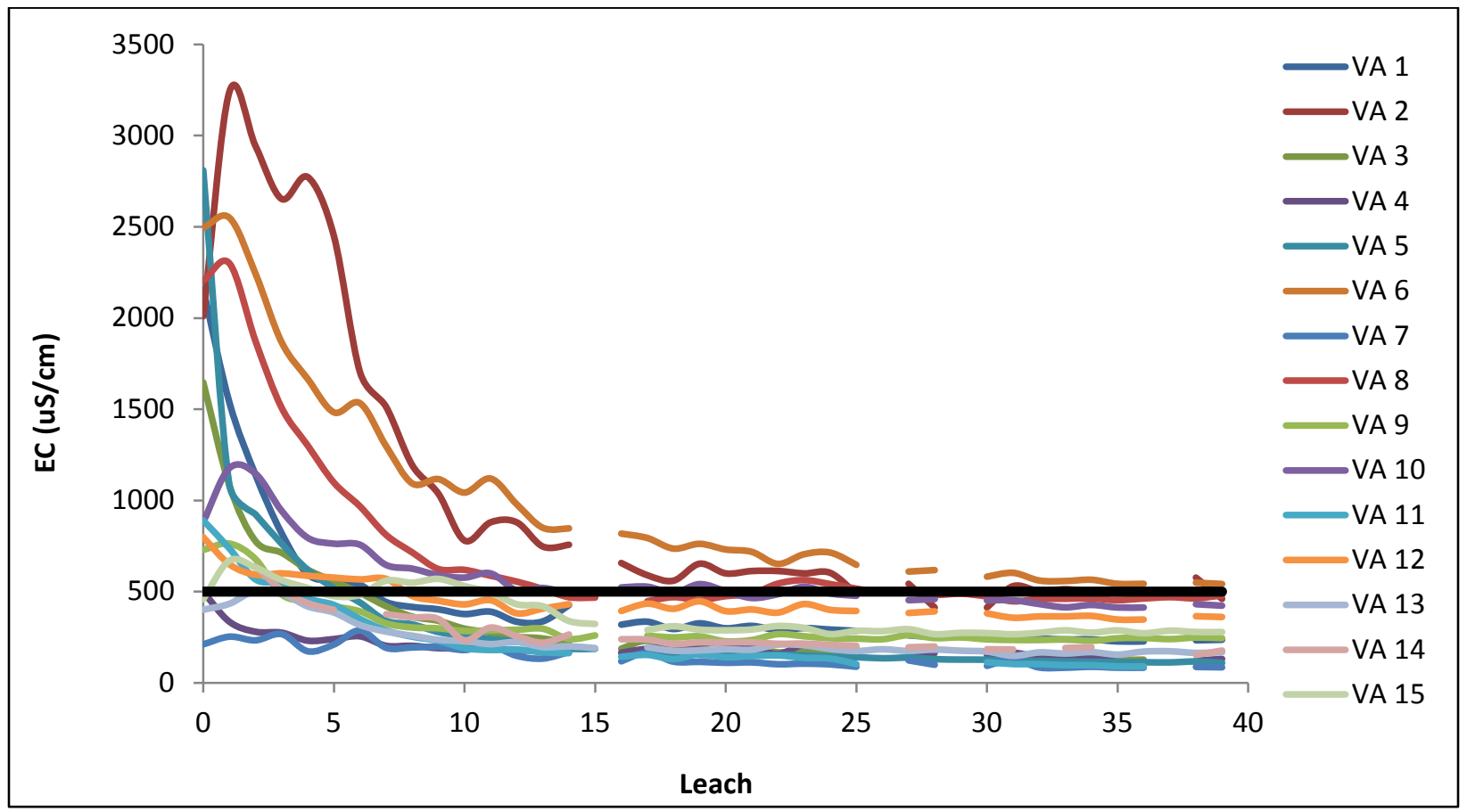

Figure 3.21: A visual representation of Virginia Tech’s column leaching data for EC. 


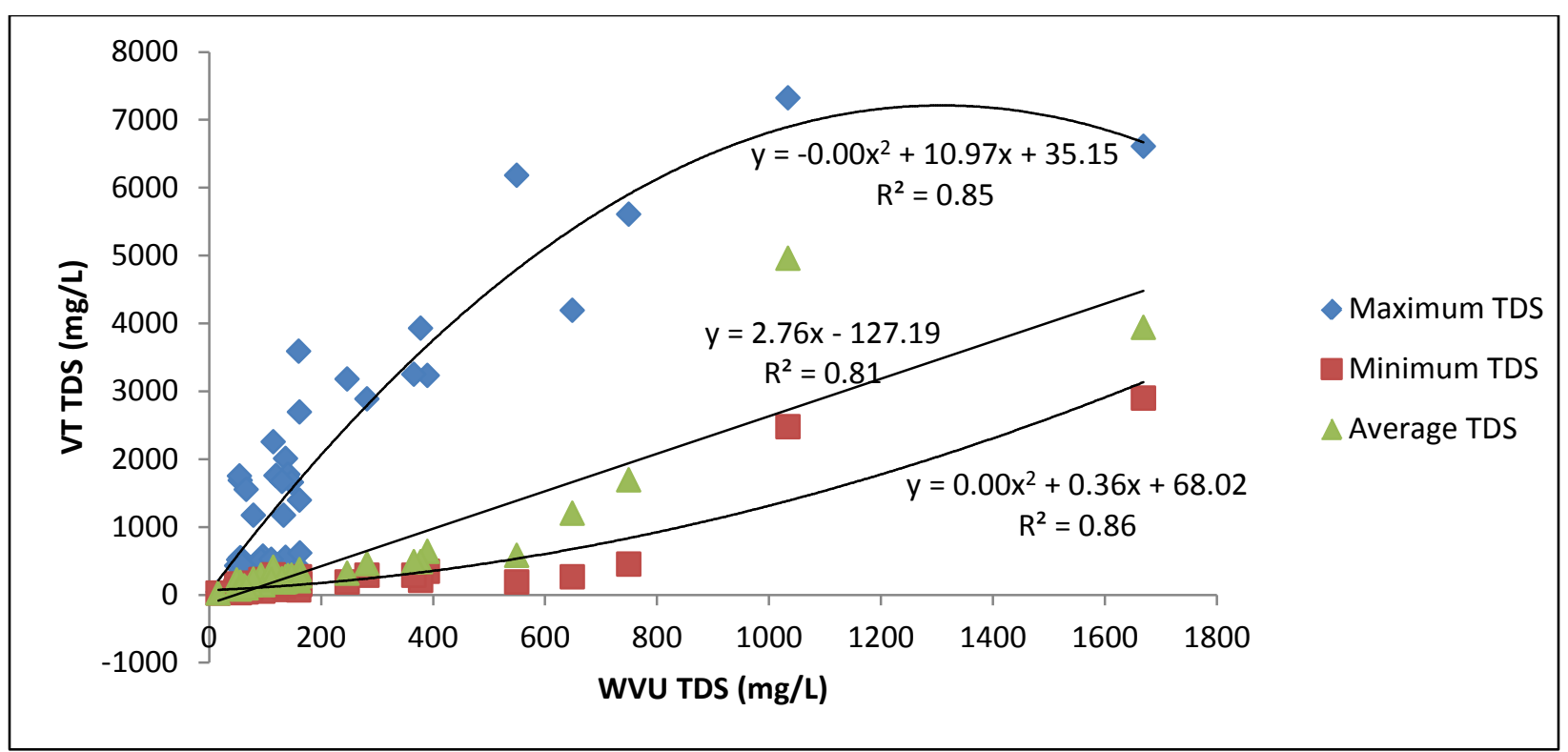

Figure 3.22: Relationship between maximum, average, and minimum TDS calculated from EC at Virginia Tech versus TDS calculated from EC at WVU.

The relationship between MPA and average TDS obtained from Virginia Tech’s leaching columns can be found in Figure 3.23. The y-axis does not need to be transformed for a strong relationship $\left(\mathrm{R}^{2}=0.96\right)$ to be apparent. Using the line of best fit, once MPA reaches 3.0, TDS is approximately $500 \mathrm{mg} \mathrm{L}^{-1}$. This finding reflects the results inferred from Figures 3.19 and 3.20, where MPA ranging from 0.0 to 1.0 produced low TDS (less than $300 \mathrm{dS} \mathrm{m}^{-1}$ ), MPA ranging from 1.0 to 3.0 produced a moderate amount of TDS (300 to $<500 \mathrm{dS} \mathrm{m}{ }^{-1}$ ), and MPA greater than 3.0 produced high TDS ( $>500 \mathrm{dS} \mathrm{m}^{-1}$ ) (Table 3.13). The minimum TDS value (long-term prediction of TDS release) was also compared to MPA (Figure 3.24), validating that an MPA of 3.0 will release approximately $500 \mathrm{mg} \mathrm{L}^{-1}$ TDS. Figure 3.25 shows the relationship between maximum EC (short-term prediction from Virginia Tech's columns) and MPA, which does not support the TDS release index. 
Figures 1Q to 1V (Appendix 1) show the relationship between average elemental concentrations released from Virginia Tech's leaching columns versus their calculated TDS. It is apparent that some samples have MPA values of $3.0 \mathrm{mt}$ per $1000 \mathrm{mt}$ of material and produce over $500 \mathrm{mg} \mathrm{L}^{-1} \mathrm{TDS}$. However, these samples may be high in NP, which may contribute to TD. They samples could also be very low in NP and not quite capable of neutralizing the acidic properties of the rock, which could contribute to TDS. NP data must be collected to fully understand this relationship.

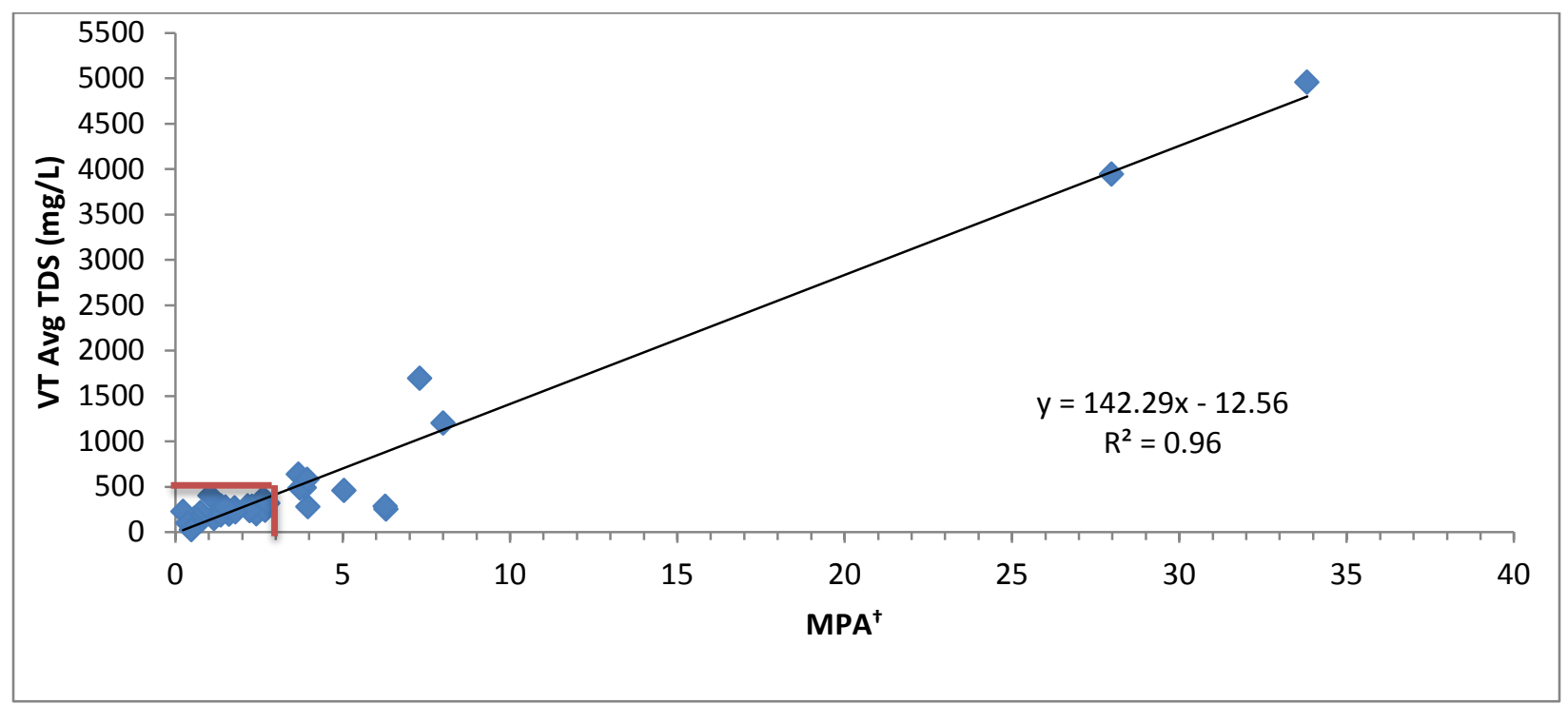

Figure 3.23: Maximum Potential Acidity versus Average TDS from Virginia Tech ${ }^{\dagger}$ MPA in units of mt per $1000 \mathrm{mt}$ of material 


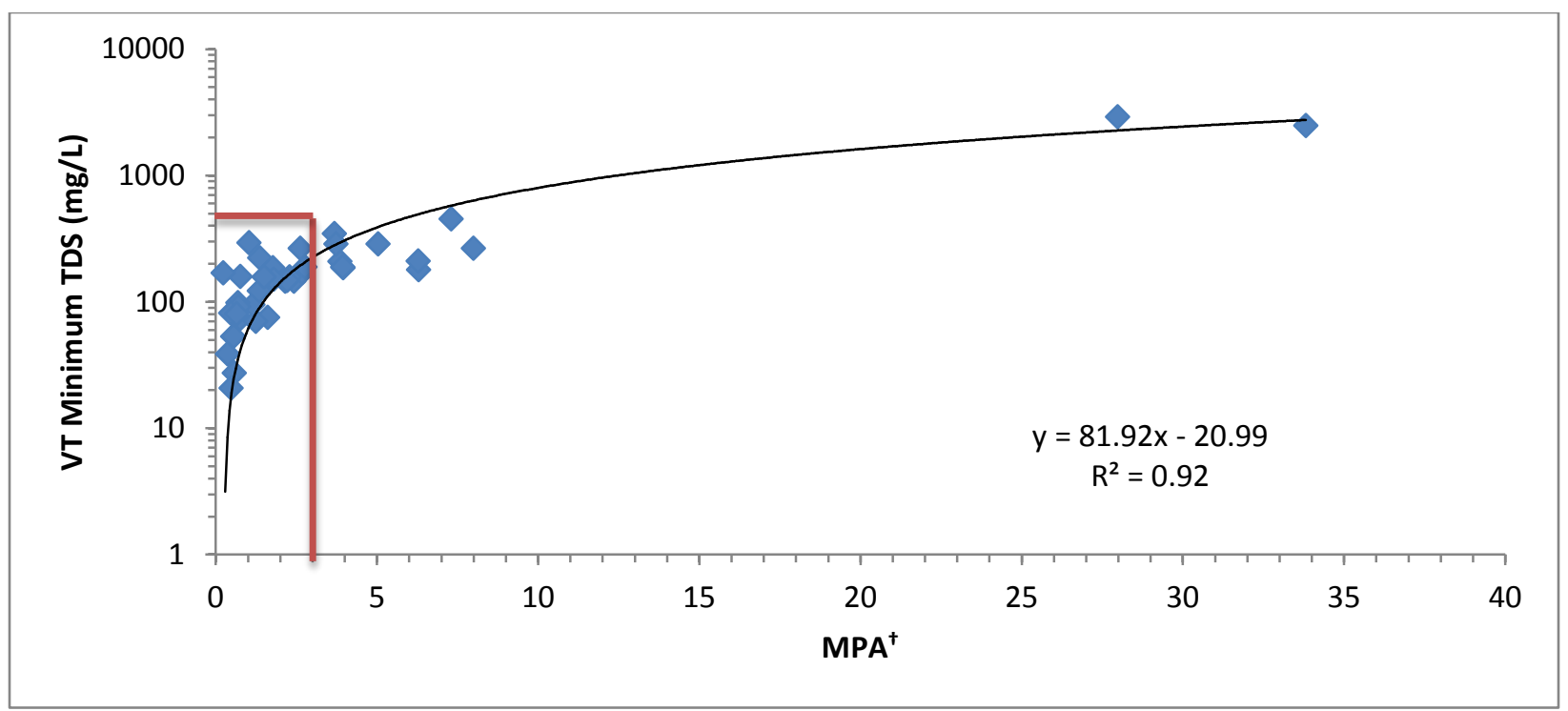

Figure 3.24: Maximum Potential Acidity versus Minimum TDS from Virginia Tech ${ }^{\dagger}$ MPA in units of mt per $1000 \mathrm{mt}$ of material

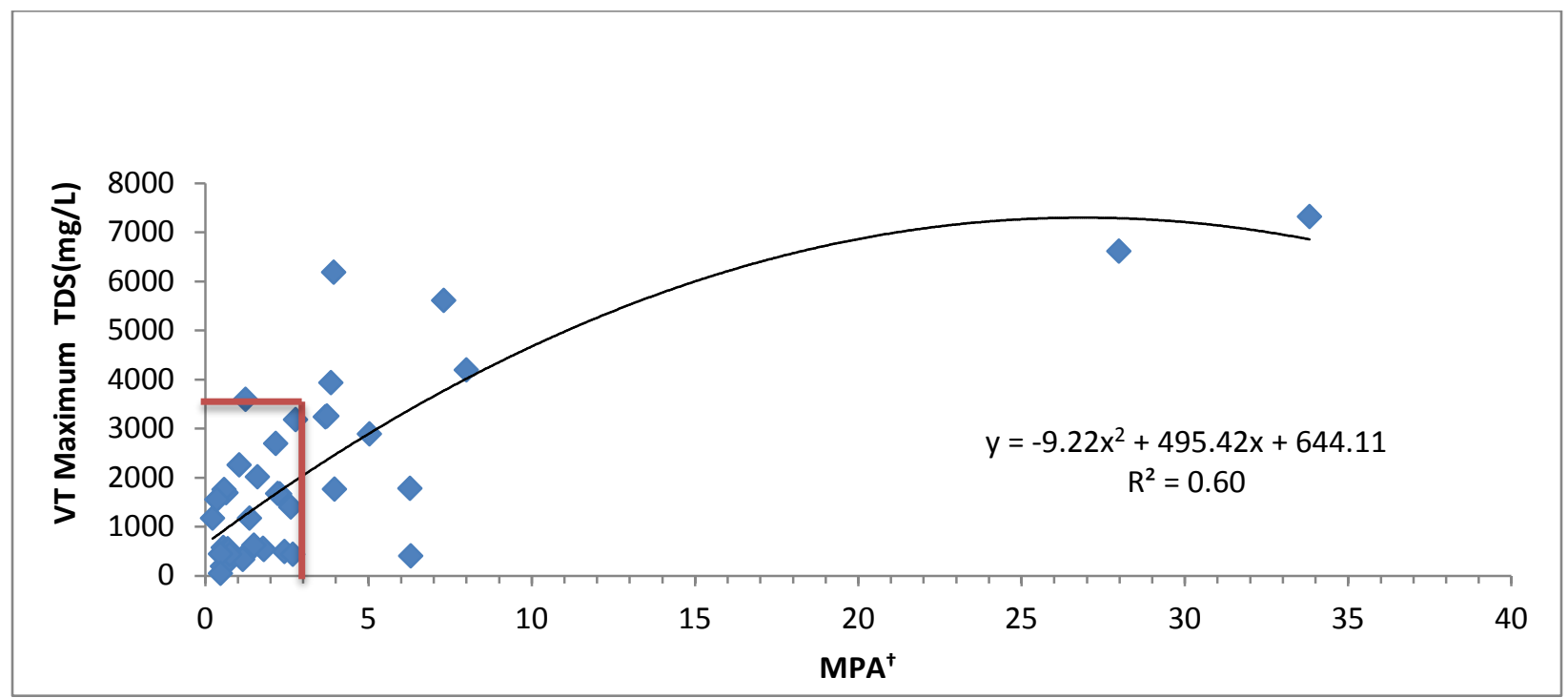

Figure 3.25: Maximum Potential Acidity versus Maximum TDS from Virginia Tech ${ }^{\dagger}$ MPA in units of mt per $1000 \mathrm{mt}$ of material 
Table 3.13: TDS release index using Maximum Potential Acidity.

\begin{tabular}{lll}
\hline TDS Release Index & TDS Concentration & MPA $^{*}$ Range \\
\hline Low & $<300$ & $0.0-1.0$ \\
Medium & $300-500$ & $1.0-3.0$ \\
High & $>500$ & $3.0+$ \\
\hline
\end{tabular}

${ }^{*}$ MPA in units of mt per $1000 \mathrm{mt}$ of material

To confidently use this TDS release index, a wider variety and number of overburden samples should be collected, and field studies must be conducted. If this release index holds true for future studies, than MPA and EC may be the only two factors necessary for a relatively quick and accurate prediction of TDS release. The dilute $\mathrm{HNO}_{3}$ method is still useful for analyzing constituent release from overburden, but may not be necessary if MPA and EC are all that is needed for the development of a TDS index. 


\section{Conclusion}

West Virginia is the largest coal-producing state in the Appalachian coal region (U.S. Energy Information Administration, 2012), and the coal industry has been at the forefront of controversy concerning human and environmental health and safety. To remove coal, overburden material must be blasted and moved. Overburden is then subjected to accelerated weathering, which promotes the release of soluble constituents into the environment. Depending on the chemical composition of the rock, weathering of these broken rocks can promote acid mine drainage, alkaline mine drainage (Berhhardst et al., 2012) as well as the release of heavy metals, and total dissolved solids. The Acid-Base Account has been a successful tool for predicting postmining water quality, by focusing on the acidity (maximum potential acidity) and alkalinity of the rock (neutralization potential), but there is no current tool for predicting TDS related water quality issues.

The goal of this research was to determine a TDS release index for overburden material. Three weathering techniques were developed to determine which parameters are most strongly linked to TDS release. EC was converted to TDS using formulas (1) and (2) from Evangelou, 1998. TDS release was compared to cations, anions, pH, EC, \%S, MPA, NP (partially provided from the coal operator), and chroma. There was a strong relationship between TDS and MPA $\left(\mathrm{R}^{2}=0.80\right)$, and provided evidence for a low, moderate, and high TDS release index using MPA ranging from $0.0-1.0,1.0-3.0$, and 3.0 +, respectively (Table 3.12).

To validate these preliminary results, Virginia Tech’s column leaching data were used for comparison. Virginia Tech’s average and minimum TDS values validated our TDS release index using MPA; however Virginia Tech’s maximum TDS did not. With these results we can use MPA to determine a TDS release index, as listed in Table 3.12. MPA and EC can be used as a 
quick test to determine which overburdens may need further analysis so that operators can

properly treat, isolate and/or handle their overburden in a manner that will decrease TDS runoff from their site.

\section{Literature Cited}

APHA (American Public Health Association). 1992. Standard methods for the examination of water and wastewater. $18^{\text {th }}$ Edn.

Chapman, P., B. Howard, and C. Edmund. 1999. Toxicity of total dissolved solids associated with two mine effluents to Chironomid larvae and early life stages of rainbow trout. Environ. Toxicol and Chem. 19:210-214.

Copeland, C. 2013. Mountaintop mining: background on current controversies. Congressional Research Service Report for Congress. Available at http://www.fas.org/sgp/crs/misc/RS21421.pdf (accessed 13 August 2013; verified 1 November 2013).

Craynon, J. (ed.) 2013. Environmental considerations in energy production. Society of Mining, Metallurgy, and Exploration, Inc. Englewood, CO.

Daniels et al., 2012.Unpublished data.

Derry, A.M., E.E. Prepas and P.D.N. Hebert, 2003.A comparison of zooplankton communities in saline lake water with variable anion composition. Hydrobiologia, 505:199-215.

Dulong, F.T., N. Fedorko, J.R. Renton, C.B. Cecil. 2002. Chemical and mineralogical analysis of coal-bearing strata in the Appalachian basin.

Evangelou, V.P. 1998. Environmental Soil and Water Chemistry. New York: John Wiley \& Sons, Inc., 1998.

Kennedy, A.J., D.S. Cherry, and R.J. Currie. 2002. Field laboratory assessment of a coal processing effluent in the leading creek watershed, Meigs County, Ohio. Environ. Contam. Toxicol. 44:324-331.

McGehee, S. 2010. A history of coal in West Virginia. Friends of Coal. Available at http://www.friendsofcoal.org/a-history-of-coal-in-west-virginia.html (accessed 13 November 2012; verified 1 October 2013). Charleston, WV.

Merricks, T.C., D.S. Cherry, C.E. Zipper, R.J. Currie, and T.W. Valenti. 2007. Coal-mine hollow fill and settling pond influences on headwater streams in southern West Virginia, USA. Environ. Monit. Assess. 129:359-378. 
Messinger, T., and K.S. Paybins. 2003. Relations between precipitation and daily and monthly mean flows in gaged, unmined and valley-filled watersheds, Ballard Fork, West Virginia, 1999-2001.Water Resources Investigation Report 03-4113. Charleston, WV: US. Geological Survey.

Mount, D.R., D.D. Gulley, J.R. Hockett, T.D. Garrison and J.M. Evans, 1997. Statistical models to predict the toxicity of major ions to C. dubia, Daphnia magna and Pimephales promelas (Fathead Minnows). Environ. Toxicol. Chem. 16:2009-2019.

Nowack, B., and L. Sigg. 1997. Dissolution of Fe(III) (hydr) oxides by metal-EDTA complexes. Geochimica et Cosmochimica Acta. 61(5) 951-963.

Odenheimer, J., S.Skousen, and L.M. McDonald. 2012. Predicting total dissolved solids release from overburden in Appalachian coal fields. In: Proceedings, Society of Mining, Metallurgy and Exploration, Denver, CO, February 24-27.

OSM, 2012. Public Law 95-87: Surface Mining Control and Reclamation Act of 1977. Office of Surface Mining Reclamation and Enforcement. Washington, DC. US Govt. Printing Office.

Peng, S.S. 2000. Mountaintop removal controversy slows West Virginia coal mining. Mining Engineering 52:53-58.

Perry, E. 1985. Overburden analysis: An evaluation of methods. In: proceedings, Proc. Symposium on Surface Mining, Hydrology, Sedimentology, and Reclamation, University of Kentucky, Lexington, December 9-13.

Pond, G., M. Passmore, F. Borsuk, L. Reynolds, and C. Rose. 2008. Downstream effects of mountaintop coal mining: comparing biological conditions using family and genus level macroinvertebrate bioassessment tools. J. North Am. Benthol. Soc. 27:717-737.

Pond, G. 2010. Patterns of Ephemeroptera taxa loss in Appalachian headwater streams. Hydrobiologia. 641:185-201.

Potts, W. T. W. 1954. The energetics of osmotic regulation in brackish and freshwater animals. Journal of Experimental Biology. 31:618-630.

Robins, J.D. 1979. Constructing spoil storage fills in the steep terrain Appalachian coalfields. In: proceedings of the first international symposium on stability in coal mining, Vancouver, British Columbia, Canada.

Schwertmann U. 1985. The effect of pedogenic environments on iron oxides minerals. Adv. Soil Sci. 1:172-200.

Skousen, J., R.M. Smith, J. Sencindiver. 1990. The development of the acid-base account. Green Lands. 20(1):32-37. 
Skousen, J., J. Renton, H. Brown, P. Evans, B. Leavitt, K. Brady, L. Cohen, P. Ziemkiewicz. 1997. Neutralization potential of overburden samples containing siderite. J. Environ. Qual. 26:673-681.

Skousen, J.G., J.C. Sencindiver, and R.M. Smith. 1987. A review of procedures for surface mining and reclamation in areas with acid-producing materials. WVU Energy and Water Research Center.Publication EWRC 871. Morgantown, WV.

Skousen, J., J. Simmons, L.M. McDonald, P. Ziemkiewicz. 2002. Acid-base accounting to predict post-mining drainage quality on surface mines. J. Environ. Qual. 31:2034-2044.

Smith, R.M., W.E. Grube, Jr., A.A. Sobek, and R.N. Singh. 1974. Rock types and laboratory analyses as a basis for managing minesoils. In: Tenth Forum on Geology of Industrial Mineral Proceedings. Misc. Report No. 1. Ohio Department of Natural Resources. Columbus, $\mathrm{OH}$.

Timpano, A., S. Schoenholtz, C. Zipper, and D. Soucek. 2010. Isolating effects of total dissolved solids on aquatic life in central Appalachian coalfield streams. In: Proceedings, American Society for Mining and Reclamation, Pittsburgh, PA, June 5-11, 2010.

U.S. Energy Information Administration. 2012. Coal explained: Where our coal comes from. Available at http://www.eia.gov/energyexplained/index.cfm?page=coal_where. (accessed 12 February 2013; verified 16 August 2013). Department of Energy, Washington, DC.

U.S. Energy Information Administration. 2013. Coal. Available at http://www.eia.gov/coal/ (accessed 22 November 2012; verified 4 January 2013). Department of Energy, Washington, DC.

USEPA. 1997. Method 3051a: Microwave assisted acid dissolution of sediments, sludges, soils, and oils. $2^{\text {nd }}$ ed. USEPA, U.S. Gov. Print. Office, Washington, DC.

USEPA. 2012. Water monitoring and assessment: Total solids. Available at http://water.epa.gov/type/rsl/monitoring/vms58.cfm. (accessed 8 September 2012; verified 12 December 2012). U.S. Environmental Protection Agency, Washington, DC.

World Coal Association, 2012.Coal statistics. World Coal Association. Available at http://www.worldcoal.org/resources/coal-statistics/ (accessed 10 September 2012; verified 2 November 2012). London, England, United Kingdom.

Wetzel, R.G. 1983. Limnology. Second Edition. Saunders College Publishing, NY.

White, M.A., and F.A. Barata.1995. State-of-the-art in mountaintop removal and contour mining. Mining Engineering 47:1111-1114.

WVDEP.2012. West Virginia Department of Environmental Protection. Benthic macroinvertebrate and fish information. Available at http://www.dep.wv.gov/WWE/watershed/bio_fish/Pages/Bio_Fish.aspx. (accessed 5 November 2012; verified 1 February 2013). Charleston Field Office, Office of Surface Mining and Enforcement. Charleston, WV. 
APPENDIX 1 


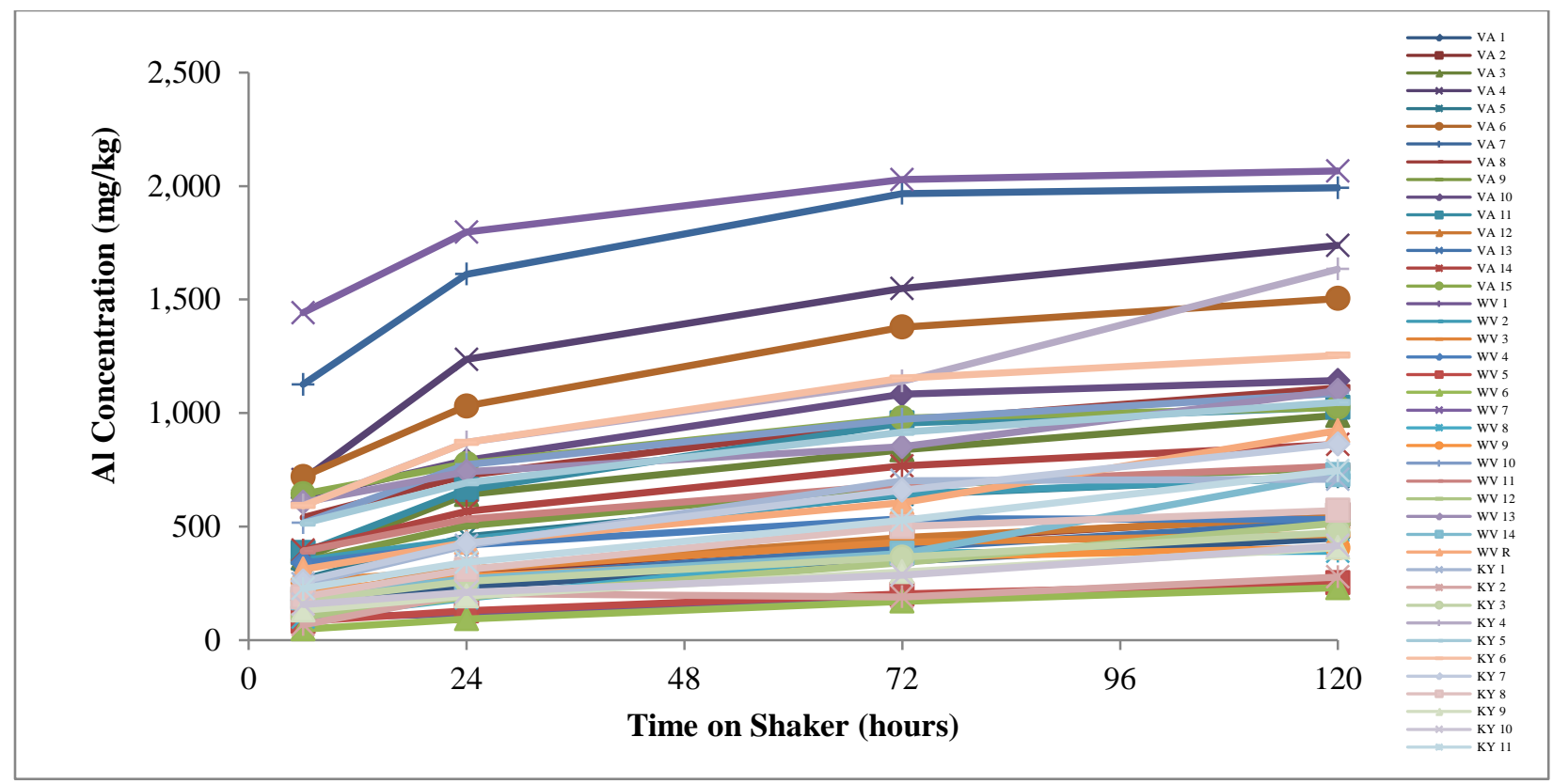

Figure 1A: Aluminum released from all forty-one samples in dilute nitric acid over time (mean of two replications).

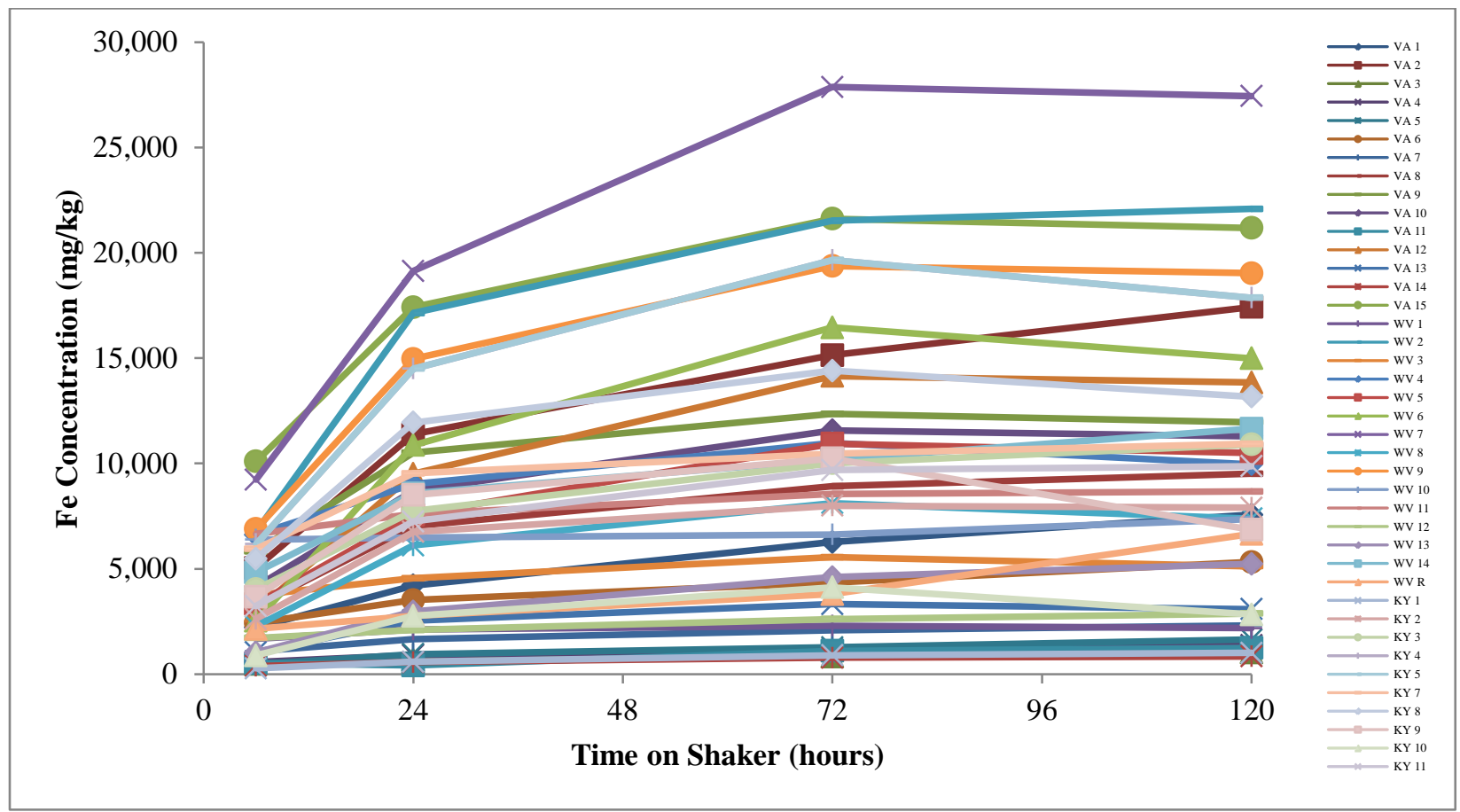

Figure 1B: Iron released from all forty-one samples in dilute nitric acid over time (mean of two replications). 


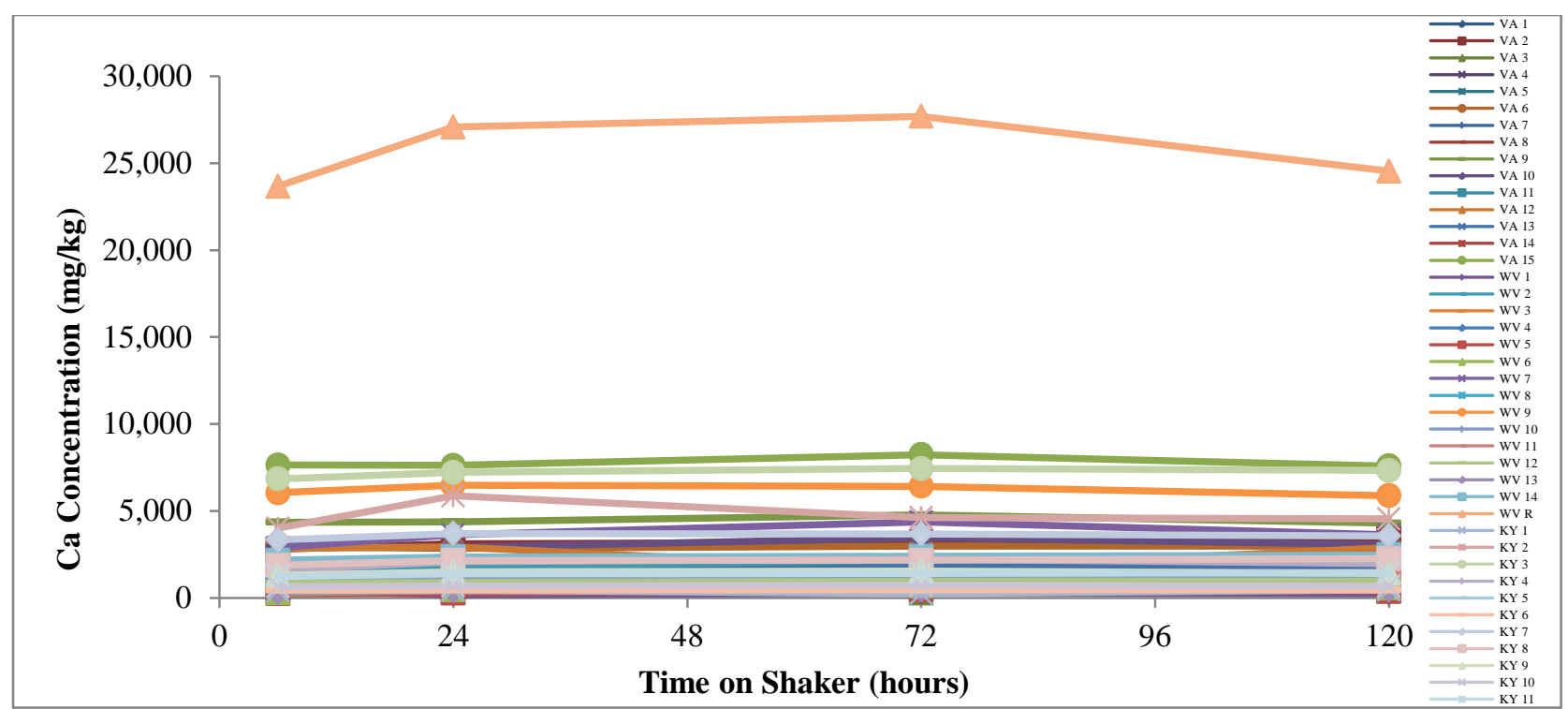

Figure 1C: Calcium released from all forty-one samples in dilute nitric acid over time (mean of two replications).

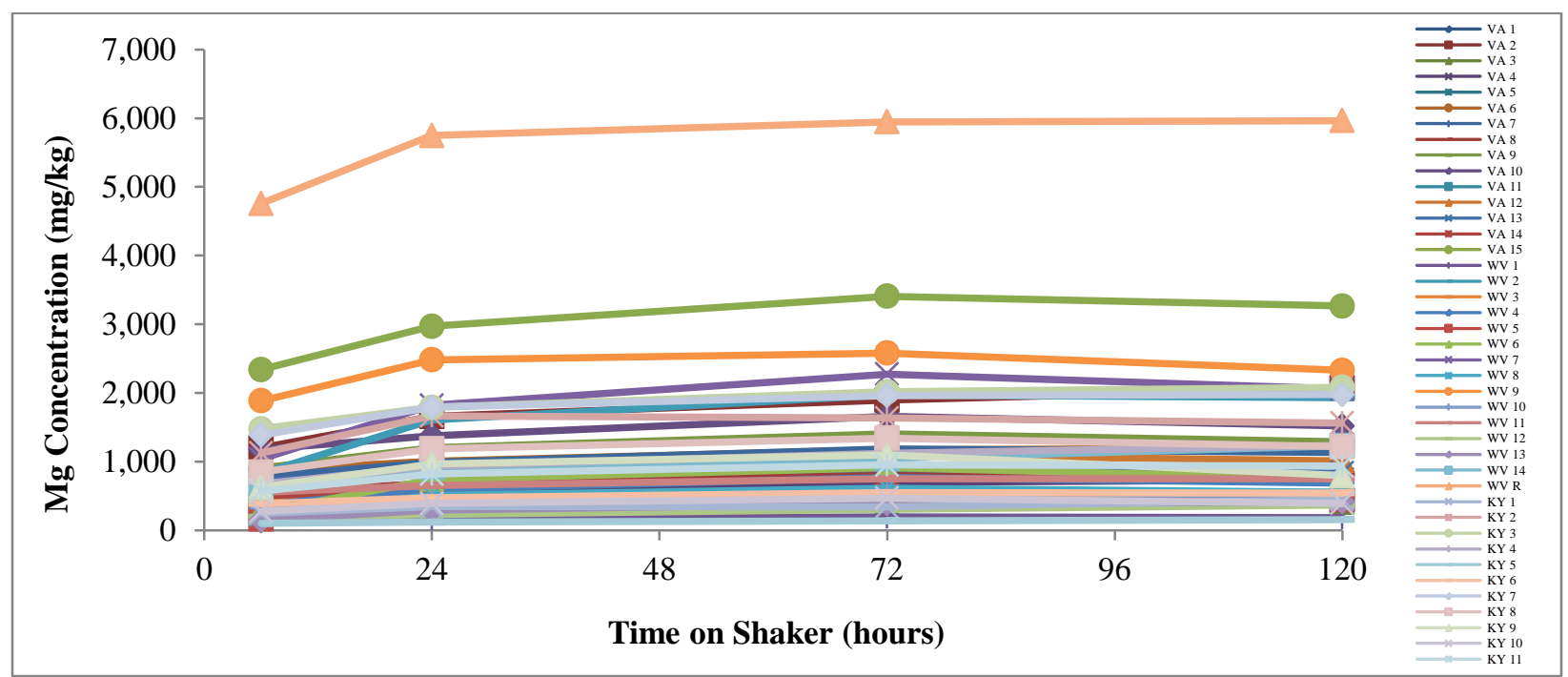

Figure 1D: Magnesium released from all forty-one samples in dilute nitric acid over time (mean of two replications). 


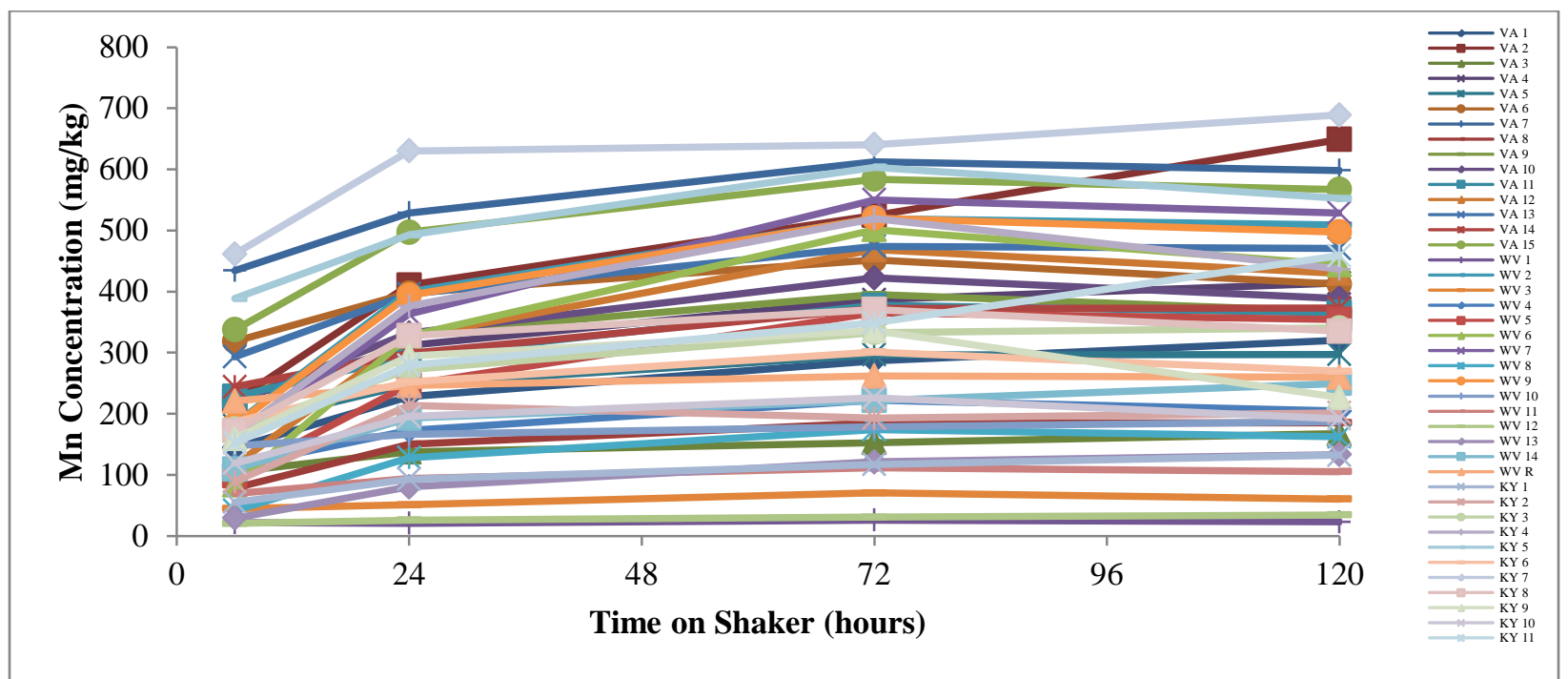

Figure 1E: Manganese released from all forty-one samples in dilute nitric acid over time (mean of two replications).

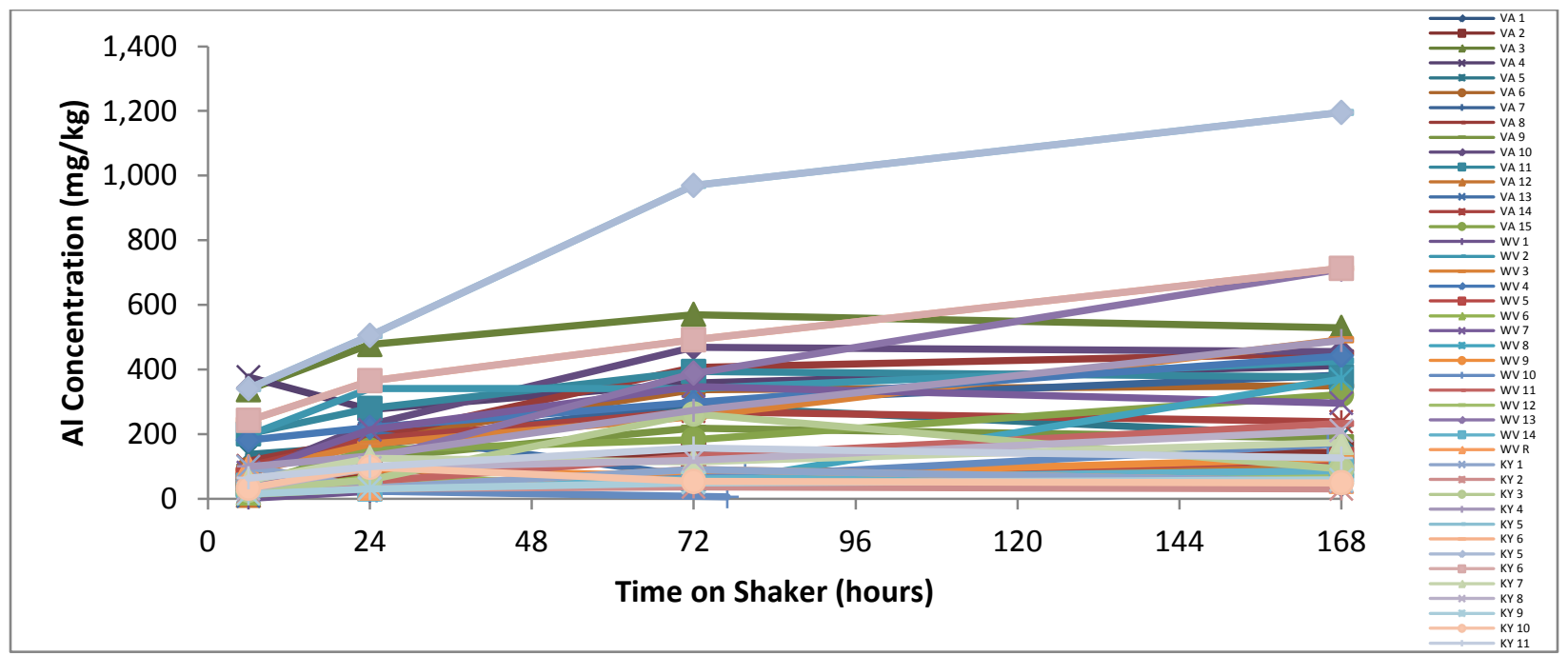

Figure 1F: Aluminum released from all forty-one samples in EDTA over time (mean of two replications). 


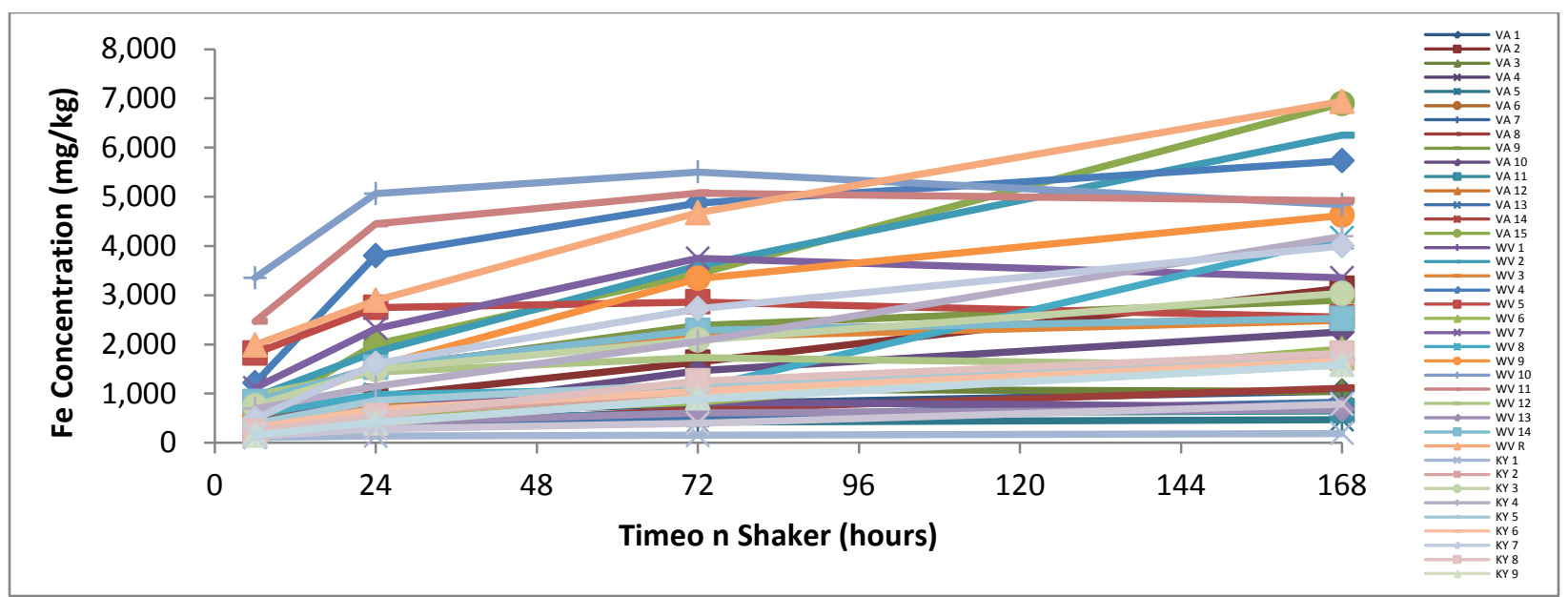

Figure 1G: Iron released from all forty-one samples in EDTA over time (mean of two replications).

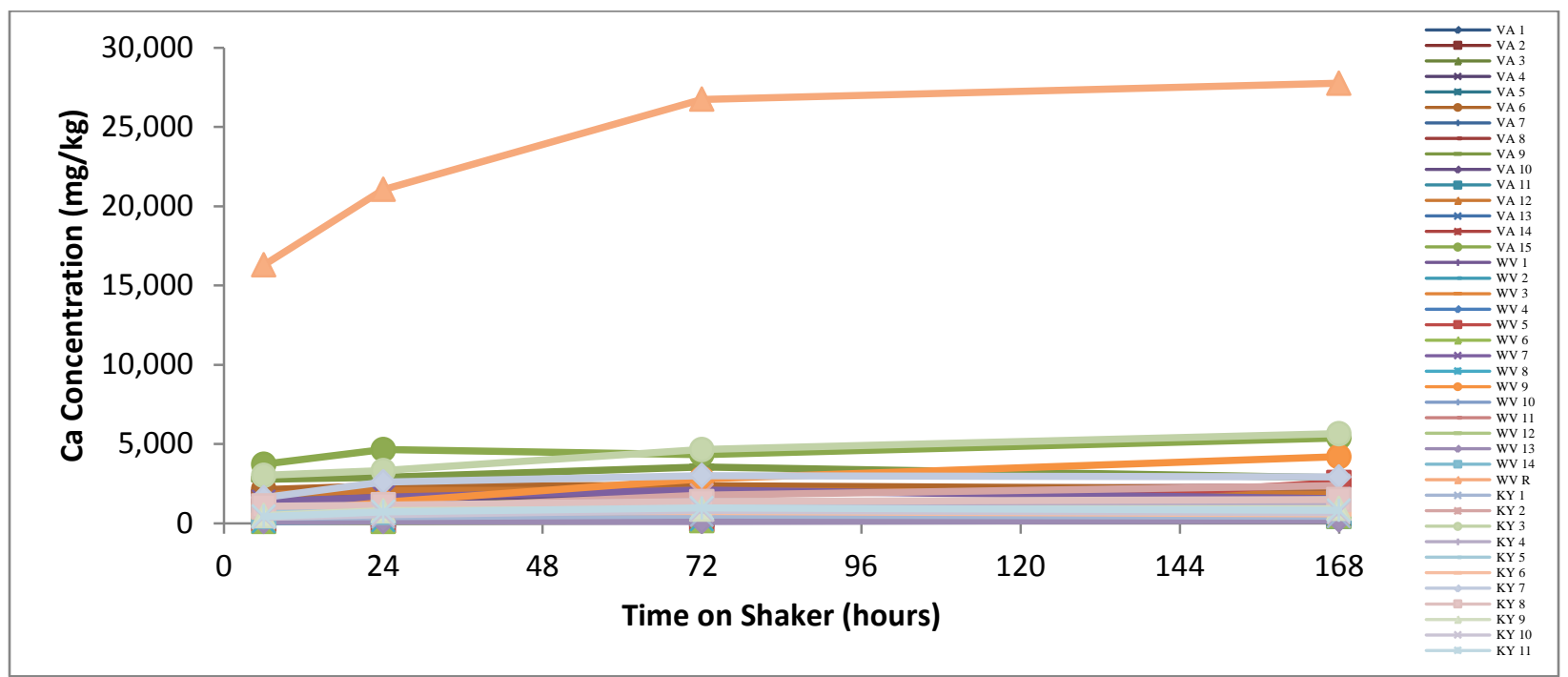

Figure 1H: Calcium released from all forty-one samples in EDTA over time (mean of two replications). 


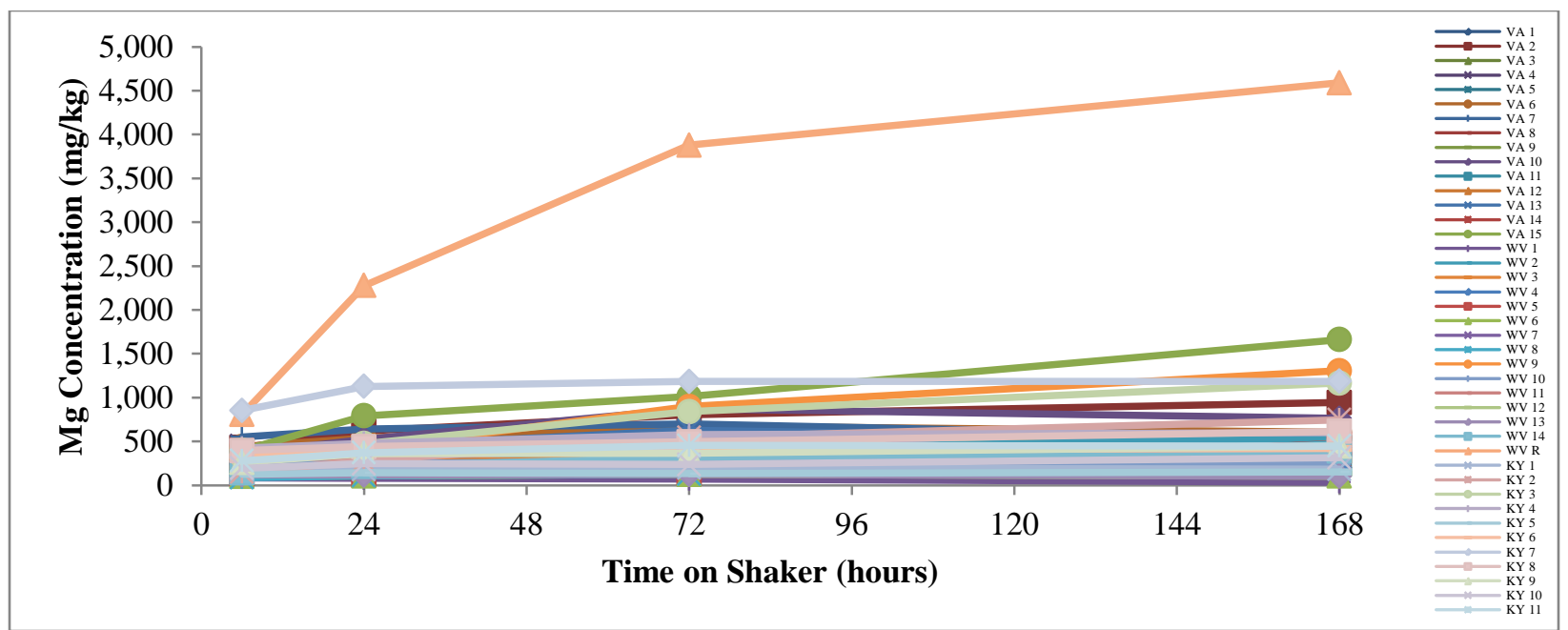

Figure 1I: Magnesium released from all forty-one samples in EDTA over time (mean of two replications).

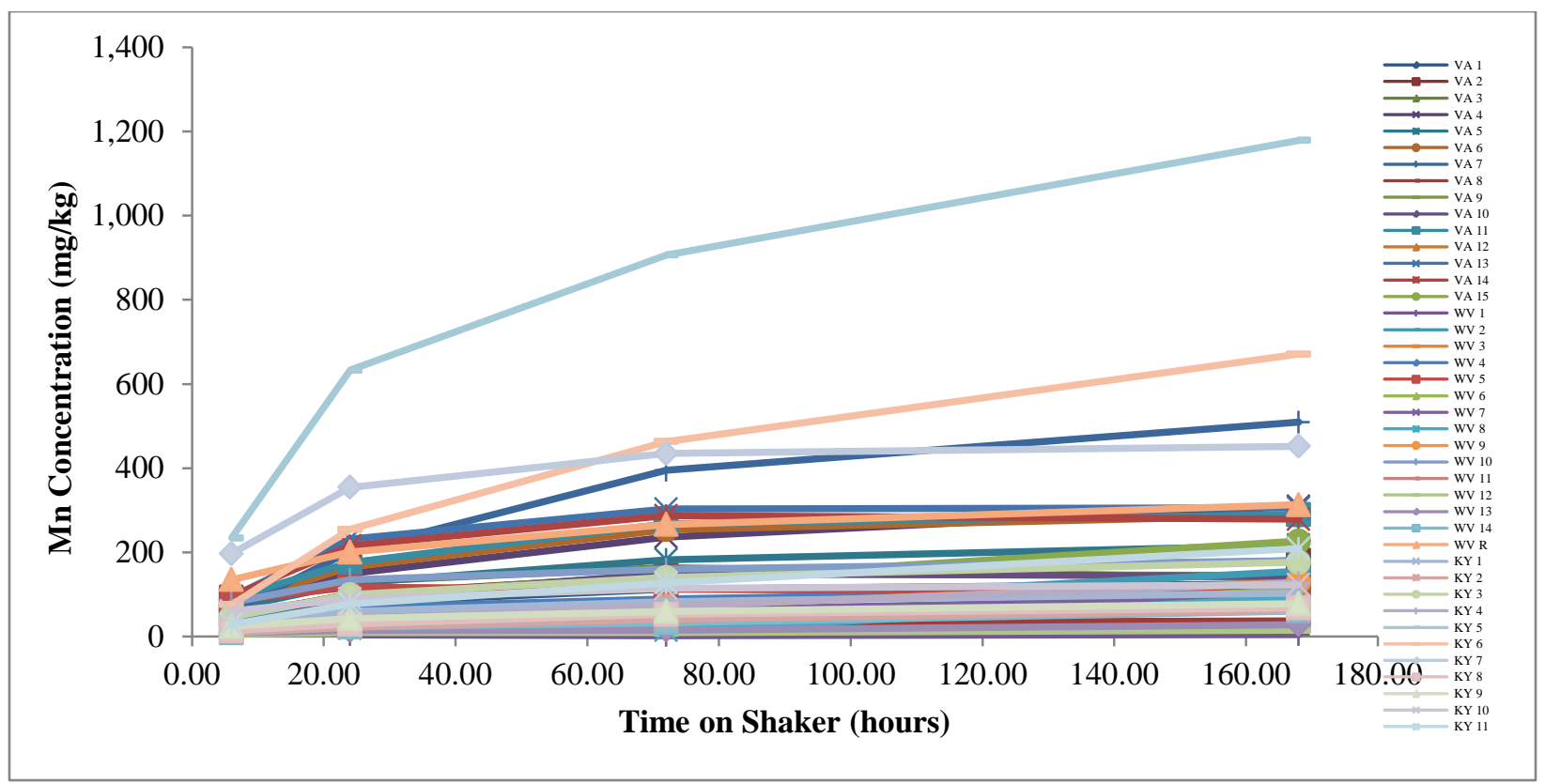

Figure 1J: Manganese released from all forty-one samples in EDTA over time (mean of two replications). 


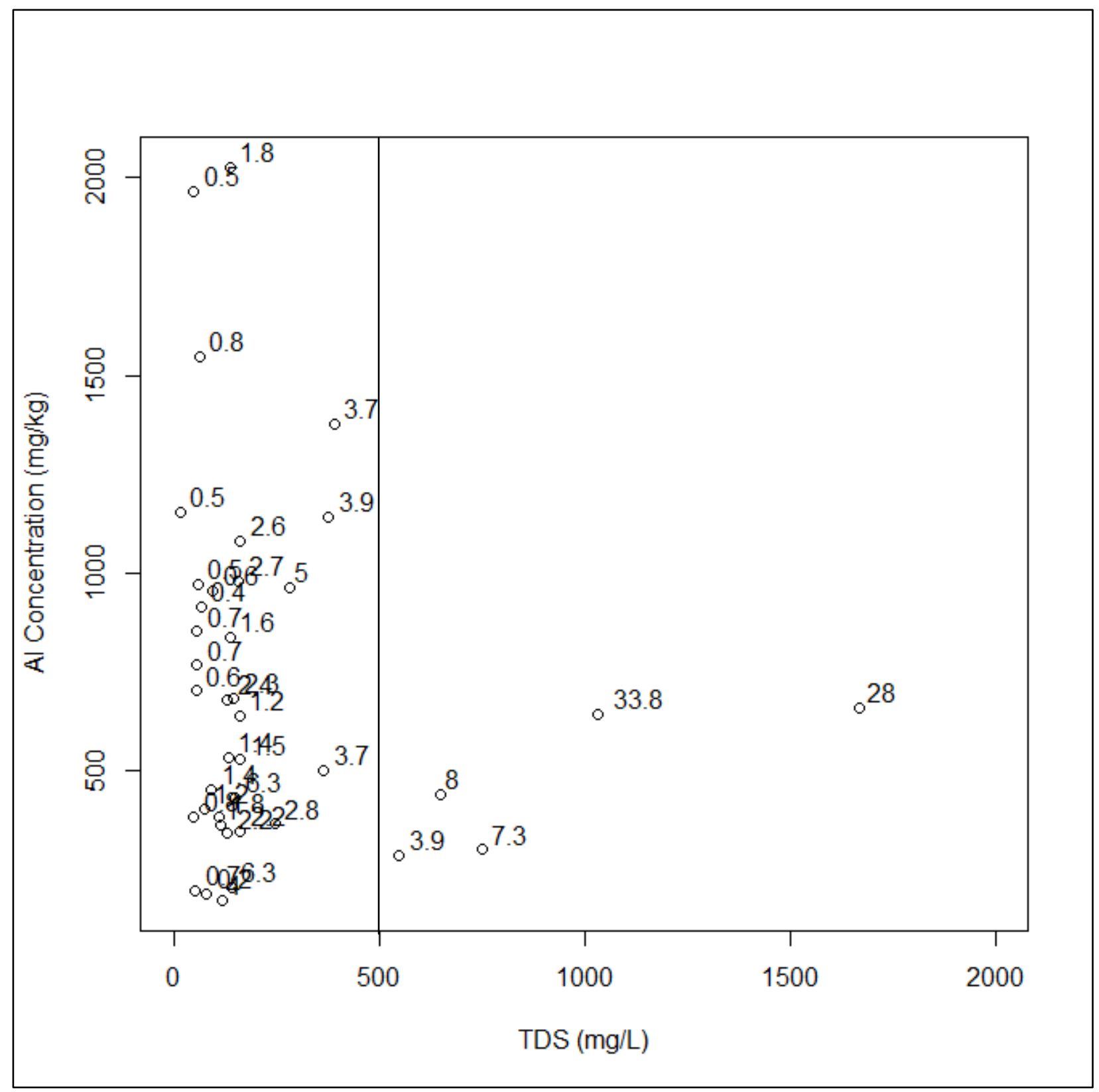

Figure 1K: Aluminum versus TDS from WVU with line indicating maximum contaminant limit of $500 \mathrm{mg} \mathrm{L}^{-1}$, numbers indicate MPA values. 


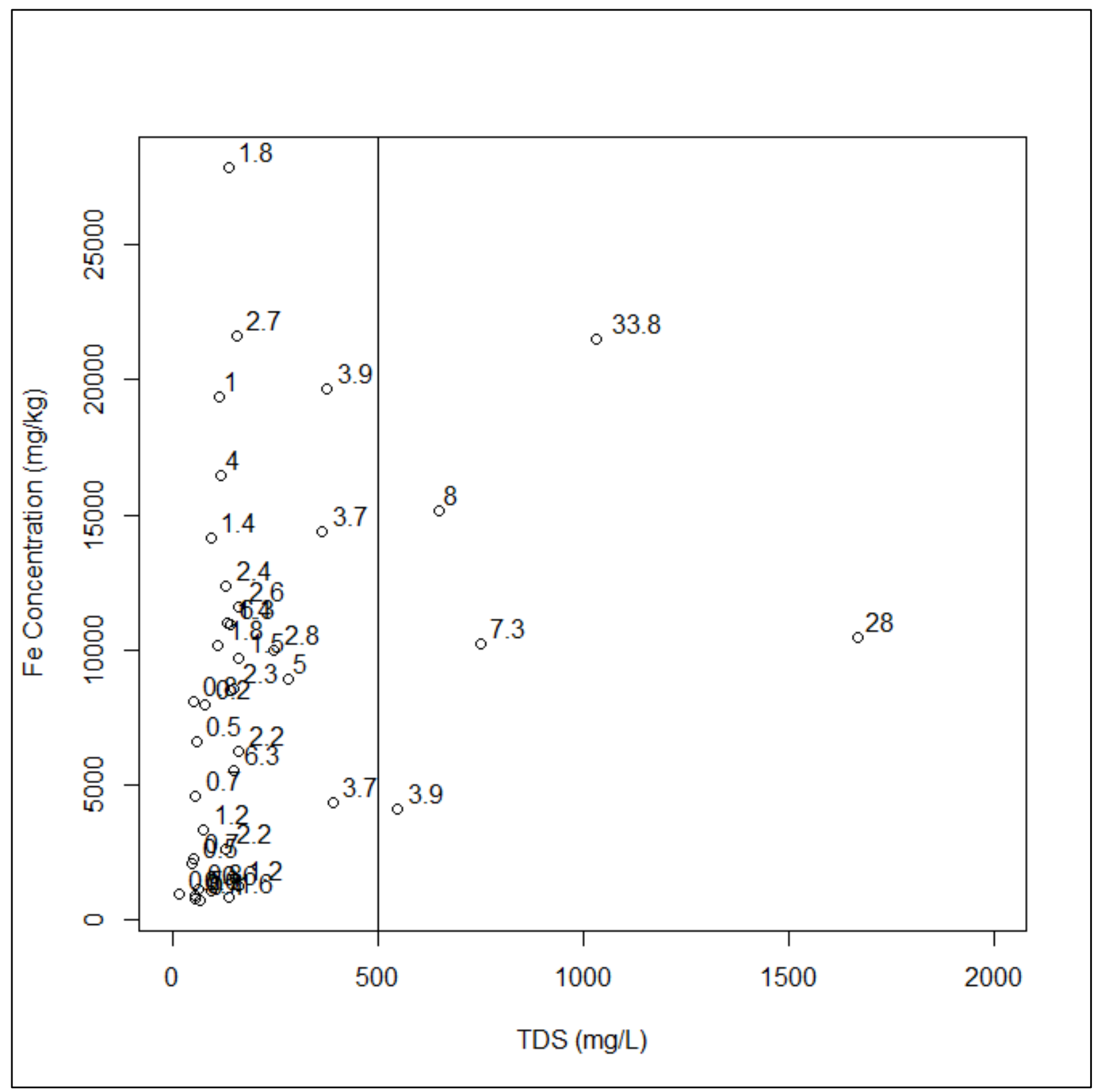

Figure 1L: Iron versus TDS from WVU with line indicating maximum contaminant limit of 500 $\mathrm{mg} \mathrm{L}^{-1}$, numbers indicate MPA values. 


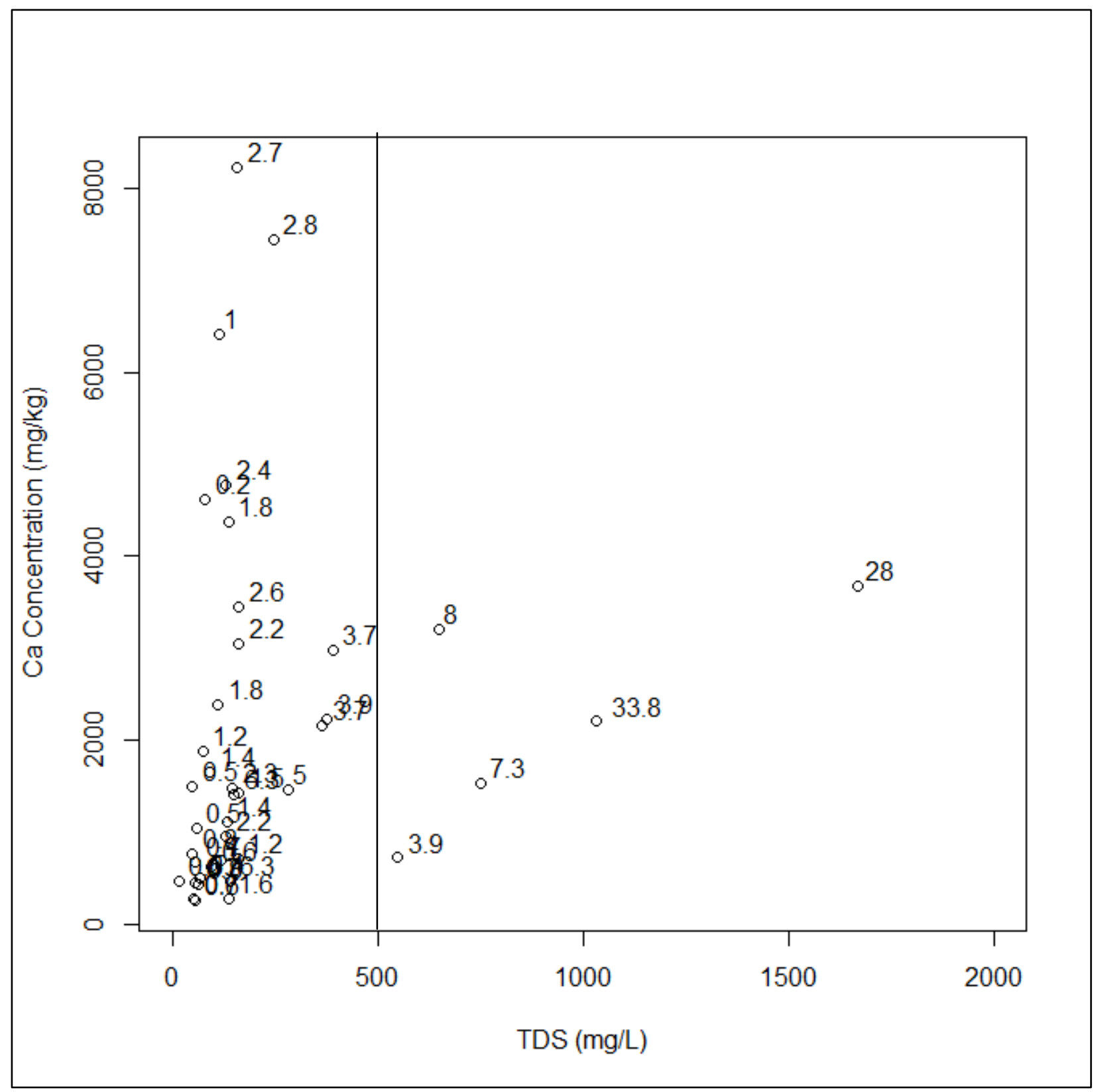

Figure 1M: Calcium versus TDS from WVU with line indicating maximum contaminant limit of $500 \mathrm{mg} \mathrm{L}^{-1}$, numbers indicate MPA values. 


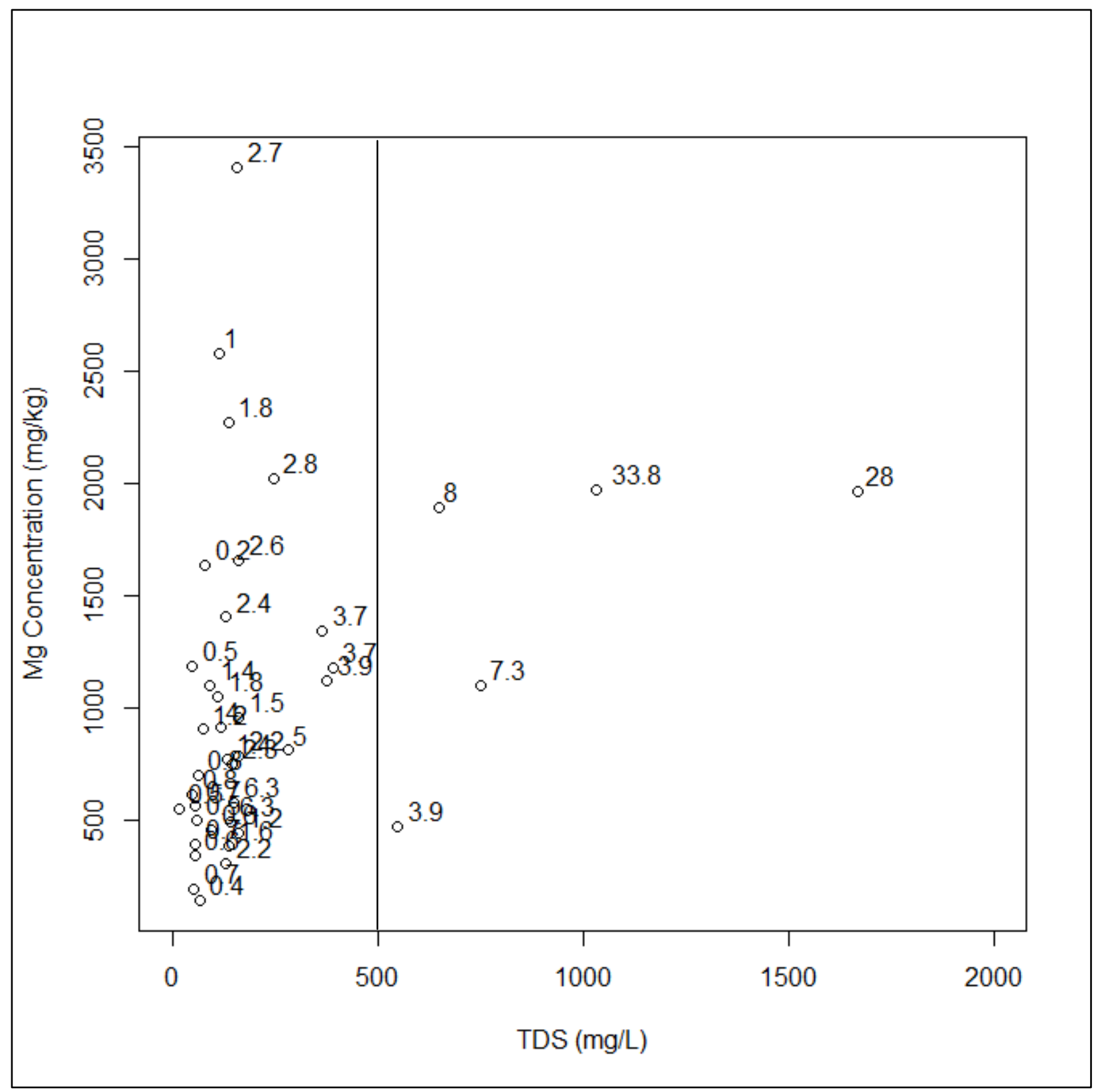

Figure 1N: Magnesium versus TDS from WVU with line indicating maximum contaminant limit of $500 \mathrm{mg} \mathrm{L}^{-1}$, numbers indicate MPA values. 


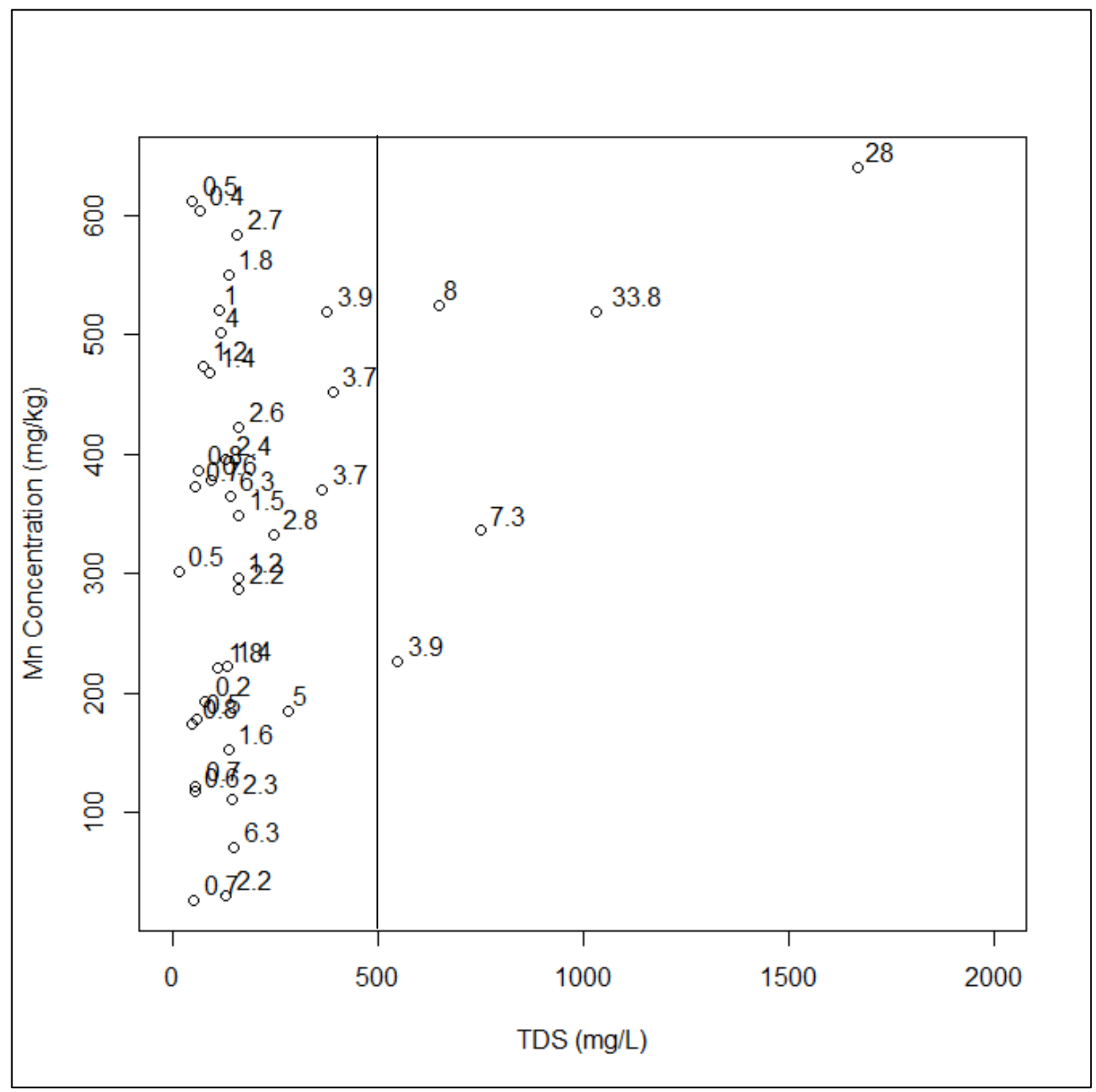

Figure 1O: Manganese versus TDS from WVU with line indicating maximum contaminant limit of $500 \mathrm{mg} \mathrm{L}^{-1}$, numbers indicate MPA values. 


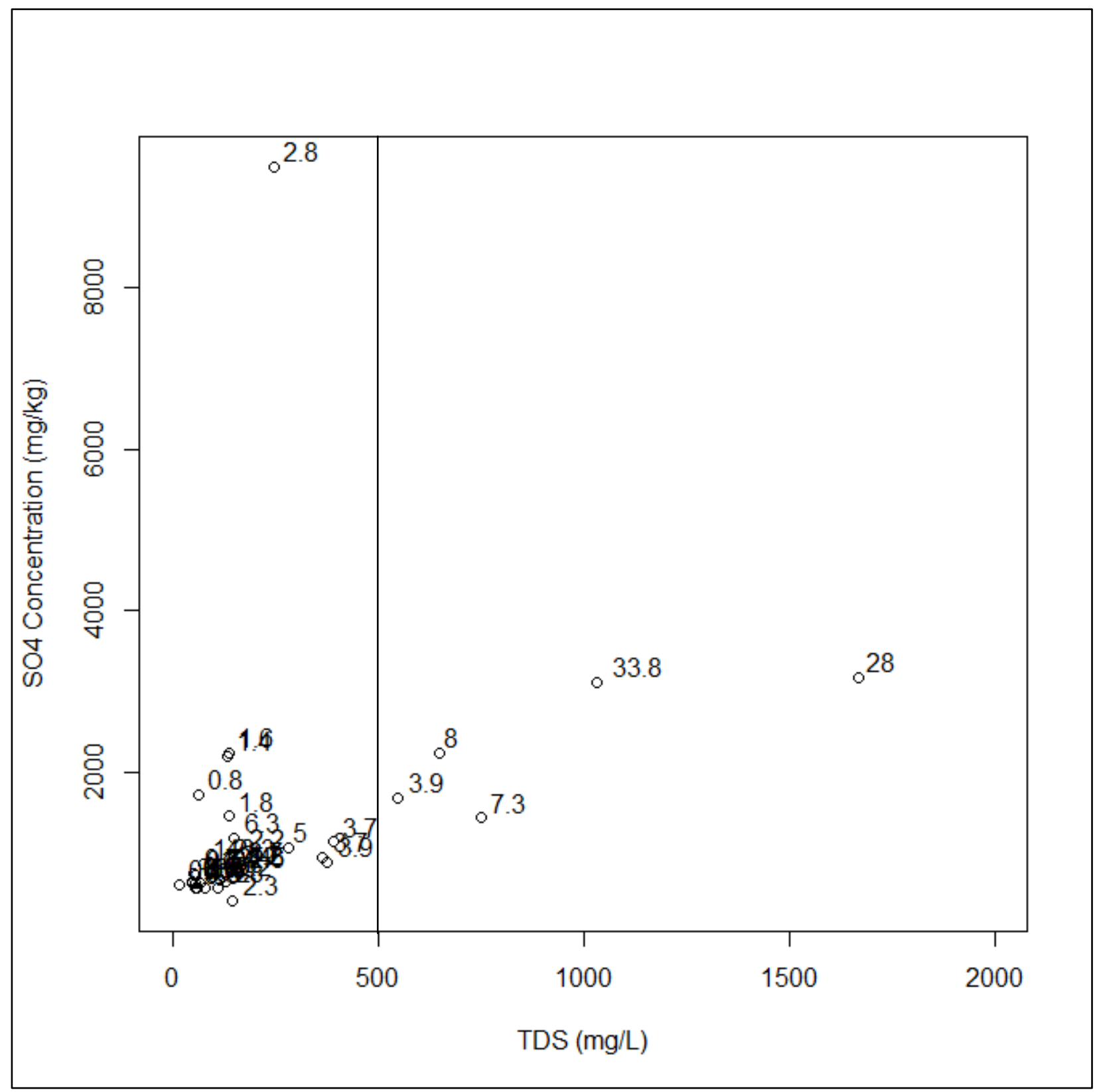

Figure 1P: Sulfate versus TDS from WVU with line indicating maximum contaminant limit of $500 \mathrm{mg} \mathrm{L}^{-1}$, numbers indicate MPA values. 


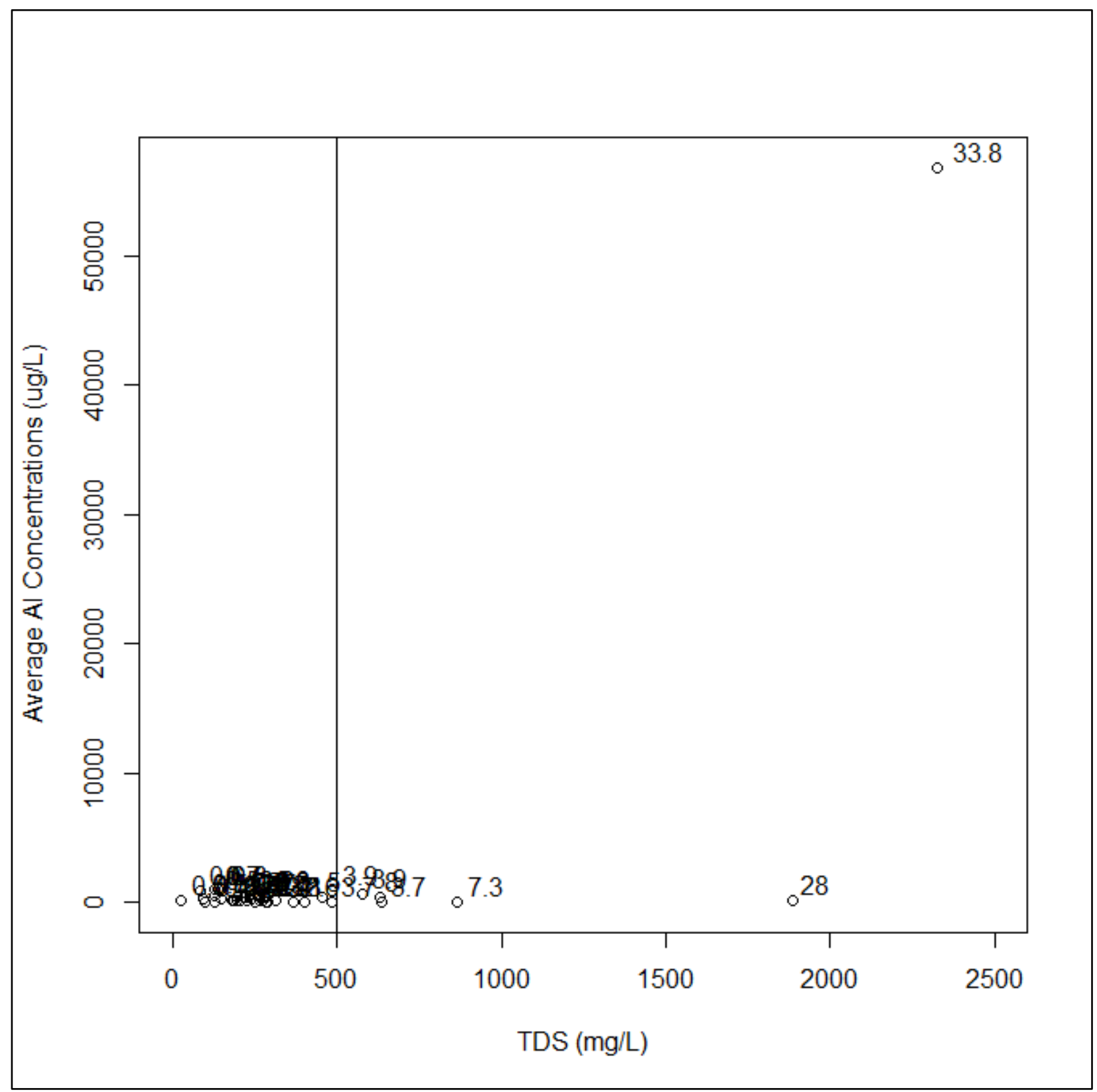

Figure 1Q: Aluminum versus TDS from Virginia Tech, with line indicating maximum contaminant limit of $500 \mathrm{mg} \mathrm{L}^{-1}$, numbers indicate MPA values. 


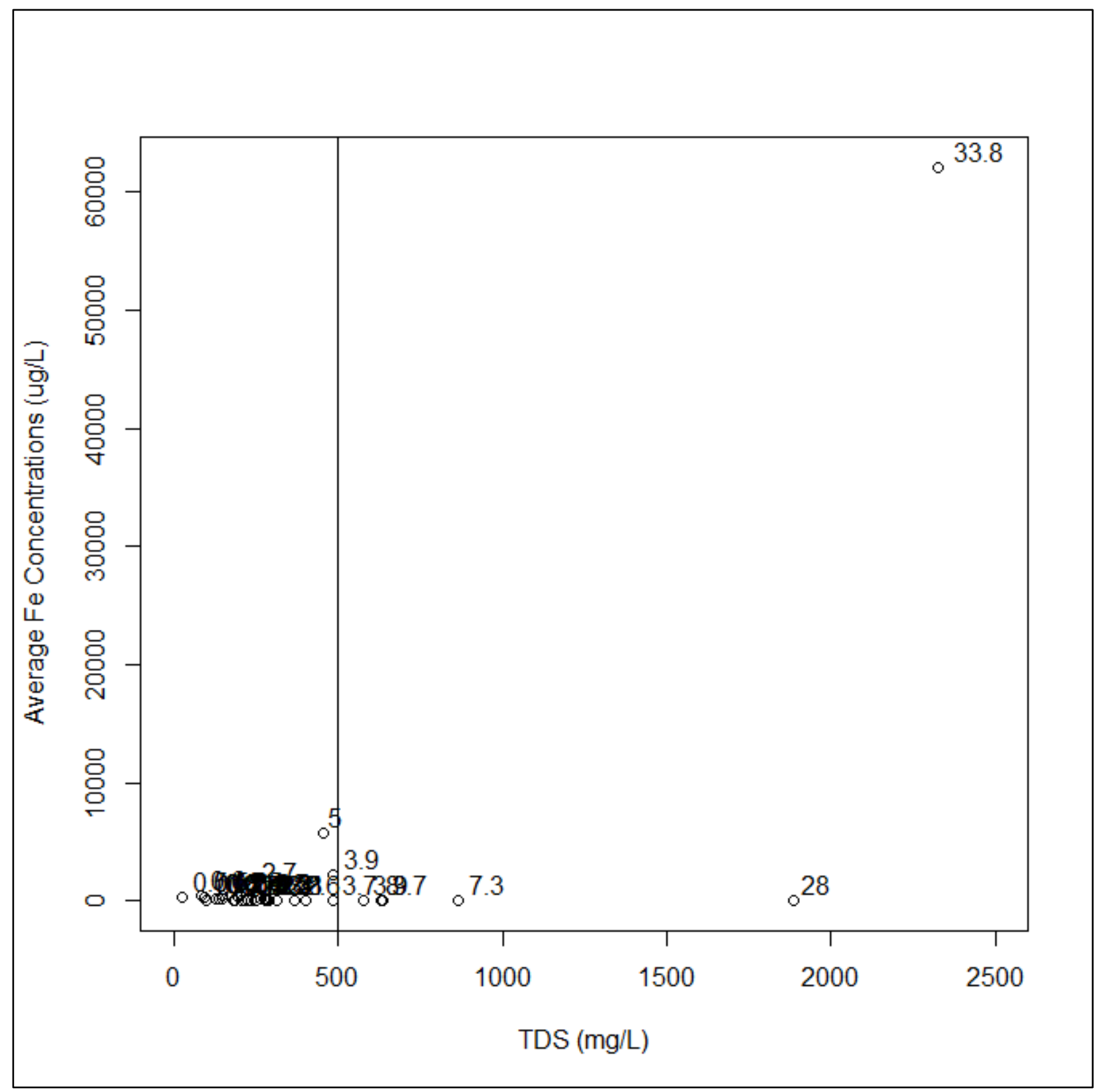

Figure 1R: Iron versus TDS, from Virginia Tech, with line indicating maximum contaminant limit of $500 \mathrm{mg} \mathrm{L}^{-1}$, numbers indicate MPA values. 


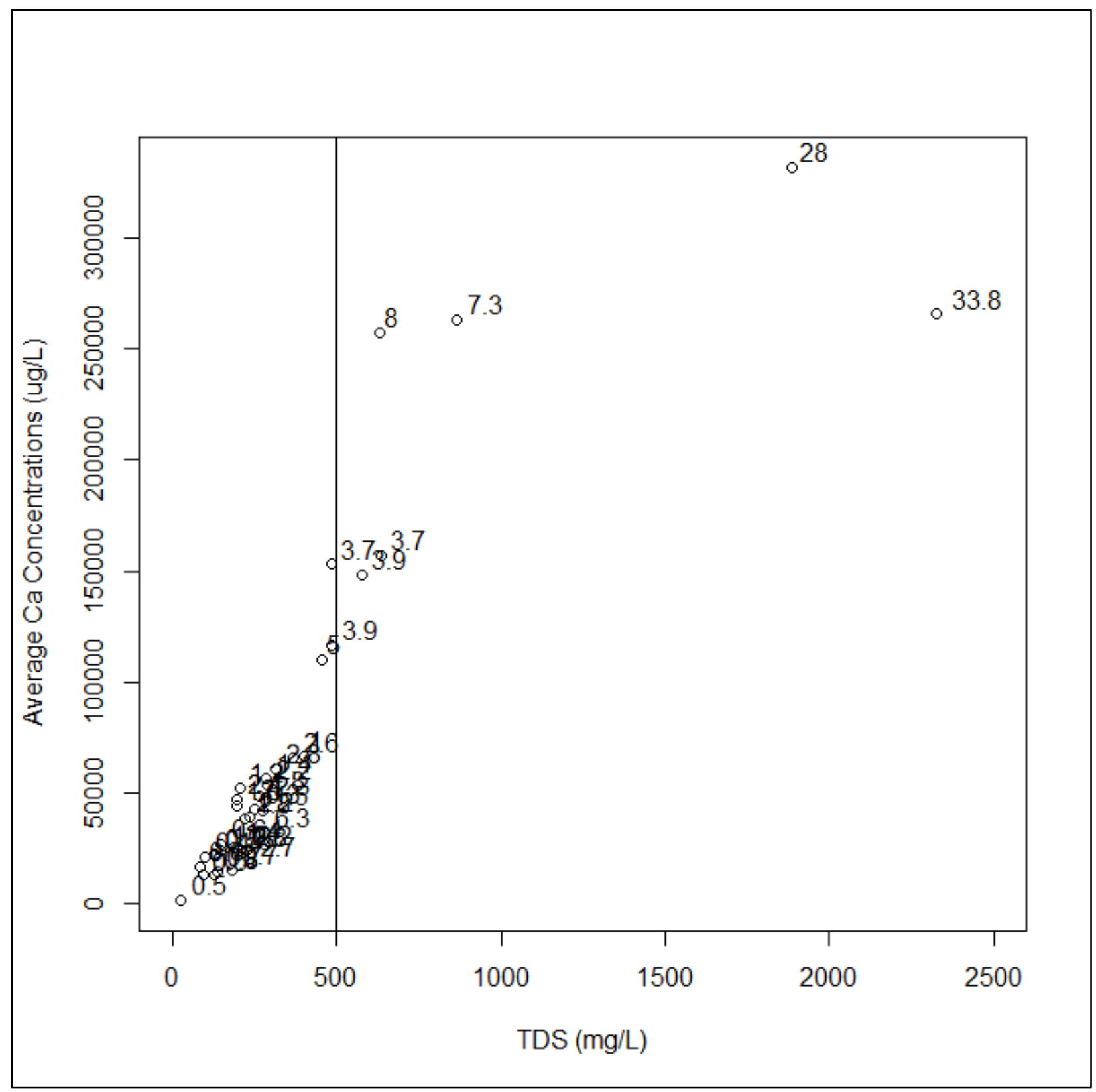

Figure 1S: Calcium versus TDS from Virginia Tech with line indicating maximum contaminant limit of $500 \mathrm{mg} \mathrm{L}^{-1}$, numbers indicate MPA values. 


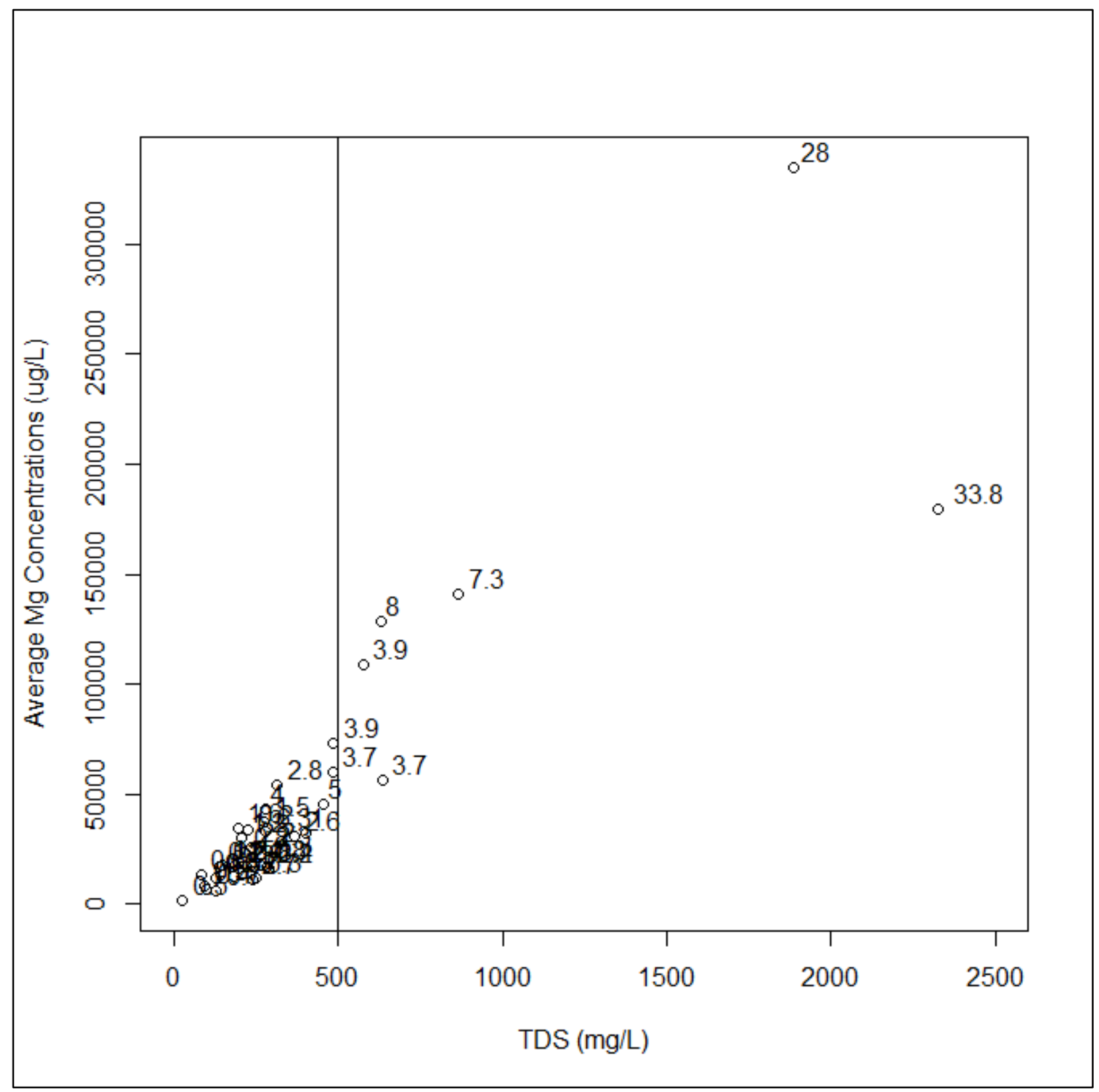

Figure 1T: Magnesium versus TDS from Virginia Tech, with line indicating maximum contaminant limit of $500 \mathrm{mg} \mathrm{L}^{-1}$, numbers indicate MPA values. 


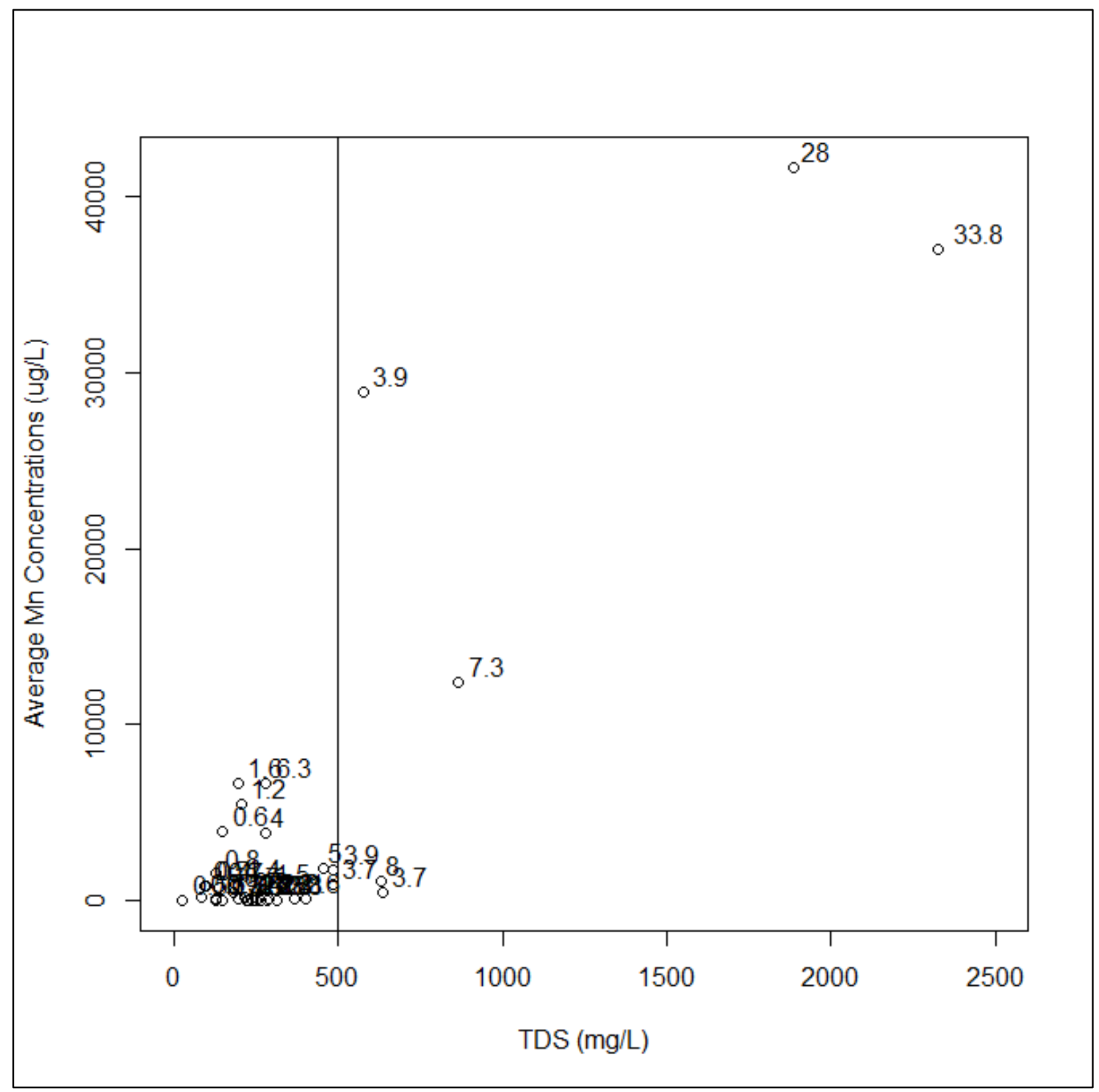

Figure 1U: Manganese versus TDS from Virginia Tech, with line indicating maximum contaminant limit of $500 \mathrm{mg} \mathrm{L}^{-1}$, numbers indicate MPA values. 


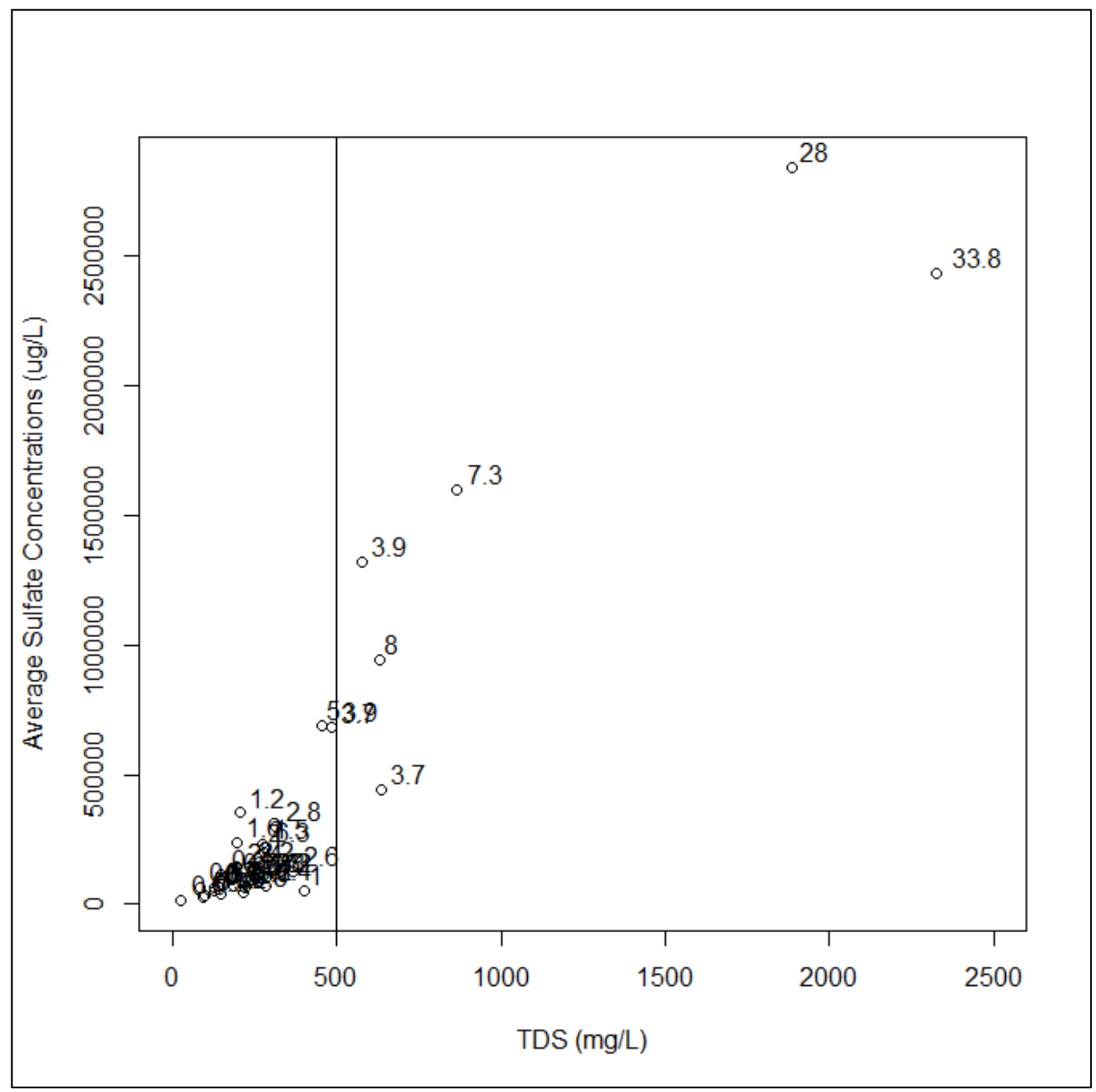

Figure 1V: Sulfate versus TDS from Virginia Tech with line indicating maximum contaminant limit of $500 \mathrm{mg} \mathrm{L}^{-1}$, numbers indicate MPA values. 


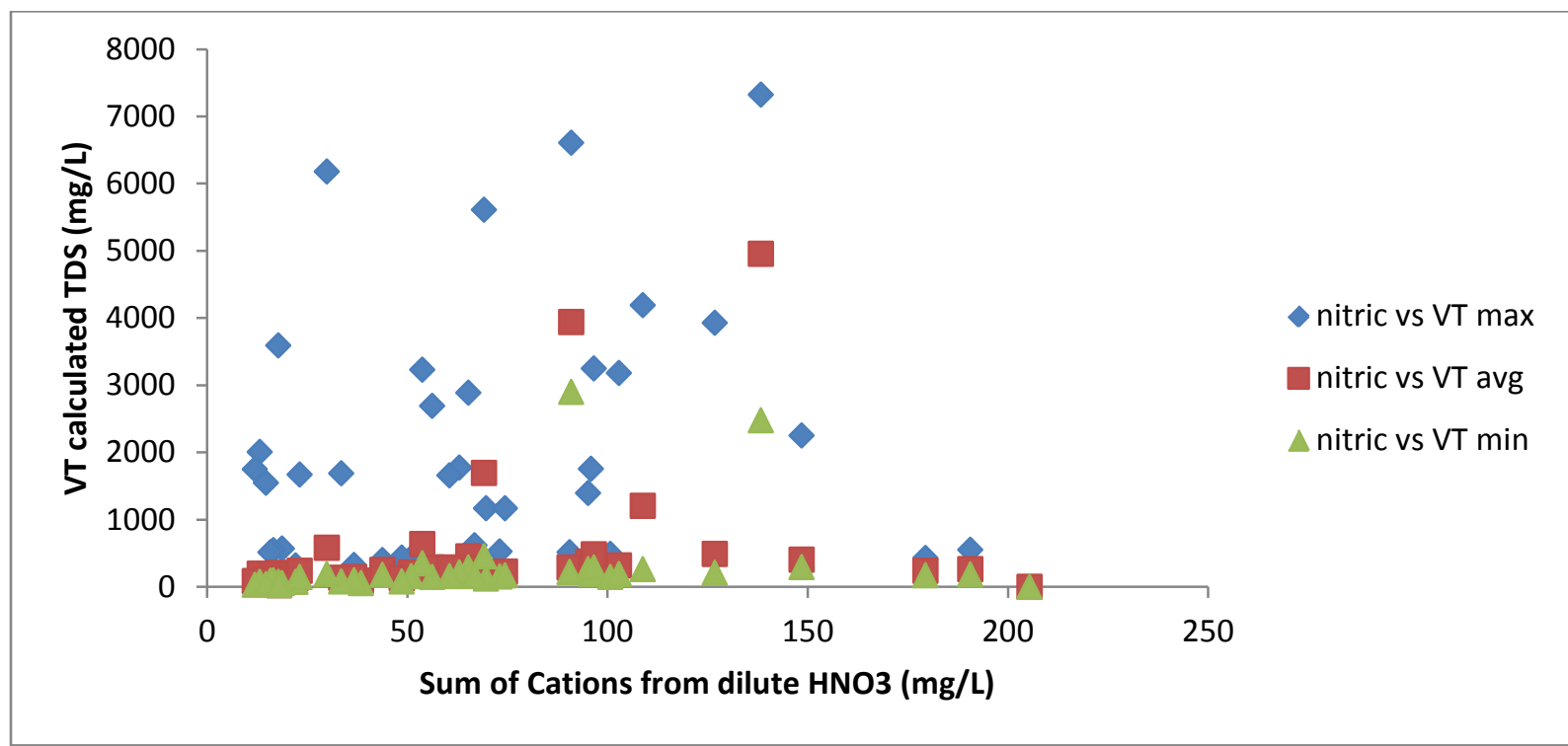

Figure 1W: Virginia Tech's calculated TDS versus the sum of cations from the dilute nitric acid solution.

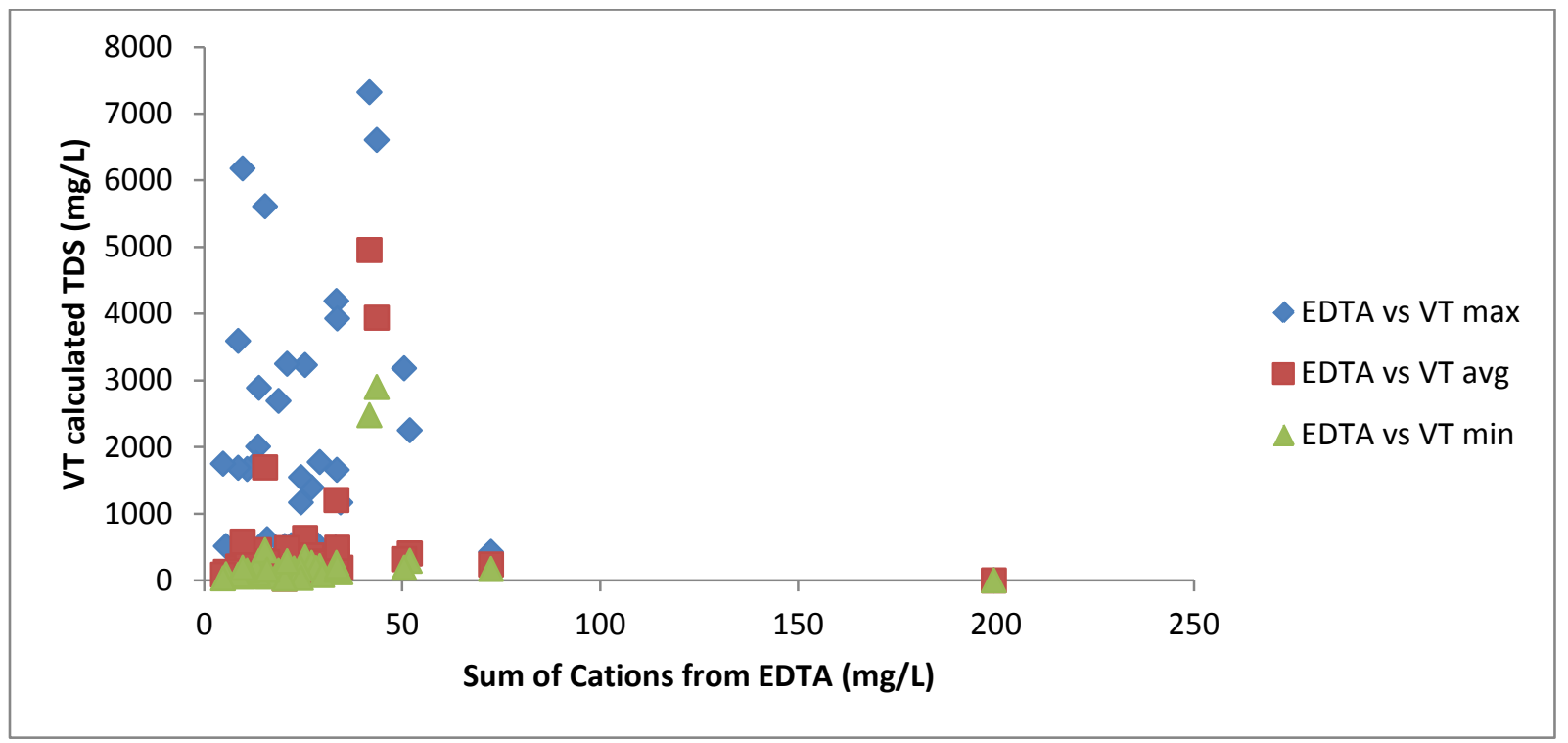

Figure 1X: Virginia Tech's calculated TDS versus the sum of cations from the EDTA solution. 


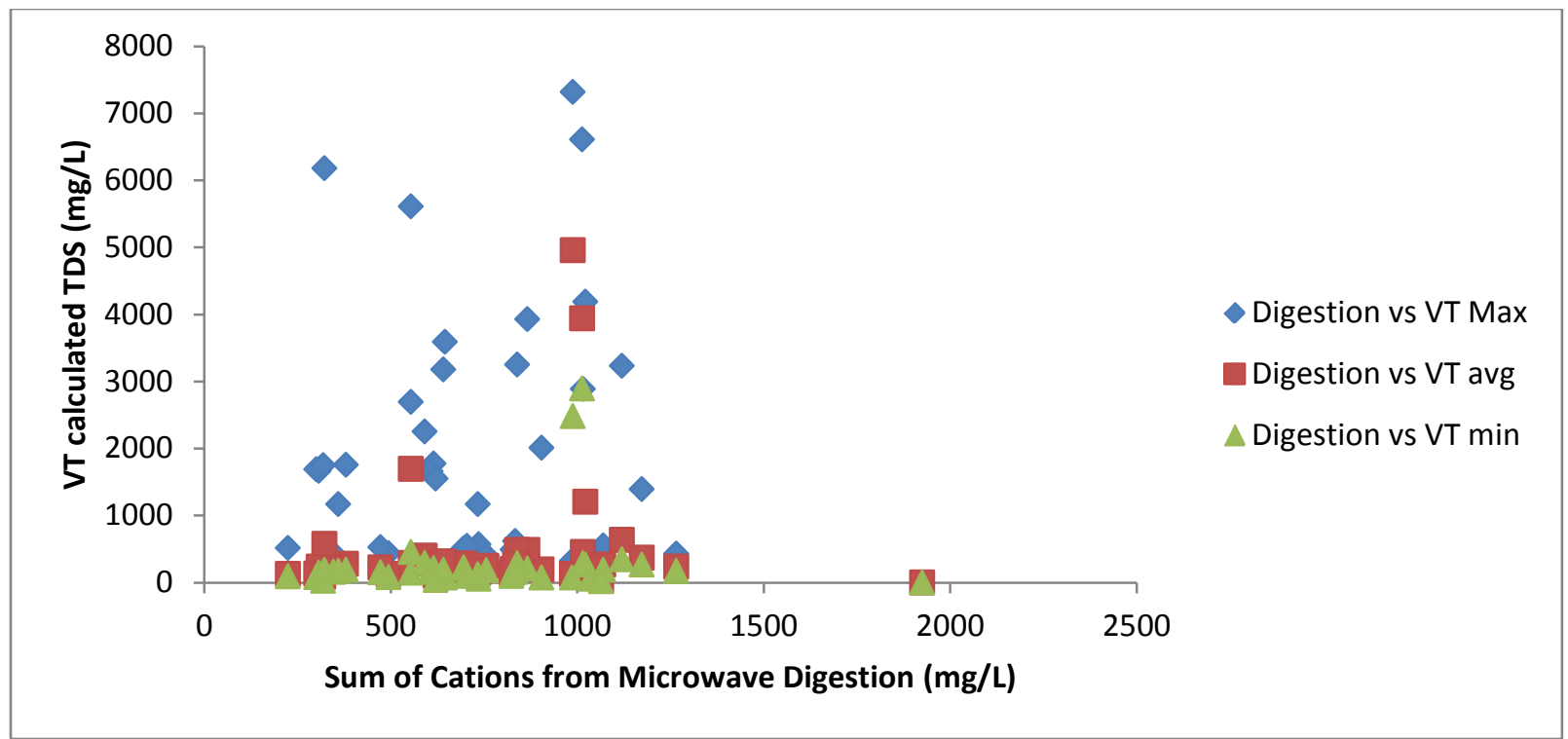

1Y: Virginia Tech's calculated TDS versus the sum of cations from microwave digestion. 